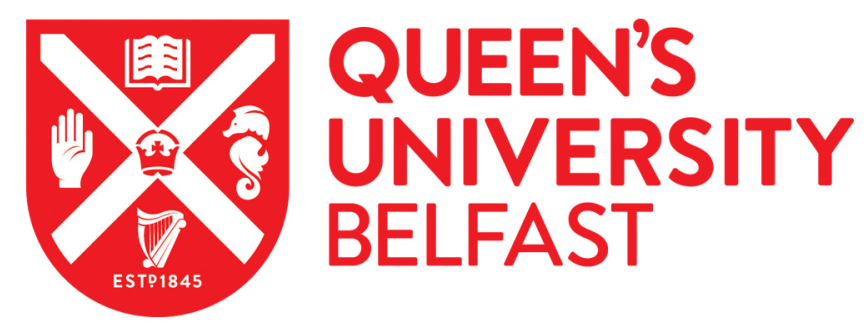

\title{
3D Scaffolds in the Treatment of Diabetic Foot Ulcers: New Trends vs Conventional Approaches
}

Glover, K., Stratakos, A. C., Varadi, A., \& Lamprou, D. A. (2021). 3D Scaffolds in the Treatment of Diabetic Foot Ulcers: New Trends vs Conventional Approaches. International Journal of Pharmaceutics, 599, [120423]. https://doi.org/10.1016/j.ijpharm.2021.120423

\section{Published in:}

International Journal of Pharmaceutics

\section{Document Version:}

Peer reviewed version

Queen's University Belfast - Research Portal:

Link to publication record in Queen's University Belfast Research Portal

\section{Publisher rights}

Copyright 2021 Elsevier Ltd.

This manuscript is distributed under a Creative Commons Attribution-NonCommercial-NoDerivs License

(https://creativecommons.org/licenses/by-nc-nd/4.0/), which permits distribution and reproduction for non-commercial purposes, provided the author and source are cited

\section{General rights}

Copyright for the publications made accessible via the Queen's University Belfast Research Portal is retained by the author(s) and / or other copyright owners and it is a condition of accessing these publications that users recognise and abide by the legal requirements associated with these rights.

Take down policy

The Research Portal is Queen's institutional repository that provides access to Queen's research output. Every effort has been made to ensure that content in the Research Portal does not infringe any person's rights, or applicable UK laws. If you discover content in the Research Portal that you believe breaches copyright or violates any law, please contact openaccess@qub.ac.uk. 
1 3D Scaffolds in the Treatment of Diabetic Foot Ulcers: New Trends vs

2 Conventional Approaches

3 Katie Glover', Alexandros Ch. Stratakos ${ }^{2}$, Aniko Varadi, Dimitrios A. Lamprou, ${ }^{1, *}$

${ }^{1}$ School of Pharmacy, Queen’s University Belfast, 97 Lisburn Road, Belfast BT9 7BL, UK.

${ }^{2}$ Faculty of Health and Applied Sciences, Center for Research in Biosciences, University of the West of England, Bristol BS16 1QY, UK

* Correspondence: d.lamprou@qub.ac.uk; Tel.: +44-28-9097-2617.

4 Abstract: Diabetic foot ulcer (DFU) is a serious complication of diabetes mellitus, affecting roughly $25 \%$ of diabetic patients and resulting in lower limb amputation in over $70 \%$ of known cases. In addition to the devastating physiological consequences of DFU and its impact on patient quality of life, DFU has significant clinical and economic implications. Various traditional therapies are implemented to effectively treat DFU. However, emerging technologies such as bioprinting and electrospinning, present an exciting opportunity to improve current treatment strategies through the development of 3D scaffolds, by overcoming the limitations of current wound healing strategies. This review provides a summary on (i) current prevention and treatment strategies available for DFU; (ii) methods of fabrication of 3D scaffolds relevant for this condition; (iii) suitable materials and commonly used molecules for the treatment of DFU; and (iv) future directions offered by emerging technologies.

Keywords: additive manufacturing; bioprinting; cold-plasma; diabetic foot ulcers; emerging technologies; electrospinning; implants

\section{Table of contents}

1. Introduction

1.1 Normal wound healing process

1.2 Diabetic wound healing process

1.3 Pathology of DFU

1.4 Diabetic foot ulcer classifications

2. Current strategies used to enhance wound healing

2.1 Advance therapies

2.1.1 Offloading/pressure control

2.1.2 Glycaemic control

2.1.3 Debridement

2.1.4 Infection management 
International Journal of Pharmaceutics

\subsection{Advanced therapies}

2.2.1 Advanced wound dressings

2.2.2 Negative pressure wound therapy

2.2.3 Skin substitutes

3. Scaffold fabrication methods for DFU

\subsection{Electrospinning}

3.2 3D Printing: Fused Deposition Modelling

\subsection{D Bioprinting}

3.3.1 Inkjet-based bioprinting

3.3.2 Extrusion-based bioprinting

3.3.3 Laser-assisted bioprinting

4. Suitable materials for 3D bioprinted scaffolds

4.1 Natural polymers

4.1.1 Collagen

4.1.2 Gelatin

4.1.3 Alginate

4.1.4 Fibrin

4.2 Synthetic polymers

4.2.1 Poly(lactic-co-glycolic acid)

4.2.2 Polycaprolactone

4.2.3 Polyurethane

4.2.4 Polyethylene glycol

5. Common drugs used in the treatment of DFU

5.1 Antibiotics

5.2 Human growth factors

5.3 Stem cells

5.4 Topical agents

5.5 Plant derived extracts and compounds

6. Cold-Plasma in the treatment of DFU

7. Future directions of DFU

7.1 Personalised treatment

7.2 Prevention

8. Conclusions

References

\section{Introduction}

Diabetes mellitus (DM) is among the top ten causes of deaths worldwide and places a significant demand on healthcare systems (World Health Organisation, 2020). The term DM encompasses two subtypes, including type 1 diabetes (T1DM) and type 2 diabetes (T2DM). T2DM accounts for approximately $90 \%$ of global diabetes cases, while T1DM is less common and accounts for approximately 5 - 10\% of global cases (Kahanovitz et al., 2017). The pathophysiology of T1DM and T2DM differ; however, both are underpinned by the failure of the body to process and utilise glucose correctly, resulting in raised levels of glucose circulating 
in the bloodstream. Currently, 463 million people are estimated to suffer from DM worldwide (International Diabetes Federation, 2020). The incidence of DM is increasing rapidly worldwide, primarily due to various social and economic factors, with a predicted 700 million people to be affected by 2045 (International Diabetes Federation, 2020).

The rising incidence of DM has huge economic implications. In the US alone, $\$ 327$ billion is spent annually on both medical costs and as a result of lost work days due to DM (Centre of Disease Control and Prevention, 2020). In the UK, an estimated £837 million and £962 million were spent on DFU treatment and associated amputations between 2014 and 2015 (Kerr et al., 2019).

One major complication of DM is the development of DFU. For diabetic patients, a simple tear of the skin can have serious consequences. Up to $25 \%$ of patients suffering from DM develop DFU, with over 70\% of these patients requiring lower limb amputation (Peter-Riesch, 2016). The DFU market alone is set to increase from $\$ 7.03$ billion USD in 2019 to $\$ 11.05$ billion USD by 2027 (Fortune Business Insights, 2019).

Several factors contribute to increase in incidence of DFU, such as inadequate wound healing, which is frequently observed in diabetic patients, and will be discussed in this review. Due to a rapid increase in DM incidence worldwide, a correlating increase in the occurrence of DFU has been predicted, as well as increasing healthcare costs and resultant amputations in the absence of effective treatment options, which is supported by current market predictions (Fortune Business Insights, 2019).

\subsection{Normal wound healing process}

Normal wound healing is a complex, interwoven process consisting of multiple stages, which can occur sequentially or simultaneously in different sections of the wound. Coagulation, inflammation, proliferation and wound remodelling contribute to an overall effective and complete wound healing process in healthy individuals. This is achieved through a tightly regulated and co-ordinated response. Numerous cells, cytokines and growth factors mediate this process to promote appropriate conditions for complete tissue repair in each stage of the wound healing process.

In the normal wound healing process, haemostasis occurs immediately following injury. Vasoconstriction of blood vessels surrounding the sight of injury is facilitated by upregulation 
of thromboxane's and prostaglandins and temporarily acts to prevent excessive blood loss. Platelets bind to exposed collagen and initiate the coagulation cascade, which results in the formation of a fibrin clot, via enzymatic conversion from fibrinogen. Circulating platelets then release platelet-derived growth factor (PDGR) and transforming growth factor (TGF), signifying progression to the inflammatory stage (Pierce et al., 1991).

Leukocyte rolling causes neutrophil migration to the site of injury, facilitated by the upregulation of integrin receptors on the endothelial surfaces of blood vessels. Leukocytes act to phagocytose debris, secrete reactive oxygen species (ROS) and pro-inflammatory cytokines (Ellis et al., 2018, Wilgus et al., 2013). Next, monocytes move to the site of injury, which differentiate into the pro-inflammatory M1 phenotype macrophages to allow the release of proinflammatory cytokines, such as IL-1 and TNF-a (Olingy et al., 2017). This encourages lymphocyte migration to the site of injury. The polarization of macrophages to the antiinflammatory M2 phenotype, and subsequent release of factors such as vascular endothelial growth factor (VEGF), then signals progression towards the third stage of wound healing. The proliferative stage of wound healing involves fibroblast migration, collagen synthesis, angiogenesis, granulation tissue formation and epithelialisation. Deposition of extracellular matrix (ECM) to replace the temporary fibrin clot occurs during the remodelling phase (Petreaca and Martins-Green, 2020), which is laid down by fibroblasts and provides structural robustness to the wound.

\subsection{Diabetic wound healing process}

Several factors throughout the wound healing process contribute to the abnormal and incomplete wound healing often observed in diabetic patients, as summarised in Fig.1. Most prominently, continued inflammation has been shown to lead to poor wound healing outcomes. Where the normal wound healing process is typically complete in $4-6$ weeks (Wallace et al., 2020), diabetic wound healing often extends beyond this timeline and is often left unresolved, leading to infection and amputation in the majority of cases (Peter-Riesch, 2016).

Dysregulation of both monocytes and macrophages plays a role in the abnormal diabetic wound healing response. An observed inability of macrophages to polarise from the pro-inflammatory M1 phenotype to the anti-inflammatory M2 phenotype following the inflammatory stage of wound healing leads to prolonged inflammation, contributing to incomplete wound healing. In addition, greater expression of monocytes as a result of modifications to hematopoietic stem 
and progenitor cells (HSPC) leads to poor wound healing and impaired phagocytosis due to overexpression of macrophages, in particular the M1 phenotype (Barman and Koh, 2020).

Other key cells involved in wound healing, such as neutrophils, have been shown to be negatively affected by the physiological conditions created by DM. Increased levels of neutrophils, as well as neutrophil extracellular traps (NETs), are known to contribute to poor wound healing in diabetic patients (Yang et al., 2020). One study found treatment with dapsone, an antibacterial agent commonly used in the treatment of skin diseases such as dermatitis, in an in vivo diabetic rat model led to improved wound healing when compared to the control group, indicating the positive effect of IL-8 inhibition and the resultant reduction in neutrophil levels during diabetic wound healing. High level of expression of other inflammatory markers such as inducible nitric oxide synthase (iNOS), IL-12 and TNF- $\alpha$, while reduced expression of anti-inflammatory markers such as IL-4 and IL-10, are indicative of a prolonged inflammatory response characteristic to chronic wounds (Ellis et al., 2018).

Moreover, studies have found transcription factors Forkhead Box M1 (FOXM1) and signal transducer and activator of transcription 3 (STAT3), which facilitate tissue repair via activation and recruitment of neutrophils and macrophages, to be reduced in diabetic wound healing (Sawaya et al., 2020).

Nitrogen oxide (NO) synthesis occurs primarily during the proliferative wound healing stage and in short facilitates wound healing via collagen formation and cell proliferation of key cells such as macrophages and keratinocytes (Malone-Povolny et al., 2019). In diabetic patients, the inhibition of nitric oxide synthase leads to a reduction in NO and increased superoxide, as well as other reactive species. Increased production of advanced glycation end products (AGEs) as a result of hyperglycaemia has been reported to contribute to increased levels of ROS and reactive nitrogen species (RNS), which can cause significant tissue damage (Malone-Povolny et al., 2019). Overall, a reduction in antioxidants due to reduced Nicotinamide Adenine Dinucleotide Phosphate (NADPH) and increased ROS and oxidative stress impel the complications of DFU.

In combination, these factors contribute to the overall impaired wound healing response observed in diabetic patients. 
International Journal of Pharmaceutics

\subsection{Pathology of DFU}

Several underlying pathological risk factors contribute to the development and abnormal healing of DFUs; however, the most prominent of these include diabetic neuropathy (DN), peripheral arterial disease (PAD) and immunosuppression.

An estimated 20\% of T1DM and 50\% of T2DM suffer from DN (Pop-Busui et al., 2017). Clinically, loss of sensation due to peripheral nerve damage means DFU can go overlooked for prolonged periods in the absence of regular foot check-ups. This allows ulcer development to progress unnoticed. During this time, the wound may be subjected to continuous pressure over prolonged periods of time, or to further physical damage due to loss of sensation, leading to more severe ulceration. The nerve damage observed in the intrinsic foot muscles of diabetic patients results in imbalance of flexion and extension, ultimately creating pressure points for where ulceration can occur (Clayton and Elasy, 2009).

Peripheral arterial neuropathy (PAD) in diabetic patients is thought to result primarily from the two-step reaction polyol pathway. This metabolic pathway accounts for $30 \%$ of glucose consumption but is implicated in diabetic patients through upregulation in response to elevated glucose levels (Yan, 2018). In this pathway, glucose is firstly reduced to sorbitol by aldose reductase enzyme, followed by conversion of sorbitol to fructose by sorbitol dehydrogenase. Under normal physiological conditions this process results in the production of nicotinamide adenine dinucleotide + hydrogen $(\mathrm{NADH})$ via NADPH consumption; however, in diabetic patients redox imbalance occurs due to increased levels of NADH (Wu et al., 2016). As a result, increased superoxide's, a precursor to ROS, are produced due to enhanced electron transportation via Complex 1. The oxidative stress as a result of enhanced NADH levels has been noted as a major contributor to DN (Mallet et al., 2020). Furthermore, in diabetic patients the upregulation of the polyol pathway results in elevated sorbitol levels in the nerves, contributing to reduced myo-inositol levels, a+, $\mathrm{K}^{+}$-ATPase activity and reduced nerve functionality (Nesterova et al., 2020).

There is an increasing need for further insight into combination therapies for pain relief, as well as long-term efficacy studies, on diabetic patients suffering from DN. Moreover, there is a need for advanced drug delivery systems to improve the treatment of DN, reflected by a predicted increase in DN market growth to meet patient demand. In North America, the DN market size is predicted to reach $\$ 7.12$ billion by 2026 (Fortune Business Insights, 2018). 
Neuropathy experienced by diabetic patients is not limited to DN. Autonomic neuropathy, caused by sweat gland dysfunction, is a common manifestation of DM and results in the inability of the body to moisturise the skin, leaving open cracks (Volmer-Thole and Lobmann, 2016). This can initiate DFU development while also providing an entry route for pathogens due to disruption of the physical protective barrier that is provided by the skin.

Once the DFU has been identified and treatment has been initiated, PAD commonly impedes the process of normal wound healing. It does so through several mechanisms and contributes to ulcer progression in up to 50\% of cases (Clayton and Elasy, 2009). Endothelial cell dysfunction caused by hyperglycaemia reduces the production of endothelial-derived vasodilators, such as NO and prostacyclin (Avogaro et al., 2011), potentially increasing the risk of atherosclerosis occurring.

Furthermore, an increase in the vasoconstrictor thromboxane $\mathrm{A} 2$ has been observed in diabetic patients, which plays a role in enhanced platelet aggregation (Santilli et al., 2020). Disruption of the microcirculation also occurs following arteriolar-venular shunting. Overall, this leads to ischemia at a time where enhanced blood flow is required to facilitate the normal wound healing process. Ischemia is observed in approximately half of diabetic patients and is a factor highly associated with lower limb amputations (Shatnawi et al., 2018).

Immune factors also play a role in the abnormal wound healing response observed in diabetic patients. Many of these patients have impaired immune function, meaning cells, which are key to a normal wound healing response are not activated or functioning properly. In addition to this, the risk of infection for these patients is higher and could act to further slow the wound healing process due to infection or biofilm development. For example, Enterococcus faecalis, a microorganism commonly associated with DFU infection, has been found to impair the wound healing response at high concentrations (Chong et al., 2017).

Several reviews have provided in detail insight into the underlying pathological risk factors and physiological factors which lead to DFU development and progression (Bandyk, 2018; Mishra et al., 2001; Patel et al., 2019) 


\subsection{Diabetic foot ulcer classifications}

Various classification systems have been established to indicate disease progression. Most importantly, the cause of the ulcer and whether it is neuropathic, neuro-ischemic or ischemic should be evaluated in order to predict DFU outcome (Alavi et al., 2014).

The most commonly used classification system for DFU is the Wagner Ulcer Classification System (WUCS). This system classifies ulcers based on ulcer depth and presence of osteomyelitis or gangrene (Swezey, 2016); however, does not address ischemia nor infection. The classification scale ranges from 0 to 5, moving from intact skin to whole foot gangrene with increasing classification numbers (Swezey, 2016).

The University of Texas Diabetic Foot Ulcer Classification System is another commonly used system. Unlike WUCS, DFU are classified based on the occurrence of ischemia or infection as well as ulcer depth. Grades 0 to 3 range from healed pre- or post-ulcerative sites to a wound that penetrates the bone or joint, respectfully. Within each Grade, four further subcategories exist to assess infection and ischemia parameters, with Stage A representing clean, noninfectious wounds while stage D represents ischemic infectious wounds (Swezey, 2016).

According to literature, the Perfusion Extent Depth Infection and Sensation (PEDIS) classification system provides excellent validity and reliability in predicting DFU outcome, based on the parameters described in the classification title (Chuan et al., 2015). Combination of grade and score, based on each of the five categories, results in a minimum score of one and maximum of 12, indicating on overall severity and prognosis (Chuan et al., 2015). It is more objective and faces stricter criteria than previous methods such as WUCS.

The Site Ischemia Neuropathy Bacterial Infection and Depth (SINBAD) system provides the tools to make predictions regarding ulcer outcome and how this varies between countries, based on a score between 0 and 6 (Arteri-, 2008). Recently, SINBAD was found to have similar accuracy and reliability in predicting DFU outcomes as the University of Texas classification system (Leese et al., 2020).

Diabetic Ulcer Severity Score (DUSS) is used to evaluate parameters such as "palpable pedal pulses, probing to bone, ulcer location, and presence of multiple ulcerations". This method has been shown to accurately predict disease progression, based on implementing a scale of 0 to 4 of increasing clinical severity, in a standardised manner (Beckert et al., 2006). 
International Journal of Pharmaceutics

Recent analysis into the accuracy and reliability of WUCS, SINBAD, UT and PEDIS concluded, that in order to ensure an accurate clinical assessment, these classification systems should be used in combination. While WUCS provided the most accurate and reliable predictions of ulcer outcome, PEDIS showed the least reliable outcomes, with moderate. Meanwhile, SINBAD and UT both showed good reliability (Camilleri, 2019).

\section{Current strategies used to enhance wound healing}

As with many diseases, early implementation of treatment is one key aspect to a successful treatment outcome for DFU healing. Wound healing strategies can fall under standard therapies or advanced therapies. As ulcer severity progresses, a transition from standard therapies, such as wound dressings, to incorporate advanced therapies, such as negative pressure wound therapy (NPWT), may be necessary to achieve successful healing outcomes. Current wound healing strategies for DFU are summarised in Table 1.

\subsection{Advance therapies}

Commonly used advanced therapies in the treatment of DFU have been summarised in Table 2.

\subsubsection{Offloading/pressure control}

Foot ulceration in diabetic patients commonly occurs due to physical damage from the outside environment. This damage may be a result of a short-term, high pressure in a small focused area or prolonged low pressure in a more widespread area. This stress on select areas of the foot can often result in ulceration, which can be further complicated by the presence of peripheral arterial disease and diabetic neuropathy. The nerve damage, which occurs due to DN can affect the patient's gait and therefore lead to abnormal cadence, focusing pressure on select of areas of the foot and making the patient susceptible to ulcer formation.

As DFU have been shown to occur in areas of high plantar pressure, this highlights the important initial role offloading plays in the treatment of DFU (Fernando et al., 2016). Various methods for offloading include crutches, surgical shoes and bandages (Mishra et al., 2001).

Comprised of specialised materials, total contact casts (TTCs) have been referred to as the gold standard for offloading when it comes to DFU treatment. For the management of DFU, the International Working Group of the Diabetic Foot (IWGDF) recommend a non-removable 
knee-high offloading device with appropriate foot-device interface as the primary treatment option for neuropathic plantar or midfoot DFU. Other treatment options for offloading include a removable knee-high device, removable ankle-high device or felted foam to be placed as cushioning in appropriate footwear (Bus et al., 2020).

As outlined in Table 1, TTCs have been shown to greatly reduce the time for DFU healing when compared to conventional dressings (Sahu et al., 2018; Sudhir et al., 2020). Nonremovable devices have been found to be more effective than removable devices (Morona et al., 2013). These may be owed to their benefits such as improved patient compliance.

There are limited risks associated with the use of TTCs. Due to immobilisation of the limb the risk of complications such as venous thrombo-embolism (VTE) would be expected to increase. A study into this matter did not find any occurrence; however, larger study samples are needed to confirm this finding (King et al., 2017). A ten-year study found very low prevalence of VTE, providing long-term insight into this potential complication associated with TTC use, but requires the same duration of insight using larger sample sizes to gain reliable conclusions on this matter. Risk of occurrence should be evaluated on an individual basis, taking into account underlying conditions (Tonge et al., 2019).

\subsubsection{Glycaemic control}

As previously outlined, prolonged hyperglycaemia in diabetic patients can lead to DN and PAD, both of which have a negative influence on DFU healing. Glycaemic control therefore has to be achieved to promote successful wound healing.

Elevated levels of HbA1C, a glycated haemoglobin, show average blood sugar levels over a two to three month period (Diabetes UK, 2020) and can act as an indicator of poor glycaemic control.

Variability in healing time of DFU has been associated with varying levels of glycaemic control in patients, with lower HbA1C levels associated with faster healing rates (Dhatariya et al., 2018). As shown in Table 1, another study found a HbA1C level between $7-8 \%$ would provide benefit to the wound healing of DFU (Xiang et al., 2019). Negative correlation has been reported between $1.0 \%$ increases in $\mathrm{HbA} 1 \mathrm{C}$ levels and the rate of DFU wound healing (Christman et al., 2011). In paradox to these findings, one study concluded that an increase in $\mathrm{HbA1C}$ has been associated with improved wound healing in patients where baseline HbA1C 
International Journal of Pharmaceutics

was below 7.5\%, which may have resulted from unidentified hypoglycaemia (Fesseha et al., 2018). Furthermore, reduced glycaemic levels have been found to improve wound healing but do not improve neuropathy or vasculopathy (Kumar et al., 2016).

\subsubsection{Debridement}

Debridement is the removal of necrotic and senescent tissues as well as foreign and infected materials from a wound (Healthline, 2019). This is generally the first step of DFU treatment and can be performed through various methods, such as surgical, mechanical, enzymatic, autolytic and biological. These methods can be used in isolation or in combination. Despite the chosen method, the overall aim of debridement is to promote wound healing through the stimulation of a chronic wound in order to create an acute wound and allow rapid, effective healing.

Ultrasound assisted debridement has also shown promising and rapid results in terms of reducing bioburden and promoting wound healing of neuro-ischemic DFU (Lázaro-Martínez et al., 2018). This method of debridement has also been shown to reduce debridement times and potential complications (Campitiello et al., 2018).

Surgical debridement involves removable of both non-viable tissue and immediately surrounding viable tissue in order to stimulate wound healing, and thus is suitable for when large areas of tissue must be removed. Surgical debridement has been found to not be necessary for patients with sufficient peripheral arterial perfusions, which could help implement the use of effective treatments such as photodynamic therapy sooner and thus reduce treatment times (Tardivo et al., 2017).

Similar to surgical debridement, sharp debridement is a cost-effective method given the limited equipment required and absence of anaesthetic; however, requires skilled personnel in order to prevent accidental enlargement of the wound area, which could reduce wound healing capabilities.

In terms of biological debridement methods, the use of maggot debridement therapy (MDT) has proven successful. MDT accelerates the rate of wound healing while also demonstrating antiseptic abilities and stimulate granulation tissue formation (Azad et al., 2016). This method is cost effective and these genetically engineered maggots can be used to secrete human platelet derived growth factor BB (PDGF-BB) (Linger et al., 2016). 
Autolytic debridement is the lysis, or breakdown, of damaged tissue at a wound site by the body's natural defence system by enzymes that digest specific components of body tissues or cells, for example fibrin and collagen (Choo et al., 2019). This method is highly selective, has little risk for complications or side effects and is suitable for small areas, but is a slow method of debridement (Manna et al., 2020).

The process of mechanical debridement involves the application of a wet gauze which then adheres to the skin and, upon its removal, results in the removal of dead tissue surrounding the wound (Ananian, 2020). This method is non-selective and requires frequent dressing changes, as well as causing pain and bleeding in some instances (Wound Source, 2019).

Enzymatic debridement makes use of natural proteolytic enzymes to remove non-viable tissue in a selective manner. Collagenase products, papain-based products and papain-ureachlorophyllin complex have all been used for this method. Neuropathic non-ischemic DFU treated with clostridial collagenase ointment (CCO) witnessed improved wound closure when compared to the daily hydrogel treatment group following 6 weeks of treatment (Jimenez et al., 2017). Using CCO in combination with sharp debridement has proven to have both clinical and economic benefits (Motley et al., 2015).

\subsubsection{Infection management}

In many instances, insufficient wound healing and amputation is preceded by the presence of pathogenic microorganisms in the ulcerated area. This is due to several factors, including the prolonged exposure of the wound area as a result of reduced healing times in diabetic patients. A study by Jia et al., suggested infections of DFU to have a prevalence of approximately $40 \%$ (Jia et al., 2017); however, earlier reports have suggested this figure to be as high as approximately 60\% (Prompers et al., 2007).

Firstly, the pathogen must be identified to ensure appropriate treatment, as the recommended treatment duration will vary between pathogens. According to the IWGDF, the severity of infection should be classified using the classification scheme proposed by Infectious Diseases Society of America/International Working Group on the Diabetic Foot (Bus et al., 2019). Identification of the pathogen involves obtaining a soft tissue or bone sample for microbiological analysis. 
Once identified, infection management is controlled primarily through the use of antibiotics. Several common candidates include penicillin's, cephalosporins, carbapenems and fluroquinolones. The choice of antibiotic is influenced by various factors such as the susceptibility of the identified pathogen, infection severity and potential for toxicity or adverse events (Bus et al., 2019).

Oral administration of these antibiotics is considered to be the primary treatment option due to the many benefits this route of administration provides; however, these treatments can also be delivered systemically in the case of moderate to severe infection. Topical administration of antibiotics such as vancomycin has been documented in the infection management of DFU, successfully promoting wound healing and reducing methicillin-resistant Staphylococcus aureus (MRSA) cultures in DFU when compared to saline dressing control (Saif et al., 2019). In instances where the patient is unresponsive to antibiotic treatment to manage DFU infection, surgery may be required.

For mild infection, NICE recommend the appropriate antibiotic to be administered orally for up to seven days (National Insititute for Health and Care Excellence (NICE), 2015). For moderate infection, primary choice of antibiotic should be administered, either orally or intravenously, for greater than seven days, or for six weeks in the case of osteomyelitis. For severe infection, combination treatment of antibiotics should be considered, as well as more frequent administration (National Insititute for Health and Care Excellence (NICE), 2015). Further insights into commonly used antibiotics will be discussed in a later in this review.

\subsection{Advanced therapies}

Often standard therapies such as those mentioned above are not themselves sufficient to allow complete DFU healing and prevent their reoccurrence. The failure of standard therapies to prevent the progression of mild DFU into moderate to severe DFU signals the requirement of advanced therapies to be initiated in the treatment strategy. Adjuvant therapies are provided with the aim of lowering the risk of re-infection and maximise the effectiveness of the wound healing process. Commonly used advanced therapies in the treatment of DFU are summarised in Table 2. 


\subsubsection{Advanced wound dressings}

Following initial debridement and cleaning of the area, wound dressings provide moisture to the site of injury. Wound dressings produced from various materials exist and the choice of the most appropriate material for fabrication must be decided based on the type of wound, its severity and characteristics. The correct choice can promote healing of DFU as well as providing patient and economic benefits due to reduced treatment times. Films used in the treatment of DFU include hydrocolloids, alginates, foams, and silver-impregnated dressings, although hydrogels are used most commonly.

Hydrogels are "two- or multi-component systems consisting of a three-dimensional network of polymer chains and water that fills the space between macromolecules" (Ahmed, 2015). One study found hydrogels to be more effective when compared to basic wound dressings in the treatment of DFU, while non-adherent dressing provided more cost-effective benefits in comparison to hydrofiber dressings (Motley et al., 2015). Hydrogels can be laden with cells, such as mesenchymal stem cells (Chen et al., 2015), or growth factors, such as recombinant human epidermal growth factor (Hajimiri et al., 2016), and have proven promising in the promotion of DFU healing.

Hydrogels provide the benefit of tuneable properties, such as porosity, whilst also mimicking the natural granulation tissue which promotes biocompatibility (Chai et al., 2017). These hydrogels can however undergo large burst release phases, reducing their viability in the treatment of chronic ulceration where sustained drug release would be more effective.

The characteristics of the hydrogel largely depends on the chosen polymer. Synthetic polymers such as polyethylene glycol (PEG) are commonly used due to their desirable mechanical properties and, although they display good biocompatibility, natural polymers such as chitosan are generally more successful in closely mimicking biological structures such as ECM.

In a study hydrophilic polymers were used for the construction of hydrocolloids, where sodium alginate displayed the more desirable swelling properties, mechanical properties and greatest adherence to biological tissue (Jin et al., 2016). Vicenin-2-loaded sodium alginate hydrocolloids have been shown to reduce pro-inflammatory cytokines under hyperglycaemic conditions and promoted diabetic wound healing in an in vivo rat model (Tan et al., 2019). 
In Negative Wound Pressure Therapy (NPWT), negative pressure is applied to a covered wound with the primary aim of removing fluids and infection to prepare a wound bed suitable for healing. NPWT promotes healing of acute and chronic wounds through use of negative pressure in a closed system (Muhammad et al., 2015).

NPWT has been found to decrease mRNA expression of pro-inflammatory factors such as IL1B and MMP-9, while upregulating VEGF and TGF-B1 expression (Karam et al., 2018). In one study, IL-6 and TNF- $\alpha$ expression and inducible NOS production was suppressed significantly following seven days of NPWT treatment, but no significant difference was observed for the expression of p38 or extracellular signal regulated kinases 1 and 2 (T. Wang et al., 2019). NPWT significantly reduces oxygenation levels in diabetic feet and improves blood flow and micro-vessel maturation in diabetic wounds (Ma et al., 2017, (Jung et al., 2016). Furthermore, this treatment method has been noted to promote a moist environment around the wound, which is favourable for healing (Junker et al., 2013).

The non-invasive nature of this procedure makes it attractive for the use of DFU treatments. Many studies have been conducted to investigate the effectiveness of NPWT versus conventional DFU treatments such as wound dressings. Findings are however contradictory, with some studies have suggested NPWT is not more effective in the treatment of DFU compared to moist wound dressings (Seidel et al., 2020).

A recent meta-analysis by Liu et al., found NPWT to reduce the size of DFU and result in faster healing when compared to standard dressings (Liu et al., 2017). This analysis however also concluded the methodological flaws, such as lack of information, how DN affected DFU formation and progression, and the need for further investigation. NPWT provided significantly greater reduction in wound size and duration of hospital stay when compared to moist wound dressings; however, there was limited effect on the reducing the frequency of amputations resulting from DFU (Abdullah Al-Mallah, 2018).

NPWT treatment can be modified to improve the DFU healing profile. NPWT using Vacuum Assisted Closure (VAC) has been found to be more efficient in the reduction of wound area and more rapid healing times in long-term diabetic patients when compared to Advanced Moist Wound Therapy (AMWT) (Muhammad et al., 2015). A recent case study showed the promising benefits on wound healing when using a collagen contact layer, with $91 \%$ wound 
International Journal of Pharmaceutics

healing occurring within 35 days (Lehrman, 2020), indicating the potential benefit of this material in future NWPT applications.

\subsubsection{Skin substitutes}

The increasing use of skin substitutes in the treatment of DFU is owed to their successful outcomes. Skin grafts such FDA-approved Dermagraft® have shown improved healing of chronic wounds, without adverse events (Marston et al., 2003). These skin substitutes mimic natural ECM, providing desirable biocompatibility, and provide a platform for the loading of cells and growth factors to promote wound healing. Despite desirable biocompatibility properties, use of skin grafts, as with any foreign material, poses risk for rejection from the body. This risk can be negated through various methods, including the use of bioengineered membranes composed of materials such as collagen. The potential of this method has been demonstrated through acellular membranes bioengineered with collagen, proteoglycans and glycoproteins, resulting in delayed onset of rejection in vivo (Stubenitsky et al., 2009).

Ananian et al., found viable cryopreserved placental membrane (vCPM) to have better wound healing outcomes and cost-effectiveness when compared to human fibroblast-derived dermal substitutes (hFDS) (Ananian et al., 2018). Additionally, a study showed that SIKVAV (SerIle-Lys-Val-Ala-Val) peptide-modified chitosan hydrogel displayed more rapid wound healing, with greater collagen deposition, myofibroblast deposition and angiogenesis, compared to positive and negative controls (Chen et al., 2018).

\section{Scaffold fabrication methods for DFU}

It is well-established that traditional treatment options such as wound dressings, while biocompatible, lack desirable mechanical properties. An effort has therefore been made in the development of 3D scaffolds, which can be fabricated through several methods including electrospinning and 3D printing technologies.

To promote the cell adhesion and proliferation required for successful wound healing, highly porous scaffolds that closely mimic the ECM are required. These constructs must also have satisfying mechanical properties. Various techniques can be implemented to produce scaffolds of controlled porosity, mechanical strength and polymeric composition for example, depending on required application. 
These scaffolds can be fabricated from a wide variety of biomaterials, which offer excellent biocompatibility profiles, while also providing structural support for the wound during tissue repair. In addition, composite scaffolds are becoming increasingly popular due to the dual benefits in terms of biocompatibility and mechanical properties offered from the biodegradable polymers used in their production.

This section will cover some of the most promising techniques used in the production of 3D scaffolds for DFU treatment. Table 3 summarises the advantages and disadvantages of each scaffold fabrication method.

\subsection{Electrospinning}

Electrospinning is a "process to obtain polymer, ceramic, metallic, and composite fibers from solutions, dispersions, or melts as a liquid jet accelerates through an electric field" (Laudenslager and Sigmund, 2012). The plastic syringe and syringe pump, shown in Figure 2, are used to expel the liquid jet. During the electrospinning process, an electric field is generated by the high power voltage supply and has a greater surface tension than that of the droplet. This produces a liquid jet, which is subjected to electrostatic repulsion within the Taylor cone and collected by the grounded collector. Solidification of the liquid jet occurs following solvent evaporation and results in a fibrous membrane (Qin, 2016). Figure 2 shows a schematic representation of the apparatus setup used for electrospinning.

One advantage of electrospinning is its ability to produce mats of high porosity, allowing them to mimic the ECM and making electrospinning an attractive option for the fabrication of scaffolds in the treatment of DFU. The porosity and pore size of the scaffold can be fine-tuned and adjusted in order to facilitate diffusion. Further advantages of the highly porous structures achieved by electrospinning includes the ability of these structures to act as physical barrier to microorganisms and allows oxygen to infiltrate the wound area to support healing (Samadian et al., 2020). Static, processing and environmental parameters can be optimised to ensure reproducibility of the electrospinning process, while parameters such as polymer concentration and voltage can be modified to achieve the desired scaffold architecture and characteristics.

The resulting high surface area to volume ratio of these porous scaffolds provides opportunity for higher drug loading at site-specific delivery, which would be particularly beneficial for sustained drug delivery. Moreover, the porous structure of the scaffold would aid in maintaining a moist wound area through fluid accumulation, which is highly desirable for 
effective wound healing (Junker et al., 2013). Moreover, a broad selection of both natural and synthetic polymers has been used in the construction of electrospun scaffolds for DFU healing. Despite this method being easy to scale-up, additional processing steps to allow for crosslinking may be required, which has the disadvantages of extending production time and extra costs.

Overall, electrospinning allows the production of scaffold fibers to the nanoscale, providing benefits such as increased surface area for cellular adhesion.

Both uniaxial and coaxial electrospinning methods have been employed to fabricate scaffolds for wound healing applications. Ren et al., demonstrated the role of highly aligned fibres using uniaxial electrospinning in significantly enhancing cellular attachment during wound healing (Ren et al., 2018). This process however required highly volatile solvent to achieve the highly porous structure. These nanofiber constructs have proven successful in localised delivery of wound healing agents, which results in complete and successful wound healing of DFU.

Progressing from traditional simple nanofiber constructs, there has been greater development of composite nanofiber scaffolds. Ahmed et al., found significant contraction of the wound area in an in vivo diabetic rabbit model for the chitosan/polyvinyl alcohol/ZnO scaffolds when compared to chitosan/polyvinyl alcohol scaffolds, as well as higher antibacterial and antioxidant potential (Ahmed et al., 2018). Curcumin-loaded scaffolds, which were generated from gum tragacanth/PCL electrospun fibres showed significant wound closure following 15 days and displayed functions characteristic of normal wound healing, such as increased collagen deposition, well-formed granulation tissue and complete regeneration of the epithelial layer. The electrospinning method allowed well-distributed cellular attachment to these scaffolds (Mohammadi et al., 2016). Core-shell scaffolds produced from chitosan and PLA through the coaxial electrospinning technique demonstrated feasibility in its application to tissue engineering, having increased elastic modulus and tensile strength of the scaffold as well as supporting cell adhesion and proliferation of fibroblasts (Surucu and Turkoglu Sasmazel, 2016).

Electrospinning has also been used in combination with 3D printing methods to produce a scaffold which successfully mimicked the ECM, promoted cell proliferation and diabetic wound healing in an ex vivo pig model (Mellor et al., 2017). 
International Journal of Pharmaceutics

551 The relative advantages and disadvantages of electrospinning scaffold fabrication methods are summarised in Table 3.

\subsection{D Printing: Fused Deposition Modelling}

554

555

556

557

558

559

560

561

562

563

564

565

566

567

568

569

570

571

572

573

574

575

576

577

578

579

580

581

Fused deposition modelling (FDM) is a "technology where the melt extrusion method is used to deposit filaments of thermal plastics according to a specific pattern" (Walker and Santoro, 2017). Prior to printing via FDM methods, the user produces a scaffold design using Computer Aided Design (CAD) which is then subject to slicing to allow printing. Using this technology, filaments of thermal plastics are extruded through a nozzle using the melt extrusion method in a predetermined pattern, which corresponds to the chosen CAD design. This process follows a layer-by-layer approach to fabricate scaffolds of various geometries and sizes. Figure 3 shows a schematic representation of the apparatus setup used for FDM.

The architecture of the porous scaffolds used in these wound healing applications can be easily designed and altered using CAD software. Like electrospinning, this method can produce scaffolds composed of a wide variety of polymeric materials, based on the desired properties of the scaffold. Scalability and rapid production of scaffolds, in a timescale of minutes to hours, provide further advantages for this method. Scaffolds produced by FDM have shown promising mechanical properties, no cytotoxicity and acute enhancement of fibroblast proliferation (Kovalcik et al., 2020).

Chitosan-based scaffolds produced by FDM showed significant cellular proliferation and infiltration by keratinocyte and fibroblasts in vitro, with optimal cell growth achieved following 35 days. These structures lead to accelerated healing of the diabetic wound in vivo and successfully prevented wound infection (Intini et al., 2018). FDM printing was used to produce a scaffold, which had an elastic modulus equal to that of collagen (24MPa) which provided optimal conditions for normal wound healing, such as polarisation of macrophages towards the M2 phenotype and increased expression of the PDGFb gene in granulation tissue (Guo et al., 2015).

FDM does not require the use of solvents, as successful extrusion of the material can be achieved through optimisation of temperature, and pressure parameters and has suggested to be more useful for production of larger scaffolds (Trachtenberg et al., 2016). As well as this, FDM is capable of printing high viscosity solutions while maintaining control over aspects such as pore size and degree of porosity (Trachtenberg et al., 2016) 
582

Meshes fabricated through 3D printing have shown to improve mechanical properties of electrospun PCL/gelatin scaffold in vivo whilst maintaining a structure which closely mimicked ECM (Pensa et al., 2019). FDM is capable of producing scaffolds with a higher Young's modulus versus solvent exchange deposition modelling (SEDM) (Gao et al., 2020). Due to the nature of the skin however, these structures produced by FDM may be too rigid and not offer the flexibility required for these applications. In this case, the combination of FDM with other scaffold production techniques such as SEDM or electrospinning should be considered. Furthermore, subject to the material used, combination of high shear, high temperature and high pressures required for this process may subject the material to phase changes and alterations, which ultimately affect the biocompatibility of the given material (Domingos et al., 2009).

FDM printing has been used in combination with other processing techniques. Song et al., achieved microporous PLA scaffolds through the combination of FDM and gas foaming processing for bone tissue engineering purposes. The FDM process produced macropores of $100-800 \mu \mathrm{m}$ in size, while micropores of $2-10 \mu \mathrm{m}$ were also produced due to gas foaming (Song et al., 2018). This work shows the potential of technologies such as gas foaming to be used in a complimentary manner with FDM to improve the resolution of FDM printing which could be applied to diabetic wound healing applications.

The relative advantages and disadvantages of FDM scaffold fabrication methods are summarised in Table 4.

\subsection{D Bioprinting}

In the production of 3D bioprinted scaffolds, the bioink is laid down in a layer-by-layer manner to fabricate a pre-specified design, allowing the user to create scaffolds with a high degree of repeatability, which mimic the target organ or tissue. Similar to FDM, in the pre-processing stage scaffolds designs are created using CAD and are subject to slicing in preparation for bioprinting. 3D bioprinting techniques, collectively known as additive manufacturing (AM), includes inkjet-based, extrusion-based and laser-based technologies. The chosen bioprinting technique should take into account factors such as the application of the scaffold, the materials used and the corresponding benefits and drawbacks of each bioprinting method.

In general, bioprinting offers several advantages, including the production of scaffolds with a highly porous structure that are capable of supporting cell adhesion and proliferation and 
allowing oxygen to permeate through the structure to ensure nutrient transport to the innermost sections of the scaffold. High loading of cells and growth factors can also be achieved (Wang et al., 2021), although the extent to which this is achieved varies between bioprinting methods. For example, stem cells, namely adipose-derived stem cells (ASCs) and endothelial progenitor cells (EPCs) have been incorporated into a skin-derived ECM bioink for wound healing applications. This patch was found to successfully enhance wound closure, improve blood flow in the early wound healing stages and promote re-epithelialisation (Kim et al., 2018).

The relative advantages and disadvantages of various bioprinting techniques are summarised in Table 5.

\subsubsection{Inkjet-based bioprinting}

Inkjet-based bioprinting is a low-cost method involving droplets of solution being dispensed in a non-contact manner to create a pre-specified design. This can be done using thermal, piezoelectric or micro-valve mechanisms (Rider et al., 2018). The size and volume of these droplets can be carefully controlled, ultimately producing high-resolution scaffolds, as well as highly complex structures when required. Figure 4 shows the schematic setup of ink-jet based bioprinting technologies.

The rapid inkjet-based bioprinting process involves two stages: firstly, the deposition of bioink droplets on a picolitre scale onto the substrate secondly followed by in situ gelation of the biomaterial to form a solid structure. In some cases, chemical, physical, or photo-crosslinking of the chosen biomaterial may be required in order to maintain the structural rigidity of the scaffold. A rapid gelation time is therefore required in order to prevent spreading of the printed bioink which would lead to poor shape fidelity of the resulting structure.

Despite rapid printing speeds, inkjet bioprinting cannot achieve high cell loading densities (Negro et al., 2018). Still, a high cell viability can be achieved, with some studies achieving up to $99 \%$ viability (Takagi et al., 2019). Furthermore, high resolutions of $100 \mu \mathrm{m}$ have been reported using inkjet bioprinting methods (Zhang et al., 2017).

Two forms of inkjet-based bioprinting exists: continuous inkjet (CIJ) printing and drop-ondemand (DOD) printing. In CIJ, a piezoelectric crystal attached to the printing nozzle sends ultrasonic vibrations to break up the continuous ink Jetstream into small droplets. Some of these droplets become charged as they pass through an electrostatic field before passing 
through a second electrostatic field, causing charged droplets to deflect towards the printing medium (Needham Coding, 2020). Polymer degradation has been observed as a result of bioink recycling during CIJ (Wheeler et al., 2014). This could have significant implication for scale up activities, including loss of a large amount of material and therefore this method should be carefully considered for large-scale activities. Meanwhile, DOD achieves higher precision and accuracy through use of a mechanism which only produces droplets when an ejection signal is reached (Haas et al., 2017).

Inkjet bioprinting has been used for direct printing of cells and biologics such as growth factors. Yanez et al., used inkjet bioprinting method to produce a bilayer skin graft in where one collagen-based layer was laden with neonatal human dermal fibroblasts and epidermal keratinocytes, while the fibrin layer was laden with endothelial cells. Overall, this scaffold demonstrated $17 \%$ improvement in wound contraction compared to FDA-approved Apligraft (Yanez et al., 2015)

Inkjet bioprinting devices capable of in situ bioprinting have recently been developed in an effort to overcome typical problems such as irregular wound topology (Albanna et al., 2019).

\subsubsection{Extrusion-based bioprinting}

In extrusion-based bioprinting, the ink is extruded through the nozzle in a continuous manner, which is driven by either a piston, screw or pneumatic pressure mechanisms, allowing the user to fabricate a product in a layer-by-layer manner. This affordable method is preferred for the preparation of larger structures and has been identified as the most suitable bioprinting method for soft tissue purposes (McCormack et al., 2020). Parameters such as nozzle diameter, pressure, temperature and extrusion speed can be altered depending on the material used and its application. Figure 5 provides an outline of the setup for extrusion-based bioprinting technologies.

Although rare in literature, given studies have demonstrated the ability of extrusion-based bioprinting to successfully extrude viable cells using nozzle diameters of 200um (Kolesky et al., 2016). Typically, compared to inkjet bioprinting, more moderate resolution values have been recorded in the range of $300 \mu \mathrm{m}$ to $600 \mu \mathrm{m}$ (Tan et al., 2016). Parameters affecting resolution include printing conditions (e.g. pressure), material properties, material extrudability and print time (Gillispie et al., 2020). Unlike inkjet-based bioprinting however, extrusion-based bioprinting allows high seeding capacities (Tan et al., 2016). 
Screw-driven extrusion is suitable for high viscosity materials such as PCL (Visser et al., 2013), primarily due to the level of control it provides over the flow of the bioink. Higher viscosity bioinks result in greater resolution (Zhuang et al., 2019). Despite this, printing at a high pressure will incur issues such as the requirement of a faster printing speed which will in turn reduce cell viability (Fakhruddin et al., 2018)

Various cell lines have been investigated in association with extrusion-based bioprinting. Each cell type will have different viability values dependent on their given ability to withstand shear stresses involved with the printing process.

Soltan et al., demonstrated the use of extrusion-based bioprinting to produce alginate dialdehyde-gelatin hydrogels for tissue engineering purposes. It was found the printability of scaffolds bioprinted at both room temperature and $4{ }^{\circ} \mathrm{C}$ could be improved with the presence of a chemical crosslinker. In addition, cell viability of HUVECs and Schwann cells was maintained for greater than 7 days (Soltan et al., 2019). In order to promote tissue repair, good cell viability and printability of materials is essential, thus demonstrating the potential this scaffold has for wound repair. Cubo et al., used extrusion-based bioprinting to produce a bilayer scaffold to closely mimic the skin. Laden with human plasma, keratinocytes and fibroblasts, these scaffolds demonstrated the suitability of extrusion-based bioprinting to produce structures which closely mimic the skin (Cubo et al., 2016).

Extrusion-based bioprinting techniques are capable of producing scaffolds with desirable mechanical properties. Frost et al., incorporated cellulose nanocrystals (CNC) into PEGDA scaffolds, resulting in scaffolds with excellent mechanical properties, which could easy tuned by varying $\mathrm{CNC}$ concentration. As a further advantage, these complex scaffolds could be fabricated at low temperatures and pressures (Frost et al., 2019).

\subsubsection{Laser-assisted bioprinting}

In this bioprinting technique, an infrared-pulsed energy source is focussed on a ribbon coated with liquid biological materials, which is spread on a metal plate. Radiation then causes removal of the ribbon through evaporation of the biological materials. These reach the substrate in droplet form (Sriphutkiat et al., 2019, Li et al., 2016). Figure 6 outlines the setup of laser-assisted bioprinting technologies. 
Laser-based bioprinting allows printing of biological material, such as cells and DNA at high speed printing of cells, in a MHz range, at a high resolution (Guillotin et al., 2010). High cell densities can also be achieved. Kerouredan et al., showed application of laser-assisted bioprinting for tissue engineering purposes, demonstrating the ability of this technique to allow controlled printing of endothelial cells co-cultured with MSC at high densities within a collagen hydrogel for the formation of vascular structures (Kérourédan et al., 2019). Laser-assisted bioprinting offers resolution values superior to that of both inkjet-based and extrusion-based bioprinting and depends on parameters including but not limited to the layer thickness, surface tension and bioink viscosity.

Laser-assisted bioprinting technique does not require a nozzle, therefore eliminating issues such as nozzle clogging, which are observed with inkjet-based and extrusion-based bioprinting methods (Li et al., 2018), and allows for greater reproducibility. Furthermore, the non-contact nature of this bioprinting method conveys a promising strategy for in situ bioprinting. The application of laser-assisted bioprinting has been demonstrated for bone engineering purposes, showing the ability of this technique to allow controlled in situ printing of endothelial cells, which resulted in bone regeneration (Kérourédan et al., 2019).

Drawbacks of this method include the time-consuming preparation of the ribbon, particularly if several cell lines are required, and the expensive nature of the technique. The laser source has been noted as a potential disruption to cell viability (Guillotin et al., 2010); however, studies using laser-assisted bioprinting have demonstrated high cell viability (Keriquel et al., 2017), indicating this to be a minor occurrence/uncommon issue.

\section{Suitable materials for 3D bioprinted scaffolds}

Wide varieties of polymeric materials are currently being used for 3D bioprinting. The suitability of the material to a particular application comes down to its printability, which in turn is influenced by various properties such as the ability of the material to undergo rapid gelation following extrusion. Importantly, the material should impart certain characteristics that allow the final scaffold to possess similar mechanical, rheological and biological properties of the therapeutic target (Gungor-Ozkerim et al., 2018).

Polymers have been reported in the literature extensively for the fabrication of 3D bioprinted scaffolds for the treatment of DFU. Polymers can be classified as either biodegradable or nonbiodegradable, but in the case of 3D bioprinting, biodegradable polymers are used more 
frequently due to the wide variety of benefits they possess. Depending on their origin, these biodegradable polymers are natural or synthetic and have been used extensively in wound healing applications for DFU, both alone and in combination.

\subsection{Natural polymers}

Natural polymers have shown excellent biocompatibility profiles, which is essential in preventing a foreign body response from the host. Natural polymers however sometimes lack the desired mechanical properties that the scaffolds require in order to provide structural support to the wound healing process. Nonetheless, the popularity of these materials remains high. Natural polymers commonly used in 3D bioprinting are summarised in Table 7.

\subsubsection{Collagen}

As the main structural protein in ECM, collagen is a commonly used material in 3D bioprinting applications for the skin, primarily due to how closely it mimics the physiochemical properties of the skin. A non-toxic and highly permeable material, collagen provides many advantages for wound healing applications and provides the greatest biocompatibility profile of natural polymers (Skardal and Atala, 2015). $\mathrm{pH}$ neutralisation at a temperature of $37^{\circ} \mathrm{C}$ is required for gelation of collagen (Carolina et al., 2020).

Common issues associated with collagen in wound healing applications include its poor mechanical properties and low viscosity (Dong and Lv, 2016). In order to overcome this issue, incorporation of a synthetic polymer may lead to improved mechanical properties whilst preserving the excellent biocompatibility properties that collagen imparts to the bioprinted scaffold. The addition of elastin-like peptide saw a threefold increase in the modulus of collagen scaffold (Gurumurthy et al., 2016). A further way of improving the mechanical issues associated with collagen is through crosslinking (Bou-Akl et al., 2013). This can be achieved through chemical or physical crosslinking methods. In literature, common chemical crosslinking methods for collagen matrices include, but are not limited to, the use of 1-ethyl3-(3-dimethylaminopropyl-carbodiimide hydrochloride (EDC)/N-hydroxy-succinimide (NHS) (Davidenko et al., 2015), genipin (Zhou et al., 2018) and glutaraldehyde (Tian et al., 2016). Physical crosslinking methods have witnessed the use of dehydrothermal treatment (Kozlowska et al., 2017) and UV (Heo et al., 2016). 
763

764

765

766

767

768

769

770

771

772

773

774

775

776

777

778

779

780

781

782

783

784

785

786

787

Collagen forms a hydrogel under physiological conditions; however longer timeframes of 30 minutes and above are required for this process to occur. To reduce these times, and thus improve printing accuracy, the combination of other materials should be considered (Gopinathan and Noh, 2018)

\subsubsection{Gelatin}

Gelatin, is another commonly used biodegradable polymer for biomedical applications, which is formed through denaturation of collagen's triple helix (Boccafoschi et al., 2019). The wide availability, low cost, low immunogenicity, high solubility and structural similarities to collagen make gelatin a popular biomaterial (Bello et al., 2020).

Due to issues experienced as a result of reversible temperature-dependent sol-gel transition of gelatin, native gelatin is rarely used alone in tissue engineering applications (Cheng et al., 2019). As a result, to overcome printability issues, gelatin is commonly used alongside other suitable biomaterials in the fabrication of 3D bioprinted scaffolds. A lack of thermal stability and faster degradation rate of gelatin are among some of the materials disadvantages, as well as the typical poor mechanical properties witnessed with other natural polymers (Bello et al., 2020).

Gelatin-alginate composites have been used extensively in literature for wound healing applications. Liu et al., demonstrated the ability of gelatin-alginate scaffolds in reducing the wound healing time in an in vivo diabetic rat model. The scaffold provided benefits such as reduced necrosis, even granulation tissue formation and reduced swelling (Liu et al., 2016). Moreover, gelatin-alginate bioink combinations have demonstrated the ability to promote cell proliferation and differentiation, good injectability, stability towards cells, regular pore structure and mechanical strength similar to that of the mouse dermal tissue (Cheng et al., 2019)

Modified forms of gelatin, such as gelatin methacryloyl (GelMA), have also been studied in literature. In wound healing applications, GelMA improved angiogenesis and enhanced proliferation fibroblasts and keratinocytes in the form of electrospun patches to promote healing of diabetic wounds via release of epidermal growth factor (EGF) (Augustine et al., 2021). 
792

793

794

795

796

797

798

799

800

801

802

803

804

805

806

807

808

809

810

811

812

813

814

815

816

817

818

819

820

821

822

\subsubsection{Alginate}

As a naturally derived anionic polymer from brown algae, alginate has proven promising in wound healing applications. This can be attributed to its desirable properties including biocompatibility, non-toxicity and low cost.

Alginate is a linear copolymer composed of alternate blocks of $(1,4)$-linked $\beta$-D-mannuronate (M) and $\alpha$-L-guluronate (G) residues (Gaspar et al., 2016). The addition of divalent cations such as $\mathrm{Ca}^{2+}$ for crosslinking purposes is known to lead to the gelation of alginate, and the resultant formation of a hydrogel suitable for biomedical application (Gwon et al., 2015). Only guluronate blocks contribute to crosslinking with divalent cations in the formation of hydrogels, meaning the composition of copolymer blocks within the alginate structure is essential to determining its physiochemical properties and feasibility as a 3D bioprinted scaffold (Chuang et al., 2017).

As a biomaterial, alginate can easily be modified. Thomas et al., retained the beneficial properties of alginate whilst undergoing modification through addition of aleo-vera gel and $\mathrm{CNC}$ to further improve antibacterial and mechanical properties in a conventional wound dressing application (Thomas et al., 2020). Its other advantages include the ability to maintain a moist microenvironment to support wound healing and prevent scar formation (Hana et al., 2014).

As discussed above, alginate has commonly been used in combination with gelatin in order to enhance the mechanical properties of the two biomaterials. In addition to this, the inclusion of $\mathrm{CaCl}_{2}$ as a chemical crosslinking agent has been shown as a successful method in improving both the mechanical and physical properties of sodium alginate films, with $0.8 \mathrm{M}$ of $\mathrm{CaCl}_{2}$ for 8 minutes producing a Young's modulus of $27.81 \pm 7 \mathrm{MPa}$, as shown in Figure 7 and Table 7 (Fadhilah et al., 2019).

Alginate forms a gel in the presence of $\mathrm{CaCl}_{2}$, between $5 \mathrm{mM} / \mathrm{L}$ and $6.25 \mathrm{mM} / \mathrm{L}$ of $\mathrm{CaCl}_{2}$ for every $2 \% \mathrm{w} / \mathrm{w}$ alginate solution ( $\mathrm{H}$. Li et al., 2016). However, at a concentration of $2 \% \mathrm{w} / \mathrm{w}$, alginate cannot form scaffolds due to poor mechanical properties. Increasing the concentration of alginate and the addition of graphene oxide have been reported to limit the effects of the materials shear-thinning behaviour, making it more suitable for bioprinting (H. Li et al., 2016). Given the poor mechanical properties of alginate, it is commonly used in combination with other biomaterials. 
International Journal of Pharmaceutics

\subsubsection{Fibrin}

A potent haemostatic agent, fibrin acts to promote cell adhesion and has desirable biocompatibility in wound healing applications (Climov et al., 2016; Robinson et al., 2017). As a bioink however, fibrin presents several issues.

The rapid degradation of fibrin remains a major obstacle in its use for 3D bioprinted scaffolds; however, recently this issue has been addressed in literature through addition of chemical crosslinking agents, such as genipin (Robinson et al., 2017). Losi et al., developed poly(ether)urethane-polydimethylsiloxane/fibrin-based scaffold for the delivery of nanoencapsulated VEGF and bFGF. These scaffolds were found to significantly increase wound healing capabilities in an in vivo diabetic mouse model, with wound closure occurring at day 15 (Losi et al., 2013). Fibrin also requires a long gelation time of 30 minutes (Cubo et al., 2016)

As with many natural polymers, scaffolds fabricated from fibrin possess poor mechanical properties. In addition to this, proper extrusion of fibrin can be compromised due to the high viscosity of the biomaterial. Similarly, poor shape fidelity is witnessed when printing fibrinogen (de Melo et al., 2020). One strategy used to overcome this issue involves using fibrinogen in combination with other biomaterials, such as gelatin and polyethylene glycol, which show desirable printing properties.

\subsection{Synthetic polymers}

Prepared by chemical synthesis, synthetic polymers used in 3D printing provide benefits such as improved mechanical properties, which helps to aid the properties of natural polymers when used in composite scaffolds. Further general advantages of synthetic polymers include the ability to easily tune their degradation rates, easy modification and functionalisation of their structures and their accessibility. Synthetic polymers commonly used in 3D bioprinting are summarised in Table 8.

\subsubsection{Poly(lactic-co-glycolic acid)}

Poly(lactic-co-glycolic acid) (PLGA) is a copolymer consisting of lactide and glycolide monomers and is synthesised through ring opening of these cyclic dimer rings (Teodora et al., 2015). As well as being biocompatible, PLGA provides desirable mechanical properties for 
scaffold applications, is a low-cost material and is highly accessible. The degradation rate of PLGA can be easily tailored through manipulation of the monomer ratio, with higher percentage of glycolic units resulting in extended degradation rates (Keles et al., 2015)

PLGA is one of the most commonly used materials in biomedical applications, including hydrogels, nanoparticles and films. PLGA has been used in combination with natural polymers in wound healing scaffold applications. A bilayer scaffold composed of PLGA and alginate, as shown in Figure 8, showed promising wound healing abilities, with PLGA playing a particular role in maintaining moisture content of the hydrogel and inhibiting infection (Wang et al., 2019).

One study concluded that in order to achieve high fidelity through printing of PLGA, concentrations greater than $80 \% \mathrm{w} / \mathrm{v}$ are required, as well as a higher ratio of lactic acid. Furthermore, a molecular weight greater than $100 \mathrm{kDa}$ and internal nozzle diameter less than $0.96 \mathrm{~mm}$ is also recommended (Naseri et al., 2020).

One drawback of PLGA in 3D printing applications is that high temperatures and pressures are required during printing (Allevi, 2020).

\subsubsection{Polycaprolactone}

Polycaprolactone (PCL) is a high molecular weight semi-crystalline thermoplastic polymer, which demonstrates desirable biocompatibility characteristics. Its low melting point of $60^{\circ} \mathrm{C}$ and gelation temperature of $37^{\circ} \mathrm{C}$ makes it appealing for $3 \mathrm{D}$ bioprinting due to its ease of processing (Burns et al., 2010, Nair et al., 2017). PCL undergoes a two-stage degradation process involving hydrolysis and intracellular degradation, with a degradation time of two to four years (Azimi et al., 2014). Moreover, PCL and its degradation products are non-toxic (Sukanya and Mohanan, 2018).

One drawback of PCL in bioprinting is the higher pressures required due to the high viscosity of the material (Cellink, 2020). Support of cellular attachment from scaffolds is an integral part in their work to aid wound healing of DFU; however, the hydrophobic nature of PCL can mean cell colonisation is insufficient. To overcome this, various strategies can be applied to improve the hydrophilicity of PCL. Techniques applied include chemical methods involving the addition of $\mathrm{NaOH}$, for example (Wang et al., 2016). Higher viscosity can also increase the printing time. 
882

883

884

885

886

887

888

889

890

891

892

893

894

895

896

897

898

899

900

901

902

903

904

905

906

907

908

909

910

Despite this, PCL has been used extensively in 3D bioprinting applications for DFU wound healing. One study investigating the effect of various nozzle shapes and sizes, printing speeds and printing temperatures concluded large nozzle sizes and high printing speeds produced the optimal printing conditions when compared to cylinder nozzles (Ortega et al., 2019).

\subsubsection{Polyurethane}

Polyurethane (PU) is a biocompatible material prepared via the addition reaction of diisocyanate and a polyol, followed by the addition of a chain extender, to create a polymer chain comprised of various hard and soft segments (Balaji et al., 2018). The chemical composition of PU directly affects key properties such as thermosensitivity and biodegradability (Tsai et al., 2015).

The excellent mechanical properties and ease of processing of PU makes it an attractive option for scaffold bioprinting applications. Furthermore, as well as its shear thinning properties, PU also shows good elasticity and biocompatibility (Hsieh and Hsu, 2019). As a thermosetting material, scaffolds fabricated from PU demonstrate thermoplastic and elastomer properties.

The biodegradability of PU can be improved through the addition of various other polymers. When used in combination with gelatin, the resultant hydrogel showed excellent printability at low temperatures $\left(24-31^{\circ} \mathrm{C}\right)$, high fidelity, shear-thinning, recovered quickly after excessive strain, could be bioprinted for more than 24 hours, could be stacked well during printing and showed good cell viability and proliferation over a ten-day period. Furthermore, chemical crosslinking with $\mathrm{CaCl}_{2}$ improved mechanical properties such as the compression modulus (Hsieh and Hsu, 2019).

\subsubsection{Polyethylene glycol}

Polyethylene glycol (PEG) is a biocompatible, hydrophilic polymer that is naturally nonbiodegradable, however modification of the PEG structure to include degradable segments induce biodegradable properties.

Composite scaffolds composed of sodium alginate and PEG loaded with Satureja cuneifolia have shown promise in wound healing applications due to suitable swelling behaviour, pore size and antimicrobial activity (Ilhan et al., 2020). GelMA/gelatin/PEG bioprinted scaffolds modified with silica nanoparticles promoted macrophage polarisation towards the anti- 
International Journal of Pharmaceutics

911

912

913

914

915

916

917

918

919

920

921

922

923

924

925

926

927

928

929

930

931

932

933

934

935

936

937

938

939

inflammatory M2 phenotype in diabetic bone repair in an in vivo rat model. As polarisation of macrophages towards M2 phenotype is compromised in diabetic wound healing, this approach could be applied to 3D bioprinted scaffolds for diabetic wound healing applications.

Cellular adhesion cannot be achieved for PEG hydrogels, therefore modification of PEG through the addition of acrylate groups to form poly(ethylene glycol) diacrylate (PEGDA) provides a medium for the adhesion and support of cells (Asawa et al., 2018). The addition of PEGDA as a hydrophilic polymer helped to improve the hydrophilicity of composite scaffolds fabricated from PCL/PEG/chitosan (Cheng and Chen, 2017).

\section{Common drugs used in the treatment of DFU}

As mentioned previously in Section 2, the treatment of DFU may involve the use of standard therapies in combination with advanced therapies. The overall aim of treatment however is to prevent or eradicate infection, encourage a normal wound healing response and control factors such as hyperglycaemia, PAD or DN which could negatively impact the wound healing process. To meet each of these aims, a combination of drugs is often required. In this section, we will review some of the commonly used drugs used in the treatment of DFU.

\subsection{Antibiotics}

One of the first steps to ensure successful wound healing of DFU is to treat any existing infection. Failure to treat any infected ulcers could result in colonisation of pathogens to form a biofilm, which often tend to be resistant to antibiotics and allow disease progression. Drug resistance and recurring infection has been associated with the formation of biofilms (Vatan et al., 2018).

The choice of antibiotic used is dependent on factors such as the severity of the ulcer and pathogen susceptibility, for example. IWGDF have published guidance on the treatment of infected DFU (Bus et al., 2019). Several commonly used antibiotics include penicillins, cephalosporins, carbapenems and fluroquinolones.

In a long-term study conducted between 2008 and 2015, Escherichia coli and Staphylococcus aureus were the two most common bacteria found to infect diabetic wounds (Zubair and Ahmad, 2019). This is supported by more recent findings in where biofilms of $S$. aureus have been found to be promoted by AGEs, which are increased in diabetic patients (Xie et al., 2020). 
May studies into the use of antibiotics to treat DFU infection involve small sample sizes and lack patients suffering from PAD and DN. Furthermore, most studies do not acknowledge the typical polymicrobial nature of DFU infections and biofilms. While many promising and effective treatment outcomes have been noted in literature, there is a strong need for larger studies, studies that focus of treating DFU in patients also suffering from PAD and DN and more studies that investigate polymicrobial biofilm nature of DFU. These aspects need to be addressed in order to achieve reliable data on infection management of DFU, which would be generalizable to clinical settings.

Nonetheless, there is growing evidence for the improved efficacy of topically administered antibiotics to treat biofilms in infected DFU versus systemic administration (Price et al., 2020). A small-scale study was conducted in 23 patients to compare the efficacy of a saline dressing loaded with 500mg vancomycin versus a non-drug loaded saline dressing against DFU infected with MRSA. The infection was resolved in approximately two thirds of patients within two weeks of topical vancomycin treatment, demonstrating its efficiency in the treatment of DFU infection in the absence of any systemic toxicity (Saif et al., 2019). While promising, larger sample sizes are needed.

Controversially, one study found the use of a collagen sponge loaded with gentamycin to have no significant benefit in the treatment of mild DFU infection, compared to the control group who did not receive treatment (Uçkay et al., 2018). Similar findings were obtained for moderate to severe DFU infections (Uçkay et al., 2018).

As well as conventional antibiotics, such as those mentioned above, broad-spectrum silver sulfadiazine has shown promising activity when applied topically to DFU. Low concentrations of silver sulfadiazine successfully eliminated DFU infection within 30 days in patients infected with S. aureus and Pseudomonas aeruginosa biofilms. (Di Domenico et al., 2020). The MBEC values for $S$. aureus and $P$. aeruginosa ranged from 1.25 to $2.5 \mathrm{mg} / \mathrm{L}$ and 0.16 to $0.31 \mathrm{mg} / \mathrm{L}$, respectively. The reduction in inflammation and collagen deposition following two weeks of treatment indicate the key role infection management plays in the successful wound healing of DFU.

\subsection{Human growth factors}

Human growth factors such as PDGF, VEGF and EGF play a key role in orchestrating a normal wound healing process. For example, PDGF is responsible for promoting chemotaxis and 
synthesis of fibroblasts and macrophages (Pierce et al., 1991), two key cells in the wound healing process. Significant association has been found between polymorphism of the VEGF gene and DFU (Talib et al., 2020). In addition, careful consideration is required for the use of TGF, as a balance must be achieved between iNOS and TGF-B1 (El-aleem et al., 2020).

Coaxial PLGA scaffolds prepared by electrospinning were loaded with PDGF, as well as antibiotics gentamicin and vancomycin, which resulted in increased angiogenesis leading to accelerated epidermal proliferation and wound healing in a diabetic rat model in vivo (Lee et al., 2020). When encapsulated in PLGA nanospheres, both PDGF and VEGF-a significantly reduced the ulcer size and promoted wound healing in a diabetic rat model (Shi et al., 2018). This method of delivery could overcome common issues associated with growth factors, such as susceptibility to degradation by enzymes.

In literature, EGF has shown effective in improving DFU healing rates. Complex coacervates fabricated from sodium alginate and gelatin were used to provide sustained release of EGF to diabetic mice in vivo. This system successfully lowered pro-inflammatory cytokines such as IL-1 by day 7 and achieved complete wound closure by day 14 (Jeong et al., 2020). Patches containing EGF have shown more favourable cell adhesion and proliferation by key cells, such as fibroblasts and endothelial cells, versus PHBV-GelMA patches, indicating the crucial and beneficial role EGF in improving the wound healing capabilities. Furthermore, the presence of EGF, and its possible positive influence on VEGF, promoted angiogenesis (Augustine et al., 2021). As angiogenesis is often insufficient in diabetic wounds, the presence of growth factor was paramount in achieving a positive healing response of the diabetic wound.

Kontopodis et al., investigated the effect of autologous platelet-rich plasma on diabetic wound healing. Nearly three quarters of patients with DFU and PAD experienced greater than $90 \%$ reduction in ulcer size and the lower limb amputation rate was considerably lower than the typical value quoted in literature (19\% versus a reported 85\%) (Kontopodis et al., 2016). This indicates platelet-rich plasma to be a promising therapy for diabetic patients simultaneously suffering from PAD; however, larger sample sizes are required to make this generalizable.

\subsection{Stem cells}

The use of stem cells to enhance DFU wound healing is another area receiving considerable attention. There is particular interest in mesenchymal stem cells (MSCs). 
1001

1002

1003

1004

1005

1006

1007

1008

1009

1010

1011

1012

1013

1014

1015

1016

1017

1018

1019

1020

1021

1022

1023

1024

1025

1026

1027

1028

1029

1030

MSCs, which are found in bone marrow and adipose tissue, have proven useful in wound healing applications. Recently, adipose-derived mesenchymal stem cells preconditioned by photobiomodulation, firstly in vitro and then followed by in vivo, were found to significantly improve healing rates of ischemic infected DFU in a rat model (Ahmadi et al., 2020). MSCs provide a great number of benefits, such as their ability to manage oxidative stress and promote an anti-inflammatory response and formation of new blood vessels in damaged tissues (Becerra-bayona et al., 2020).

Case studies indicate the promising ability of allogenic bone marrow MSC derivatives administered via intradermal injection on healing grade 2 DFU, as classified by IWGDF, when compared to a combination treatment of allogenic bone marrow MBC and a conventional dressing. No difference however was observed in the derivative treatment or MSC treatment (Becerra-bayona et al., 2020).

The ability of human umbilical cord MSC to migrate to the site of DFU following intravenous administrated was demonstrated in a rat model. Treatment with human umbilical cord MSC lead to a gradual decrease in ulcer size over time, reduced inflammation, increased secretion of key growth factors such as VEGF, enhanced angiogenesis, promoted re-epithelialisation and reduced apoptosis (Shi et al., 2020), demonstrating the feasibility of IV administered huc-MSC to successfully treat DFU.

While studies in literature indicate promising results of stem cells for wound healing, many of these studies only examine the short-term efficacy of this treatment method. Longer studies are required in order to establish long-term effectiveness and safety of stem cells for wound healing applications.

\subsection{Topical agents}

While many topical agents have been investigated in the treatment of DFU, one group is receiving particular interest.

Monoterpenes, comprising of two isoprene units and 10 carbon atoms, belong to the class of drugs known as terpenes, or isoprenoids. Terpenes are the main constituents found in essential oils and demonstrate excellent wound healing capabilities due to their anti-inflammatory and antimicrobial properties (Buckle, 2015). Monoterpenes commonly used in wound healing applications include: borneol, thymol, $\alpha$-terpineol, genipin, aucubin, $d$-Limonene and sericin. 
1031

1032

1033

1034

1035

1036

1037

1038

1039

1040

1041

1042

1043

1044

1045

1046

1047

1048

1049

1050

1051

1052

1053

1054

1055

1056

1057

1058

1059

1060

1061

Thymol when incorporated into a collagen-based film showed significant improvement in wound retraction on day 7 and 14 compared to wounds dressed with non-drug-loaded collagen films and the untreated control group. On day 7, thymol-collagen dressing groups showed formation of mature granulation tissue, well-formed blood vessels and denser deposition of collagen when compared to undressed and collagen dressed wounds (Riella et al., 2012).

An electrospun PCL patch, loaded with thymol (PCL-THY), which showed similar activity to corticosteroid dexamethasone was demonstrated, with an effective reduction inflammation when used in the PCL scaffold versus when used in combination with tyrosol or tyrosol alone. PCL-THY showcased a $7.33 \%$ burst release of THY in the first 60 min while PCL-TYR resulted in release of $61.74 \%$ after $8 \mathrm{~h}$ (García-Salinas et al., 2020). While promising wound healing capabilities were demonstrated, the drug release of this formulation should be modified in order to achieve sustained drug release over a period of weeks.

Other existing drugs are also showing promising results. Topical application of $0.5 \%$ timolol maleate, a beta blocker, in combination with antibiotics and dressings to diabetic ulcers found significant improvement in wound healing versus the control group who received only antibiotics and dressings, with an approximate $60 \%$ reduction in ulcer size by week 12 irrespective of ulcer type (Thomas et al., 2017). Similarly, successful treatment of DFU with the use of another beta blocker has been noted. Re-epithelialization, increased angiogenesis and ECM formation was observed in diabetic mice receiving $1 \%$ propranolol cream to chronic diabetic wounds (Zheng et al., 2017)

Previously, topical delivery of phenytoin has demonstrated effectiveness in the treatment of grade 1 and 2 DFU (Patil et al., 2013). Phenytoin is a commonly prescribed anticonvulsant used to treat seizures (National Institue for Health and Care Excellence, 2020), but is showing promising use as a wound healing agent. More recently, delivery of topical phenytoin through a nanostructured lipid carrier dressing demonstrated greater healing abilities of neuropathic DFU when compared to phenytoin hydrogel of the same concentration (Motawea et al., 2019).

Patients with Wagner stage 1 and 2 DFU treated with daily $5 \%$ topical potassium permanganate saw greater than $50 \%$ reduction in ulcer size following 21 days. This demonstrates the potential of potassium permanganate to treat mild DFU but larger studies are needed (Delgado-Enciso et al., 2018).

\subsection{Plant derived extracts and compounds}


Medical plants extracts and compounds are often used in wound management, in particular for disinfection, debridement and the provision of a suitable environment for the natural healing process (Firdous and Sautya, 2018). A large number of surveys and studies suggest the beneficial properties of plant derived extracts on wound healing as well as on a wide range of skin diseases (Sabale et al., 2012; Sharma et al., 2013). Potentially, these plant extracts/compounds can be used alone or in combination with antibiotics to limit the infections of wound related bacteria, or to prevent opportunistic infections. They could be used prophylactically in pharmaceutical formulations for topical applications or in combination with lower doses of antibiotics, thus reducing the healing time and severity of infections, as well as the potential development of antibiotic resistance, particularly in patients with DFU.

Acyranthes aspera has been shown to possess wound healing activity due to its astringent and vasoconstrictor actions (Edwin et al., 2008). Also, honey has been shown to possess antioxidant, antibacterial and anti-inflammatory properties that promote wound healing (Yaghoobi et al., 2013). Dwivedi et al., investigated wound healing, antimicrobial and antioxidant capacity of Pongamia Pinnata leaf methanolic extracts in wistar rats, showing orally administered extract in rats an increased wound contraction and tensile strength, as well as TNF- $\alpha$ and IL-6 levels, compared to the controls. The extract exhibited antioxidant activity, as well as antimicrobial activity against gram-positive and gram-negative bacteria which further supports the early wound healing capacity of the $P$. pinnata extract (Dwivedi et al., 2017). Yaseen et al., found the quercetin-rich extract of Ephedra ciliata to have wound healing and anti-inflammatory potential, via downregulation of TNF- $\alpha$ in vivo models, and promoted wound closure in a dose- and time-dependent manner. The antimicrobial activity of the extract also suggested to contribute to wound healing (Yaseen et al., 2020).

Although various studies have shown the beneficial role of plant-derived extracts/compounds in wound management, only a small number of these studies has been focused specifically on the healing of DFUs. As previously discussed, delayed DFU wound healing is underpinned by many factors, particularly including chronic bacterial and fungal infections (Gu et al., 2013). Methicillin-resistant Staphylococcus aureus (MRSA), in addition to being multidrug resistant, has also emerged as a serious and common problem in patients with DFU (Kim et al., 2012). Lavender (Urtica dioica) and nettle (Lavandula angustifolia) extracts were tested against MRSA isolated from DFU, showing great antimicrobial activity against this microorganism. Positive correlation was noted between increasing the content of hydroxycinnamic acids and 
International Journal of Pharmaceutics

1094

1095

1096

1097

1098

1099

1100

1101

1102

1103

1104

1105

1106

1107

1108

1109

1110

1111

1112

1113

1114

1115

1116

1117

1118

1119

1120

flavonoids (quercetin) in the extracts and decreasing bacterial growth activity (Zenão et al., 2017).

Both in vitro and in vivo studies using animal models have explored the wound healing capacity of plant extracts and compounds. The tetrasaccharide stachyose from Radix Rehmanniae and the extract of Radix Astragali have been shown to significantly enhance the proliferation of human keratinocytes in vitro and thus could potentially contribute to wound healing. It is noteworthy, that the effect of both stachyose and the extract on the proliferation of keratinocytes was not affected by increased glucose levels, a condition that is met in patients who suffer from DFU (Ren et al., 2012). According to Alerico et al., who conducted a comprehensive in vitro testing of several plant species, aqueous extracts from Achyrocline satureioides, Matricaria recutita, Melia azedarach and Mirabilis jalapa have demonstrated the ability to stimulate keratinocyte growth (Alerico et al., 2015). Ponnusamy et al., also showed that the polyphenols rich fraction obtained from the organic extract of Dicranopteris linearis promotes fibroblast proliferation and migration in vitro (Ponnusamy et al., 2015).

The aqueous extract of $C$. papaya fruit was studied for its wound healing activity in diabetic rats using excision and dead space wound models. The extract treated rats showed a $77 \%$ reduction in the wound area compared to controls which showed a 59\% reduction. The $C$. papaya extract treated wounds were also found to epithelize faster. $C$. papaya extract also exhibited antimicrobial activity against wound related Pseudomonas aeruginosa, Proteus murabilis, Enterobacter agglumerans and Staphylococcus aureus (Nayak et al., 2007). Candida is the most common yeast that infects diabetic ulcers and results in delaying the wound healing process (Missoni et al., 2006). The study of Kandimalla et al., investigated the antiCandida and wound healing activity of the essential oil obtained from the Cymbopogon nardus leaves in diabetic wounds in mice (Kandimalla et al., 2016). Essential oil treatment resulted in significant reduction of Candida load on diabetic wounds and acceleration of wound healing, evidenced by the reduced inflammatory cytokines levels in the wounded areas compared to non-treated controls. The complete healing of the wounds was also confirmed by histopathological analysis. Rosmarinus officinalis (rosemary) aqueous extract and essential oil has also been found to accelerate the wound healing in diabetic BALB/c mice. The healing effect of the essential oil however, was more pronounced compared to the aqueous extract. The authors in support of the healing capacity of Rosmarinus officinalis found reduced inflammation, wound debridement, closure of the wound area due to rapid wound contraction, full-thickness epidermal regeneration and organization, and increase in the wet weight of 
granulation tissue. Although it was not studied, the authors also attribute the healing capacity to the antimicrobial activity of extract and essential oil (Abu-Al-Basal, 2010).

There is significant evidence to support the use of plant-derived extracts and compounds in the treatment of diabetic wounds, which can indeed lead to new and exciting therapeutic strategies for DFUs. Further research is required to identify and isolate the active ingredients in the plant extracts that are involved in the wound healing processes in diabetic conditions. The application of plant-derived extracts and compounds is hindered however by the lack of clinical trials. Therefore, appropriately designed large-scale clinical trials on the use of the most promising plant extracts/compounds should to be conducted in order to fully elucidate their capacity as a DFU management tool. The application of plant extracts in combination with conventional wound management methods (e.g., wound dressings) should also be explored in depth.

\section{Cold-Plasma in the treatment of DFU}

Plasma medicine is a multidisciplinary field of study, combining plasma physics and chemistry, biology, and engineering. Plasma is regarded as the fourth state of matter and it can be produced by applying high voltages to specific gases resulting in the excitation, dissociation and ionisation of molecules. More specifically, plasma medicine is about producing controllable amounts of chemically reactive species that interact with biological matrices including cells and tissues (Laroussi, 2020). Plasma generators that are able to operate under atmospheric pressure and in low temperature conditions can help in the treatment of sensitive matrices including living matter (e.g. human skin/tissue) without thermal damage (Fridman et al., 2008).

Two types of plasma discharges have been mainly used in biomedical applications: the dielectric barrier discharge (DBD) and the non-equilibrium atmospheric pressure plasma jet (APPJ). Cold atmospheric pressure plasma (CAP) contains chemically reactive species including reactive oxygen species (ROS) and reactive nitrogen species (RNS), which are known to play important biological roles. Other agents present in the plasma such as electrons and ions, UV radiation, and electric fields are also suspected to play active roles in biological applications (Laroussi, 2020; Lietz and Kushner, 2018). CAP has been proposed as a tool for various biological and medical applications for its capacity to reduce bacterial load in a wound and to initiate wound healing (Haertel et al., 2014; Weltmann et al., 2010). 
Therefore, CAP could be used as a possible new treatment for patients suffering from DFUs (Heinlin et al., 2010). CAP has proven its benefits in the reduction of various bacteria and fungi in both in vitro and in vivo studies with effects becoming apparent immediately after treatment. For example, it has been shown that the generated CAP has antibacterial effects that can work against antibiotic-resistant bacteria without harming the surrounding tissue (Bourke et al., 2017; Zimmermann et al., 2012). Bacterial infection is a major contributor to the impaired and incomplete healing of DFUs. Therefore, the CAP antimicrobial effect is considered as a key factor in the application in wounds presenting with bacterial load (Haertel et al. 2014). Also, its ability to reduce the microbial load makes CAP a viable option for the potential replacement of antibiotics and the growing issue of antibiotic resistance (Petruzzi et al., 2020). Isbary et al., reported that a 2-minute CAP treatment was able to decrease the microbial load in different types of chronic ulcers, including diabetic ulcers, irrespective of bacterial species (Isbary et al., 2012).

CAP has also shown to have positive effects in chronic wound treatment. In the study of Cardinal et al., CAP treatment resulted in improved microcirculation and granulation in wound models (Cardinal et al., 2008). There are several factors, which cause impairment in diabetic wound healing process. One of the main reasons for this issue is poor blood circulation in the tissue, which leads to the lack of sufficient nutrients, and oxygen in the wound closure area (Lüscher et al., 2003). Therefore, neovascularization is one of the most important factors contributing to diabetic wound healing. According to Fathollah et al., CAP treatment of wounds in diabetic rats for 10 min induced neovascularization 7 days post treatment (Fathollah et al., 2016), with new epidermal layers being formed 3 days post treatment in the diabetic rats. Hirata et al., also reported plasma treatment resulted in angiogenesis in burn wounds, hypothesised to result from the reactive agents in plasma inducing the release of growth factors (Hirata et al., 2014). Indeed, it has now been revealed that plasma enhances the wound-healing rate in diabetic rodents, presumably due to increased levels of TGF- $\beta 1$, superoxide dismutase, glutathione peroxidase and catalase (Cheng et al., 2018; Fathollah et al., 2016).

There is only a small number of clinical trials done so far on the effects of cold plasma on DFU. Stratmann et al. (2020) conducted a placebo-controlled, patient-blinded study to assess the effect of CAP, generated using argon, in addition to standard care treatment compared with placebo on DFU healing. CAP treatment resulted in a significant increase in wound healing, both in total mean area reduction and mean time to relevant wound area reduction. Interestingly, reduction of infection and wound microbial load was not significantly different 
between CAP and the placebo treatment. These results suggested that CAP led to accelerated wound healing reaching the $10 \%$ and the $20 \%$ surface reduction mark earlier compared to the placebo treatment irrespective of infection and bacterial load reduction and infection status. Mirpour et al., conducted a randomized double-blinded clinical trial for the use of CAP in DFU. They used helium as the inducer gas to produce cold plasma and their results showed that that three sessions of CAP treatment (for $5 \mathrm{~min}$ ) per week, for three consecutive weeks, accelerate wound healing in DFU. Specifically, CAP treatment effectively reduced the wound size and also resulted in an immediate but brief reduction of wound bacterial load. No correlation for bacterial load and wound size was found (Mirpour et al., 2020).

The application of CAP in biomedicine opens up many new possibilities. Although, new fundamental knowledge is continually being developed in this area, there are still unanswered questions. Based on the information presented here, there is clear potential for CAP to be used for DFU treatment, as it is able to both reduce the wound microbial load and accelerate wound healing. It is important to note that potential differences in the antibacterial effects and healing times are to be expected between studies, as these will be dependent on the treatment time, the plasma generator system, working gas composition, distance to plasma source, different environmental variables, and the characteristics of the tissue/wound being treated. Another important factor that needs to be considered in the future is how CAP treatments is tolerated amongst patients with DFUs.

\section{Future directions of DFU}

Due to the increasing incidence of both DM and DFU globally, as well as predicted increases in market growth to meet patient demand, more advanced treatments for DFU wound healing will be required in order to cope with clinical demand.

3D bioprinting has the potential to revolutionise the treatment of DFU. The ability of this technique to rapidly produce complex scaffolds, which can incorporate effective therapeutics or cells, could potentially eliminate the need for some traditional therapies to be implemented, reducing both costs and time involved in treating DFU. Moreover, the development towards in situ bioprinting provides the additional benefit of personalised treatment where other scaffold fabrication techniques do not. 
International Journal of Pharmaceutics

1221

1222

1223

1224

1225

1226

1227

1228

1229

1230

1231

1232

1233

1234

1235

1236

1237

1238

1239

1240

1241

1242

1243

1244

1245

1246

1247

1248

1249

This alone however will not be sufficient. A greater focus on preventative methods is required, something which is currently underrepresented in literature. Nonetheless, by tackling these issues and incorporating 3D bioprinting as a key tool in treating DFU, we believe it is possible to lower the rate of amputations associated with DFU as well as lowering the economic burden.

In this section, we will offer some of our views into how greater focus on DFU prevention and $3 \mathrm{D}$ bioprinting innovations in particular could act to improve the care of DFU in the near future.

\subsection{Personalised treatment}

The use of personalised medicine is expected to increase greatly over the coming years, due to the substantial benefits that this provides.

3D bioprinting allows scaffolds of various structural geometries and sizes to be easily modified in order to be moulded to patient wound topology on an individual level, for example. This would allow complete contact with and coverage of the wound to maximise the potential for successful wound healing outcomes. One technique incorporating this approach in in situ bioprinting, which is gaining considerable interest and has shown feasibility of producing bioinks suitable for this application.

Albanna et al., developed a mobile in situ bioprinting system with built in imaging system to provide delivery of fibrin/collagen hydrogel laden with keratinocytes and fibroblasts. This technique allowed the scaffolds to be tailored to each patient based on individual wound topology, showing successful wound healing characterised by extensive collagen deposition and well-developed vasculature (Albanna et al., 2019). Moeinzadeh et al., developed injectable, in-situ forming collagen/alginate hydrogels suitable for the delivery of cells and growth factors for potential use as a bioink in bioprinting applications. Pre-crosslinking maintained stability following injection. This overcomes printability issues that are associated with collagen and produced a scaffold which retained $90 \%$ cell viability for 7 days following injection, lead to healing of bone defects in a rat model within 8 weeks through release of bovine serum albumin (BSA) and bone morphogenetic protein 2 (BMP2) (Moeinzadeh et al., 2021).

O'Connell et al., demonstrated rapid crosslinking (less than 1 second) of a coaxial bioink directly following extrusion. At an optimal formulation of GelMA $10 \%$, gelatin $3 \%$ and HA 
International Journal of Pharmaceutics

1250

1251

1252

1253

1254

1255

1256

1257

1258

1259

1260

1261

1262

1263

1264

1265

1266

1267

1268

1269

1270

1271

1272

1273

1274

1275

1276

1277

1278

$1 \%$, this overcomes printability and gelation issues observed with some pre- and postcrosslinking methods in bioprinting (Connell et al., 2020).

\subsection{Prevention}

With increasing prevalence of diabetes globally and the expectant increase in DFU, prevention will play a key role in both limiting the costs of treating DFU as well as reducing clinical burden on healthcare systems. It has been estimated that up to $75 \%$ of DFU are preventable (Bus, 2016).

Currently, many existing barriers are preventing effective diagnosis and treatment of DFU. Despite an increase in knowledge and awareness in how to prevent and manage DFU over the years (Desalu et al., 2011), recent studies suggest there is room for considerable improvement in patients compliance with these practices (Abdulghani et al., 2018). One way to tackle this is through greater disease awareness and patient education. However, these need to be studied on a larger scale and in various countries to accurately reflect global attitudes towards DFU prevention.

There is also the need for greater research into prevention of DFU. Although extensive research has been conducted into treatment options for DFU, prevention strategies, and how these can be translated into clinical practice, remain underexposed in research. Currently, for every one randomised control trial investigating DFU prevention, ten exist on DFU treatment (Bus, 2016).

\section{Conclusions}

The incidence of DFU is expected to increase globally, in correlation with an expected increase of diabetes. In order to meet patient demand, new innovative treatment options are required to overcome the limitations of existing treatments. Current evidence suggests the effectiveness of 3D bioprinted scaffolds in the treatment of DFU due to their ability to achieve high cell densities and rapid production of complex structures of various geometries. Furthermore, the progression of bioprinting capabilities towards in situ bioprinting presents exciting opportunities for future treatment options in diabetic wound healing, increasing the prospect of personalised treatment, which would help to revolutionise current treatment options. These developments, combined with increased research focus and patient compliance with critical 
International Journal of Pharmaceutics

prevention strategies are expected to reduce clinical need and improve current diabetic wound healing outcomes.

Funding: This research received no external funding.

Conflicts of Interest: The authors declare no conflict of interest.

\section{References}

Abdulghani, M.H., AlRajeh, A.S., AlSalman, B.H., AlTurki, L.S., AlNajashi, N.S., Irshad, M., Alharbi, K.H., AlBalawi, Y.E., AlSuliman, Y.A., Ahmad, T., 2018. Prevalence of diabetic comorbidities and knowledge and practices of foot care among diabetic patients : a cross-sectional study. Diabetes, Metab. Syndr. Obes. Targets Ther. 11, 417425.

Abdullah Al-Mallah, A.B.A.A.-S., 2018. Negative Pressure Wound Therapy Versus Conventional Dressing in Treatment of Diabetic Foot Wound. Egypt. J. Hosp. Med. 72, 4054-4059. https://doi.org/10.21608/ejhm.2018.9115

Abu-Al-Basal, M.A., 2010. Healing potential of Rosmarinus officinalis L. on full-thickness excision cutaneous wounds in alloxan-induced-diabetic BALB/c mice. J. Ethnopharmacol. 131, 443-450. https://doi.org/10.1016/j.jep.2010.07.007

Ahmadi, H., Amini, A., Fathabady, F.F., Mostafavinia, A., Zare, F., Ebrahimpour-malekshah, R., Ghalibaf, M.N., Abrisham, M., 2020. Transplantation of photobiomodulationpreconditioned diabetic stem cells accelerates ischemic wound healing in diabetic rats. Stem Cell Res. Ther. 2, 1-14.

Ahmed, E.M., 2015. Hydrogel: Preparation, characterization, and applications: A review. J. Adv. Res. 6, 105-121. https://doi.org/10.1016/j.jare.2013.07.006

Ahmed, R., Tariq, M., Ali, I., Asghar, R., Noorunnisa Khanam, P., Augustine, R., Hasan, A., 2018. Novel electrospun chitosan/polyvinyl alcohol/zinc oxide nanofibrous mats with antibacterial and antioxidant properties for diabetic wound healing. Int. J. Biol. Macromol. 120, 385-393. https://doi.org/10.1016/j.ijbiomac.2018.08.057

Alamán, J., Alicante, R., Peña, J.I., Sánchez-Somolinos, C., 2016. Inkjet printing of functional materials for optical and photonic applications. Materials (Basel). 9. https://doi.org/10.3390/ma9110910

Alavi, A., Sibbald, R.G., Mayer, D., Goodman, L., Botros, M., Armstrong, D.G., Woo, K., Boeni, T., Ayello, E.A., Kirsner, R.S., 2014. Diabetic foot ulcers: Part I. Pathophysiology and prevention. J. Am. Acad. Dermatol. 70, 1.e1-1.e18. https://doi.org/10.1016/j.jaad.2013.06.055

Albanna, M., Binder, K.W., Murphy, S. V., Kim, J., Qasem, S.A., Zhao, W., Tan, J., ElAmin, I.B., Dice, D.D., Marco, J., Green, J., Xu, T., Skardal, A., Holmes, J.H., Jackson, J.D., Atala, A., Yoo, J.J., 2019. In Situ Bioprinting of Autologous Skin Cells Accelerates Wound Healing of Extensive Excisional Full-Thickness Wounds. Sci. Rep. 9, 1-15. https://doi.org/10.1038/s41598-018-38366-w

Alerico, G.C., Beckenkamp, A., Vignoli-Silva, M., Buffon, A., Von Poser, G.L., 2015. Proliferative effect of plants used for wound healing in Rio Grande do Sul state, Brazil. J. Ethnopharmacol. 176, 305-310. https://doi.org/10.1016/j.jep.2015.11.001

Allevi, 2020. Bioprinting Hard Tissues Using PLGA [WWW Document]. URL https://www.allevi3d.com/plga-protocol/ (accessed 1.6.20).

Ananian, C.E., 2020. Wound Care, in: Jain, K.M. (Ed.), Office-Based Endovascular Centers. 
Elsevier, pp. 2017-213. https://doi.org/https://doi.org/10.1016/B978-0-323-679695.00027-7.

Ananian, C.E., Dhillon, Y.S., Van Gils, C.C., Lindsey, D.C., Otto, R.J., Dove, C.R., Pierce, J.T., Saunders, M.C., 2018. A multicenter, randomized, single-blind trial comparing the efficacy of viable cryopreserved placental membrane to human fibroblast-derived dermal substitute for the treatment of chronic diabetic foot ulcers. Wound Repair Regen. 26, 274-283. https://doi.org/10.1111/wrr.12645

Arteri-, S., 2008. Use of the SINBAD Classification System and Score inArteri-, S. (2008). Use of the SINBAD Classification System and Score in Comparing Outcome of Foot. Diabetes Care, 31(5), 964-967. http://doi.org/10.2337/dc07-2367.Abbreviations Comparing Outcome of Foot. Diabetes Care 31, 964-967. https://doi.org/10.2337/dc072367.Abbreviations

Asawa, R.R., Belkowski, J.C., Schmitt, D.A., Hernandez, E.M., Babcock, E., Lochner, C.K., Baca, H.N., Rylatt, C.M., Steffes, I.S., Vansteenburg, J., Diaz, K.E., Doroski, D.M., 2018. Transient cellular adhesion on poly ( ethylene-glycol ) -dimethacrylate hydrogels facilitates a novel stem cell bandage approach. PLoS One 13, 1-20. https://doi.org/https://doi.org/10.1371/journal.pone.0202825

Augustine, R., Hasan, A., Dalvi, Y.B., Raza, S., Rehman, U., Varghese, R., Narayanan, R., Yalcin, H.C., Alfkey, R., Thomas, S., Moustafa, A. Al, 2021a. Materials Science \& Engineering $\mathrm{C}$ Growth factor loaded in situ photocrosslinkable poly ( 3hydroxybutyrate- co - 3-hydroxyvalerate )/ gelatin methacryloyl hybrid patch for diabetic wound healing. Mater. Sci. Eng. C 118, 111519. https://doi.org/10.1016/j.msec.2020.111519

Augustine, R., Hasan, A., Dalvi, Y.B., Rehman, S.R.U., Varghese, R., Unni, R.N., Yalcin, H.C., Alfkey, R., Thomas, S., Al Moustafa, A.E., 2021b. Growth factor loaded in situ photocrosslinkable poly(3-hydroxybutyrate-co-3-hydroxyvalerate)/gelatin methacryloyl hybrid patch for diabetic wound healing. Mater. Sci. Eng. C 118, 111519. https://doi.org/10.1016/j.msec.2020.111519

Avogaro, A., Albiero, M., Menegazzo, L., De Kreutzenberg, S., Fadini, G.P., 2011. Endothelial dysfunction in diabetes: The role of reparatory mechanisms. Diabetes Care 34, 285-290. https://doi.org/10.2337/dc11-s239

Azad, A.K., Wan Azizi, W.S., Adham, S.A., Yee, B.L., 2016. Maggot debridement therapy for diabetic foot ulcer : Experience from Maggot treatment Centers. Asian J. Pharm. Pharmacol. 2, 23-25.

Azimi, B., Nourpanah, P., Rabiee, M., Arbab, S., 2014. Poly ( $\varepsilon$-caprolactone ) Fiber : An Overview. J. Eng. Fiber. Fabr. 9. https://doi.org/10.1177/155892501400900309

Balaji, A.B., Pakalapati, H., Khalid, M., Walvekar, R., Siddiqui, H., 2018. Natural and synthetic biocompatible and biodegradable polymers, in: Shimpi, N.G. (Ed.), Biodegradable and Biocompatible Polymer Composites. Woodhead Publishing, pp. $3-$ 32. https://doi.org/https://doi.org/10.1016/B978-0-08-100970-3.00001-8

Bandyk, D.F., 2018. The diabetic foot: Pathophysiology, evaluation, and treatment. Semin. Vasc. Surg. 31, 43-48. https://doi.org/10.1053/j.semvascsurg.2019.02.001

Barman, P.K., Koh, T.J., 2020. Macrophage Dysregulation and Impaired Skin Wound Healing in Diabetes. Front. Cell Dev. Biol. 8, 1-9. https://doi.org/10.3389/fcell.2020.00528

Becerra-bayona, S.M., Solarte-david, V.A., Sossa, C.L., Mateus, L.C., Villamil, M., Pereira, J., Arango-rodríguez, M.L., 2020. Mesenchymal stem cells derivatives as a novel and potential therapeutic approach to treat diabetic foot ulcers. Endocrinol. Diabetes Metab. https://doi.org/10.1530/EDM-19-0164

Beckert, S., Witte, M., Wicke, C., Königsrainer, A., Coerper, S., 2006. A new wound-based 
severity score for diabetic foot ulcers: A prospective analysis of 1,000 patients. Diabetes Care 29, 988-992. https://doi.org/10.2337/dc05-2431

Bello, A.B., Kim, Deogil, Kim, Dohyun, Park, H., Lee, S., 2020. Engineering and Functionalization of Gelatin Biomaterials : From Cell Culture to Medical Applications. Tissue Eng. - Part B Rev. 26, 164-181. https://doi.org/10.1089/ten.teb.2019.0256

Boccafoschi, F., Ramella, M., Fusaro, L., Catoira, M.C., Casella, F., 2019. Biological Grafts: Surgical Use and Vascular Tissue Engineering Options for Peripheral Vascular Implants, in: Narayan, R. (Ed.), Encyclopedia of Biomedical Engineering. Elsevier, pp. 310-321.

Bou-Akl, T., Banglmaier, R., Miller, R., Vandevord, P.J., 2013. Effect of crosslinking on the mechanical properties of mineralized and non-mineralized collagen fibers. J. Biomed. Mater. Res. - Part A 101A. https://doi.org/10.1002/jbm.a.34549

Bourke, P., Ziuzina, D., Han, L., Cullen, P.J., Gilmore, B.F., 2017. Microbiological interactions with cold plasma. J. Appl. Microbiol. 123, 308-324. https://doi.org/10.1111/jam.13429

Buckle, J., 2015. Basic Plant Taxonomy, Basic Essential Oil Chemistry, Extraction, Biosynthesis, and Analysis, in: Buckle, J. (Ed.), Clinical Aromathepary. Churchill Livingstone, London, pp. 37-72. https://doi.org/https://doi.org/10.1016/B978-0-70205440-2.00003-6

Burns, S.P., Xing, D., Shapley, R.M., 2010. Comparison of the Dynamics of LFP and MUA Signals in Macaque Visual Cortex. J. Neurosci. 30, 13739-13749. https://doi.org/10.1007/s00396-011-2476-y.Effect

Bus, S.A., 2016. A shift in priority in diabetic foot care and research : $75 \%$ of foot ulcers are preventable. Diabetes. Metab. Res. Rev. 32, 195-200. https://doi.org/10.1002/dmrr

Bus, S.A., Armstrong, D.G., Gooday, C., Jarl, G., Caravaggi, C., Viswanathan, V., Lazzarini, P.A., 2020. Guidelines on offloading foot ulcers in persons with diabetes (IWGDF 2019 update). Diabetes. Metab. Res. Rev. 36, 1-18. https://doi.org/10.1002/dmrr.3274

Bus, S.A., Lavery, L.A., Monteiro-Soares, M., Rasmussen, A., Raspovic, A., Sacco, I.C.N., Netten, J.J. van, 2019. IWGDF guideline on the prevention of foot ulcers in persons with diabetes. IWGDF Guidel. 1-36.

Camilleri, A., 2019. A reliability study of four validated diabetic foot ulcer classification systems.

Campitiello, F., Mancone, M., Corte, A. Della, Guerniero, R., Canonico, S., 2018. An evaluation of an ultrasonic debridement system in patients with diabetic foot ulcers: A case series. J. Wound Care 27, 222-228. https://doi.org/10.12968/jowc.2018.27.4.222

Cardinal, M., Eisenbud, D.E., Phillips, T., Harding, K., 2008. Early healing rates and wound area measurements are reliable predictors of later complete wound closure. Wound Repair Regen. 16, 19-22. https://doi.org/10.1111/j.1524-475X.2007.00328.x

Carolina, A., Mercedes, P., Gonz, A., Hermida, B., 2020. Collagen and chitosan blends for 3D bioprinting: A rheological and printability approach. Polym. Test. 82. https://doi.org/10.1016/j.polymertesting.2019.106297

Cellink, 2020. Printing Protocol PCL 1-3.

Centre of Disease Control and Prevention, 2020. Cost-Effectiveness of Diabetes Interventions [WWW Document]. URL https://www.cdc.gov/chronicdisease/programsimpact/pop/diabetes.htm\#: :text=Diabetes is the most expensive chronic condition in our nation.\&text $=\% 241$ out of every $\% 244$,caring for people with diabetes.\&text $=\% 24237$ billion $\$(d)$ is, $\% 2490$ billion on reduced pr (accessed 11.20.20).

Chai, Q., Jiao, Y., Yu, X., 2017. Hydrogels for Biomedical Applications: Their Characteristics and the Mechanisms behind Them. Gels 3, 6. https://doi.org/10.3390/gels3010006 
Chen, K., Chou, W., Liu, L., Cui, Y., Xue, P., Jia, M., 2019. Electrochemical sensors fabricated by electrospinning technology: An overview. Sensors (Switzerland) 19. https://doi.org/10.3390/s19173676

Chen, S., Shi, J., Zhang, M., Chen, Y., Wang, X., Zhang, Lei, Tian, Z., Yan, Y., Li, Q., Zhong, W., Xing, M., Zhang, Lu, Zhang, Lin, 2015. Mesenchymal stem cell-laden antiinflammatory hydrogel enhances diabetic wound healing. Sci. Rep. 5, 1-12. https://doi.org/10.1038/srep18104

Chen, X., Cao, X., Jiang, H., Che, X., Xu, X., Ma, B., Zhang, J., Huang, T., 2018. SIKVAVmodified chitosan hydrogel as a skin substitutes for wound closure in mice. Molecules 23, 1-12. https://doi.org/10.3390/molecules23102611

Cheng, K.., Lin, Z.., Cheng, Y.., Chiu, H.., Yeh, N.., Wu, T.K., Wu, J.S., 2018. Wound healing in streptozotocin-induced diabetic rats using atmospheric-pressure argon plasma jet. Sci. Rep. 8, 1-15.

Cheng, L., Yao, B., Hu, T., Cui, X., Shu, X., Tang, S., Wang, R., Wang, Y., Liu, Y., Song, W., Fu, X., Li, H., Huang, S., 2019. Properties of an alginate-gelatin-based bioink and its potential impact on cell migration, proliferation, and differentiation. Int. J. Biol. Macromol. 135, 1107-1113. https://doi.org/10.1016/j.ijbiomac.2019.06.017

Cheng, Y.L., Chen, F., 2017. Preparation and characterization of photocured poly ( $\varepsilon-$ caprolactone) diacrylate/poly (ethylene glycol) diacrylate/chitosan for photopolymerization-type 3D printing tissue engineering scaffold application. Mater. Sci. Eng. C 81, 66-73. https://doi.org/10.1016/j.msec.2017.07.025

Chong, K.K.L., Tay, W.H., Janela, B., Yong, A.M.H., Liew, T.H., Madden, L., Keogh, D., Barkham, T.M.S., Ginhoux, F., Becker, D.L., Kline, K.A., 2017. Enterococcus faecalis Modulates Immune Activation and Slows Healing during Wound Infection. J. Infect. Dis. 216, 1644-1654. https://doi.org/10.1093/infdis/jix541

Choo, J., Nixon, J., Nelson, A., McGinnis, E., 2019. Autolytic debridement for pressure ulcers. Cochrane Database Syst. Rev. 2019, 2-5. https://doi.org/10.1002/14651858.CD011331.pub2

Christman, A.L., Selvin, E., Margolis, D.J., Lazarus, G.S., Garza, L.A., 2011. Hemoglobin A1c is a Predictor of Healing Rate In Diabetic Wounds. J. Invest. Dermatol. 131, 21212127.

Chuan, F., Tang, K., Jiang, P., Zhou, B., He, X., 2015. Reliability and validity of the perfusion, extent, depth, infection and sensation (PEDIS) classification system and score in patients with diabetic foot ulcer. PLoS One 10, 1-9. https://doi.org/10.1371/journal.pone.0124739

Chuang, J., Huang, Y., Lo, S., Hsu, T., Huang, W., Huang, S., Lin, Y., 2017. Effects of pH on the Shape of Alginate Particles and Its Release Behavior 2017.

Clayton, W., Elasy, T.A., 2009. A review of the pathophysiology, classification, and treatment of foot ulcers in diabetic patients. Clin. Diabetes 27, 52-58. https://doi.org/10.2337/diaclin.27.2.52

Climov, M., Leavitt, T., Molnar, J., Orgill, D., 2016. Natural Biomaterials for Skin Tissue Engineering, in: Albanna, M.Z., Holmes, J.H. (Eds.), Skin Tissue Engineering and Regenerative Medicine. Academic Press, pp. 145-161. https://doi.org/https://doi.org/10.1016/B978-0-12-801654-1.00008-5

Connell, C.D.O., Konate, S., Onofrillo, C., Kapsa, R., Baker, C., Duchi, S., Eekel, T., Yue, Z., Beirne, S., Barnsley, G., Di, C., Choong, P.F., Wallace, G.G., 2020. Bioprinting Free-form co-axial bioprinting of a gelatin methacryloyl bio-ink by direct in situ photocrosslinking during extrusion. Bioprinting 19, e00087. https://doi.org/10.1016/j.bprint.2020.e00087

Cubo, N., Garcia, M., Cañizo, J.F. Del, Velasco, D., Jorcano, J.L., 2016. 3D bioprinting of 
functional human skin: production and in vivo analysis. Biofabrication 9. https://doi.org/10.1088/1758-5090/9/1/015006

Davidenko, N., Schuster, C.F., Bax, D. V., Raynal, N., Farndale, R.W., Best, S.M., Cameron, R.E., 2015. Control of crosslinking for tailoring collagen-based scaffolds stability and mechanics. Acta Biomater. 25, 131-142. https://doi.org/10.1016/j.actbio.2015.07.034

de Melo, B.A.., Jodat, Y.A., Cruza, E.M., Benincasaa, J.C., Shin, S.R., Porcionattoa, M.A., 2020. Strategies to use fibrinogen as bioink for 3D bioprinting fibrin-based soft and hard tissues. Acta Biomater. 117, 60-76. https://doi.org/https://doi.org/10.1016/j.actbio.2020.09.024.

Delgado-Enciso, I., Madrigal-Perez, V.M., Lara-Esqueda, A., Diaz-Sanchez, M.G., GuzmanEsquivel, J., Rosas-Vizcaino, L.E., Virgen-Jimenez, O.O., Kleiman-Trujillo, J., LagardaCanales, M.R., Ceja-Espiritu, G., Rangel-Salgado, V., Lopez-Lemus, U.A., DelgadoEnciso, J., Lara-Basulto, A.D., Hernández, A.D.S., 2018. Topical 5\% potassium permanganate solution acceleratesthe healing process in chronic diabetic foot ulcers. Biomed. Reports 8, 156-159. https://doi.org/10.3892/br.2018.1038

Desalu, O.O., Salawu, F.K., Jimoh, A.K., Adekoya, A.O., Busari, O.A., 2011. DIABETIC FOOT CARE : SELF REPORTED KNOWLEDGE AND PRACTICE AMONG PATIENTS ATTENDING THREE TERTIARY HOSPITAL IN NIGERIA. Ghana Med. J. 45.

Dhatariya, K.K., Li Ping Wah-Pun Sin, E., Cheng, J.O.S., Li, F.Y.N., Yue, A.W.Y., Gooday, C., Nunney, I., 2018. The impact of glycaemic variability on wound healing in the diabetic foot - A retrospective study of new ulcers presenting to a specialist multidisciplinary foot clinic. Diabetes Res. Clin. Pract. 135, 23-29. https://doi.org/10.1016/j.diabres.2017.10.022

Di Domenico, E.G., De Angelis, B., Cavallo, I., Sivori, F., Orlandi, F., Fernandes Lopes Morais D’Autilio, M., Di Segni, C., Gentile, P., Scioli, M.G., Orlandi, A., D’Agosto, G., Trento, E., Kovacs, D., Cardinali, G., Stefanile, A., Koudriavtseva, T., Prignano, G., Pimpinelli, F., Lesnoni La Parola, I., Toma, L., Cervelli, V., Ensoli, F., 2020. Silver Sulfadiazine Eradicates Antibiotic-Tolerant Staphylococcus aureus and Pseudomonas aeruginosa Biofilms in Patients with Infected Diabetic Foot Ulcers. J. Clin. Med. 9, 3807. https://doi.org/10.3390/jcm9123807

Diabetes UK, 2020. What is HBA1C [WWW Document]. URL https://www.diabetes.org.uk/guide-to-diabetes/managing-your-diabetes/hbalc (accessed 12.16.20).

Domingos, M., Dinucci, D., Cometa, S., Alderighi, M., Bártolo, P.J., Chiellini, F., 2009. Polycaprolactone Scaffolds Fabricated via Bioextrusion for Tissue Engineering Applications. Int. J. Biomater. 2009, 1-9. https://doi.org/10.1155/2009/239643

Dong, C., Lv, Y., 2016. Application of Collagen Scaffold in Tissue Engineering: Recent Advances and New Perspectives. Polymers (Basel). 8. https://doi.org/https://doi.org/10.3390/polym8020042

Dwivedi, D., Dwivedi, M., Malviya, S., Singh, V., 2017. Evaluation of wound healing, antimicrobial and antioxidant potential of Pongamia pinnata in wistar rats. J. Tradit. Complement. Med. 7, 79-85. https://doi.org/10.1016/j.jtcme.2015.12.002

Edwin, S., Jarald, E.E., Deb, L., Jain, A., Kinger, H., Dutt, K.R., Raj, A.A., 2008. Wound healing and antioxidant activity of achyranthes aspera. Pharm. Biol. 46, 824-828. https://doi.org/10.1080/13880200802366645

El-aleem, S.A.A., Mohammed, H.H., Saber, E.A., Embaby, A.S., Djouhri, L., 2020. Mutual inter-regulation between iNOS and TGF- $\beta 1$ Possible molecular and cellular mechanisms of iNOS in wound healing. BBA - Mol. Basis Dis. 1866, 165850. https://doi.org/10.1016/j.bbadis.2020.165850 
Ellis, S., Lin, E.J., Tartar, D., 2018. Immunology of Wound Healing. Curr. Dermatol. Rep. 7, 350-358. https://doi.org/10.1007/s13671-018-0234-9

Fadhilah, S., Aisyah, N., Mohd, N., Mat, K.A., 2019. Sodium alginate film : the effect of crosslinker on physical and mechanical properties Sodium alginate film : the effect of crosslinker on physical and mechanical properties. https://doi.org/10.1088/1757899X/509/1/012063

Fakhruddin, K., Hamzah, M.S.A., Razak, S.I.A., 2018. Effects of extrusion pressure and printing speed of 3D bioprinted construct on the fibroblast cells viability. IOP Conf. Ser. Mater. Sci. Eng. 440, 2-7. https://doi.org/10.1088/1757-899X/440/1/012042

Fathollah, S., Mirpour, S., Mansouri, P., Dehpour, A.R., Ghoranneviss, M., Rahimi, N., Safaie Naraghi, Z., Chalangari, R., Chalangari, K.M., 2016. Investigation on the effects of the atmospheric pressure plasma on wound healing in diabetic rats. Sci. Rep. 6, 1-9. https://doi.org/10.1038/srep19144

Fernando, M.E., Crowther, R.G., Lazzarini, P.A., Sangla, K.S., Wearing, S., Buttner, P., Golledge, J., 2016. Plantar pressures are higher in cases with diabetic foot ulcers compared to controls despite a longer stance phase duration. BMC Endocr. Disord. 16. https://doi.org/10.1186/s12902-016-0131-9

Fesseha, B.K., Abularrage, C.J., Hines, K.F., Sherman, R., Frost, P., Langan, S., Canner, J., Likes, K.C., Hosseini, S.M., Jack, G., Hicks, C.W., Yalamanchi, S., Mathioudakis, N., 2018. Association of hemoglobin A1c and wound healing in diabetic foot ulcers. Diabetes Care 41, 1478-1485. https://doi.org/10.2337/dc17-1683

Firdous, S.M., Sautya, D., 2018. Medicinal plants with wound healing potential. Bangladesh J. Pharmacol. 13, 41-52. https://doi.org/10.3329/bjp.v13i1.32646

Fortune Business Insights, 2019. Diabetic Foot Ulcer Treatment Market Size, Share and COVID-19 Impact Analysis [WWW Document]. URL https://www.fortunebusinessinsights.com/industry-reports/diabetic-foot-ulcer-dfutreatment-market-101948 (accessed 11.20.20).

Fortune Business Insights, 2018. Diabetic Neuropathy Market Size, Share and Industy Analysis [WWW Document]. URL https://www.fortunebusinessinsights.com/industryreports/diabetic-neuropathy-market-100598 (accessed 12.30.20).

Fridman, G., Friedman, G., Gutsol, A., Shekhter, A.B., Vasilets, V.N., Fridman, A., 2008. Applied plasma medicine. Plasma Process. Polym. 5, 503-533. https://doi.org/10.1002/ppap.200700154

Frost, B.A., Sutliff, B.P., Thayer, P., Bortner, M.J., Foster, E.J., 2019. Gradient Poly ( ethylene glycol ) Diacrylate and Cellulose Nanocrystals Tissue Engineering Composite Scaffolds via Extrusion Bioprinting. Front. Bioeng. Biotechnol. 7, 1-14. https://doi.org/10.3389/fbioe.2019.00280

Gao, D., Wang, Z., Wu, Z., Guo, M., Wang, Y., Gao, Z., Zhang, P., Ito, Y., 2020. 3D-printing of solvent exchange deposition modeling (SEDM) for a bilayered flexible skin substitute of poly (lactide-co-glycolide) with bioorthogonally engineered EGF. Mater. Sci. Eng. C 112, 110942. https://doi.org/10.1016/j.msec.2020.110942

García-Salinas, S., Evangelopoulos, M., Gámez-Herrera, E., Arruebo, M., Irusta, S., Taraballi, F., Mendoza, G., Tasciotti, E., 2020. Electrospun anti-inflammatory patch loaded with essential oils for wound healing. Int. J. Pharm. 577. https://doi.org/https://doi.org/10.1016/j.ijpharm.2020.119067

Gaspar, V.M., F.Moreira, A., Melo-Diogo, D., C.Costa, E., A.Queiroz, J., Sousa, F., Pichon, C., Corriea, I.J., 2016. Multifunctional nanocarriers for codelivery of nucleic acids and chemotherapeutics to cancer cells, in: Grumezescu, A.M. (Ed.), Nanobiomaterials in Medical Imaging. William Andrew Publishing, pp. 163-207. https://doi.org/https://doi.org/10.1016/B978-0-323-41736-5.00006-6 
Gebisa, A.W., Lemu, H.G., 2018. Investigating effects of Fused-deposition modeling (FDM) processing parameters on flexural properties of ULTEM 9085 using designed experiment. Materials (Basel). 11, 1-23. https://doi.org/10.3390/ma11040500

Gillispie, G., Prim, P., Copus, J., Fisher, J., Mikos, A.G., Yoo, J.J., Atala, A., Lee, S.J., 2020. Assessment methodologies for extrusion-based bioink printability. Biofabrication 12, 128. https://doi.org/10.1088/1758-5090/ab6f0d

Gopinathan, J., Noh, I., 2018. Recent trends in bioinks for 3D printing. Biomater. Res. 22, $1-$ 15.

Gorantla, S., Rapalli, V.K., Waghule, T., Singh, P.P., Dubey, S.K., Saha, R.N., Singhvi, G., 2020. Nanocarriers for ocular drug delivery: Current status and translational opportunity. RSC Adv. 10, 27835-27855. https://doi.org/10.1039/d0ra04971a

Gu, X. yan, Shen, S. e., Huang, C. fa, Liu, Y. na, Chen, Y. chen, Luo, L., Zeng, Y., Wang, A. ping, 2013. Effect of activated autologous monocytes/macrophages on wound healing in a rodent model of experimental diabetes. Diabetes Res. Clin. Pract. 102, 53-59. https://doi.org/10.1016/j.diabres.2013.08.004

Guillotin, B., Souquet, A., Catros, S., Duocastella, M., Pippenger, B., Bellance, S., Bareille, R., Rémy, M., Bordenave, L., Amédée j, J., Guillemot, F., 2010. Laser assisted bioprinting of engineered tissue with high cell density and microscale organization. Biomaterials 31, 7250-7256. https://doi.org/10.1016/j.biomaterials.2010.05.055

Gungor-Ozkerim, P.S., Inci, I., Zhang, Y.S., Khademhosseinia, A., Dokmecia, M.R., 2018. Bioinks for 3D bioprinting: an overview. Biomater. Sci. 6, 915-946.

Guo, R., Merkel, A.R., Sterling, J.A., Davidson, J.M., Guelcher, S.A., 2015. Substrate Modulus of 3D-Printed Scaffolds Regulates the Regenerative Response in Subcutaneous Implants through the Macrophage Phenotype and Wnt Signaling. Biomaterials 73, 8595. https://doi.org/10.1016/j.biomaterials.2015.09.005.

Guo, X., Su, B., Zhou, Z., Sha, J., 2009. Rapid evolution of mammalian X-linked testis microRNAs. BMC Genomics 10. https://doi.org/10.1186/1471-2164-10-97

Gurumurthy, B., Bierdeman, P.C., Janorkar, A. V., 2016. Composition of elastin like polypeptide-collagen composite scaffold influences in vitro osteogenic activity of human adipose derived stem cells. Dent. Mater. 32, 1270-1280.

Gwon, S.H., Yoon, J., Seok, H.K., Oh, K.H., Sun, J., 2015. Gelation Dynamics of Ionically Crosslinked Alginate Gel with Various Cations 23, 1112-1116. https://doi.org/10.1007/s13233-015-3151-9

Haas, R., Lohse, S., Düllmann, C.E., Eberhardt, K., Mokry, C., Runke, J., 2017. Development and characterization of a Drop-on-Demand inkjet printing system for nuclear target fabrication. Nucl. Instruments Methods Phys. Res. Sect. A Accel. Spectrometers, Detect. Assoc. Equip. 874. https://doi.org/https://doi.org/10.1016/j.nima.2017.08.027.

Haertel, B., von Woedtke, T., Weltmann, K.D., Lindequist, U., 2014. Non-thermal atmospheric-pressure plasma possible application in wound healing. Biomol. Ther. 22, 477-490. https://doi.org/10.4062/biomolther.2014.105

Hajimiri, M., Shahverdi, S., Esfandiari, M.A., Larijani, B., Atyabi, F., Rajabiani, A., Dehpour, A.R., Amini, M., Dinarvand, R., 2016. Preparation of hydrogel embedded polymer-growth factor conjugated nanoparticles as a diabetic wound dressing. Drug Dev. Ind. Pharm. 42, 707-719. https://doi.org/10.3109/03639045.2015.1075030

Hana, F., Dong, Y., Song, A., Yin, R., Li, S., 2014. Alginate/chitosan based bi-layer composite membrane as potential sustained-release wound dressing containing ciprofloxacin hydrochloride. Appl. Surf. Sci. 311, 626-634. https://doi.org/https://doi.org/10.1016/j.apsusc.2014.05.125.

Healthline, 2019. What Is Wound Debridement and When Is It Necessary? [WWW 
Document]. URL https://www.healthline.com/health/debridement (accessed 12.17.20).

Heinlin, J., Morfill, G., Landthaler, M., Stolz, W., Isbary, G., Zimmermann, J.L., Shimizu, T., Karrer, S., 2010. Plasma-Medizin: Anwendungsmöglichkeiten in der Dermatologie. JDDG - J. Ger. Soc. Dermatology 8, 968-977. https://doi.org/10.1111/j.16100387.2010.07495.x

Heo, J., Koh, R.H., Shim, W., Kim, H.D., Yim, H.G., Hwang, N.S., 2016. Riboflavininduced photo-crosslinking of collagen hydrogel and its application in meniscus tissue engineering. Drug Deliv. Transl. Res. 6, 148-158. https://doi.org/10.1007/s13346-0150224-4

Hirata, T., Kishimoto, T., Tsutsui, C., Kanai, T., Mori, A., 2014. Healing burns using atmospheric pressure plasma irradiation. Jpn. J. Appl. Phys. 53. https://doi.org/10.7567/JJAP.53.010302

Hsieh, C., Hsu, S., 2019. Double-Network Polyurethane-Gelatin Hydrogel with Tunable Modulus for High-Resolution 3D Bioprinting. ACS Appl. Mater. Interfaces 11, 3274632757. https://doi.org/10.1021/acsami.9b10784

Ilhan, E., Cesur, S., Guler, E., Topal, F., Albayrak, D., Guncu, M.M., Cam, M.E., Taskin, T., Sasmazel, H.T., Aksu, B., Oktar, F.N., Gunduz, O., 2020. Development of Satureja cuneifolia-loaded sodium alginate/polyethylene glycol scaffolds produced by 3Dprinting technology as a diabetic wound dressing material. Int. J. Biol. Macromol. 161, 1040-1054. https://doi.org/10.1016/j.ijbiomac.2020.06.086

International Diabetes Federation, 2020. About Diabetes [WWW Document]. URL https://www.idf.org/aboutdiabetes/what-is-diabetes/facts-figures.html\#: :text=Diabetes facts $\% 26$ figures,-Last update\%3A 12\&text=The IDF Diabetes Atlas Ninth,will rise to 700 million (accessed 11.20.20).

Intini, C., Elviri, L., Cabral, J., Mros, S., Bergonzi, C., Bianchera, A., Flammini, L., Govoni, P., Barocelli, E., Bettini, R., Mcconnell, M., 2018. 3D-printed chitosan-based sca ff olds : An in vitro study of human skin cell growth and an in-vivo wound healing evaluation in experimental diabetes in rats. Carbohydr. Polym. 199, 593-602. https://doi.org/10.1016/j.carbpol.2018.07.057

Isbary, G., Heinlin, J., Shimizu, T., Zimmermann, J.L., Morfill, G., Schmidt, H.U., Monetti, R., Steffes, B., Bunk, W., Li, Y., Klaempfl, T., Karrer, S., Landthaler, M., Stolz, W., 2012. Successful and safe use of 2 min cold atmospheric argon plasma in chronic wounds: Results of a randomized controlled trial. Br. J. Dermatol. 167, 404-410. https://doi.org/10.1111/j.1365-2133.2012.10923.x

Jeong, S., Kim, B., Park, M., Ban, E., Lee, S., Kim, A., 2020. Improved Diabetic Wound Healing by EGF Encapsulation in Gelatin-Alginate Coacervates. Pharmaceutics 12, 117.

Jia, L., Parker, C.N., Parker, T.J., Kinnear, E.M., Derhy, P.H., Alvarado, A.M., Huygens, F., Lazzarini, P.A., 2017. Incidence and risk factors for developing infection in patients presenting with uninfected diabetic foot ulcers. PLoS One 12, 1-15. https://doi.org/10.1371/journal.pone.0177916

Jimenez, J.C., Agnew, P.S., Mayer, P., Clements, J.R., Slade, J.M., Caporusso, Darrell B. Herbert, L.L., Dickerson, J.E., 2017. Enzymatic Debridement of Chronic Nonischemic Diabetic Foot Ulcers: Results of a Randomized, Controlled Trial. Wounds uk 29, 133139.

Jin, S.G., Yousaf, A.M., Kim, K.S., Kim, D.W., Kim, D.S., Kim, J.K., Yong, C.S., Youn, Y.S., Kim, J.O., Choi, H.G., 2016. Influence of hydrophilic polymers on functional properties and wound healing efficacy of hydrocolloid based wound dressings. Int. J. Pharm. 501, 160-166. https://doi.org/10.1016/j.ijpharm.2016.01.044

Jung, J.A., Yoo, K.H., Han, S.K., Lee, Y.N., Jeong, S.H., Dhong, E.S., Kim, W.K., 2016. 
Influence of Negative-Pressure Wound Therapy on Tissue Oxygenation in Diabetic Feet. Adv. Ski. Wound Care 29, 364-370. https://doi.org/10.1097/01.ASW.0000483038.18331.a4

Junker, J.P.E., Kamel, R.A., Caterson, E.J., Eriksson, E., 2013. Clinical Impact Upon Wound Healing and Inflammation in Moist, Wet, and Dry Environments. Adv. Wound Care 2, 348-356. https://doi.org/10.1089/wound.2012.0412

Kačarević, Ž.P., Rider, P.M., Alkildani, S., Retnasingh, S., Smeets, R., Jung, O., Ivanišević, Z., Barbeck, M., 2018. An introduction to 3D bioprinting: Possibilities, challenges and future aspects. Materials (Basel). 11. https://doi.org/10.3390/ma11112199

Kahanovitz, L., Sluss, P.M., Russell, S.J., 2017. Type 1 diabetes-a clinical perspective. Point Care 16, 37-40. https://doi.org/10.1097/POC.0000000000000125

Kandimalla, R., Kalita, S., Choudhury, B., Dash, S., Kalita, K., Kotoky, J., 2016. Chemical composition and anti-candidiasis mediated wound healing property of Cymbopogon nardus essential oil on chronic diabetic wounds. Front. Pharmacol. 7, 1-8. https://doi.org/10.3389/fphar.2016.00198

Karam, R.A., Rezk, N.A., Abdel Rahman, T.M., Al Saeed, M., 2018. Effect of negative pressure wound therapy on molecular markers in diabetic foot ulcers. Gene 667, 56-61. https://doi.org/10.1016/j.gene.2018.05.032

Keles, H., Naylor, A., Clegg, F., Sammon, C., 2015. Investigation of factors in fl uencing the hydrolytic degradation of single PLGA microparticles. Polym. Degrad. Stab. 119, 228241. https://doi.org/10.1016/j.polymdegradstab.2015.04.025

Keriquel, V., Oliveira, H., Rémy, M., Ziane, S., Delmond, S., Rousseau, B., Rey, S., Catros, S., Amédée, J., Guillemot, F., Fricain, J.C., 2017. In situ printing of mesenchymal stromal cells, by laser-assisted bioprinting, for in vivo bone regeneration applications. Sci. Rep. 7, 1-10. https://doi.org/10.1038/s41598-017-01914-X

Kérourédan, O., Bourget, J.M., Rémy, M., Crauste-Manciet, S., Kalisky, J., Catros, S., Thébaud, N.B., Devillard, R., 2019a. Micropatterning of endothelial cells to create a capillary-like network with defined architecture by laser-assisted bioprinting. J. Mater. Sci. Mater. Med. 30. https://doi.org/10.1007/s10856-019-6230-1

Kérourédan, O., Hakobyan, D., Rémy, M., Ziane, S., Dusserre, N., Fricain, J.-C., Delmond, S., Thébaud, N.B., Devillard, R., 2019b. In situ prevascularization designed by laserassisted bioprinting: effect on bone regeneration. Biofabrication 11.

Kerr, M., Barron, E., Chadwick, P., Evans, T., Kong, W.M., Rayman, G., Sutton-Smith, M., Todd, G., Young, B., Jeffcoate, W.J., 2019. The cost of diabetic foot ulcers and amputations to the National Health Service in England. Diabet. Med. 36, 995-1002.

Kim, B.S., Kwon, Y.W., Kong, J.S., Park, G.T., Gao, G., Han, W., Kim, M.B., Lee, H., Kim, J.H., Cho, D.W., 2018. 3D cell printing of in vitro stabilized skin model and in vivo prevascularized skin patch using tissue-specific extracellular matrix bioink: A step towards advanced skin tissue engineering. Biomaterials 168, 38-53. https://doi.org/10.1016/j.biomaterials.2018.03.040

Kim, H.K., Thammavongsa, V., Schneewind, O., Missiakas, D., 2012. Recurrent infections and immune evasion strategies of Staphylococcus aureus. Curr. Opin. Microbiol. 15, 9299. https://doi.org/10.1016/j.mib.2011.10.012

King, R., Platt, S., Jackson, G., 2017. Prevalence of Symptomatic Venous ThromboEmbolism in Patients with Total Contact Cast for Diabetic foot Complications; A Retrospective Case Series. Foot Ankle Orthop. 2, 2473011417S0002. https://doi.org/10.1177/2473011417s000245

Kolesky, D.B., Homan, K.A., Skylar-Scott, M.A., Lewis, J.A., 2016. Three-dimensional bioprinting of thick vascularized tissues. Proc. Natl. Acad. Sci. U. S. A. 113, 31793184. https://doi.org/10.1073/pnas.1521342113 
Kontopodis, N., Tavlas, E., Papadopoulos, G., Pantidis, D., Kafetzakis, A., Chalkiadakis, G., Ioannou, C., 2016. Effectiveness of Platelet-Rich Plasma to Enhance Healing of Diabetic Foot Ulcers in Patients With Concomitant Peripheral Arterial Disease and Critical Limb Ischemia. Int. J. Low. Extrem. Wounds 15, 45-51. https://doi.org/10.1177/1534734615575829

Kovalcik, A., Sangroniz, L., Kalina, M., Skopalova, K., Humpolíček, P., Omastova, M., Mundigler, N., Müller, A.J., 2020. Properties of scaffolds prepared by fused deposition modeling of poly(hydroxyalkanoates). Int. J. Biol. Macromol. 161, 364-376. https://doi.org/10.1016/j.ijbiomac.2020.06.022

Kozlowska, J., Sionkowska, A., Osyczka, A.M., Dubiel, M., 2017. Stabilizing effect of carbodiimide and dehydrothermal treatment crosslinking on the properties of collagen/hydroxyapatite scaffolds. Polym. Int. 66, 1164-1172. https://doi.org/10.1002/pi.5371

Kryou, C., Leva, V., Chatzipetrou, M., Zergioti, I., 2019. Bioprinting for liver transplantation. Bioengineering 6. https://doi.org/10.3390/bioengineering6040095

Kumar, B., Mishra, M., Sinha, A., Soni, R., Patel, D., 2016. Prospective study to correlate the level of glycosylated haemoglobin with wound healing, vasculopathy and neuropathy in diabetic foot patients. Int. Surg. J. 3, 2087-2091. https://doi.org/10.18203/23492902.isj20163579

Laroussi, M., 2020. Cold Plasma in Medicine and Healthcare: The New Frontier in Low Temperature Plasma Applications. Front. Phys. 8, 1-7. https://doi.org/10.3389/fphy.2020.00074

Laudenslager, M.J., Sigmund, W.M., 2012. Electrospinning, in: Bhushan, B. (Ed.), Encyclopedia of Nanotechnology. Springer, Dordrecht. https://doi.org/https://doi.org/10.1007/978-90-481-9751-4

Lázaro-Martínez, J.L., Álvaro-Afonso, F.J., García-Álvarez, Y., Molines-Barroso, R.J., García-Morales, E., Sevillano-Fernández, D., 2018. Ultrasound-assisted debridement of neuroischaemic diabetic foot ulcers, clinical and microbiological effects: A case series. J. Wound Care 27, 278-286. https://doi.org/10.12968/jowc.2018.27.5.278

Lee, C.H., Liu, K.S., Cheng, C.W., Chan, E.C., Hung, K.C., Hsieh, M.J., Chang, S.H., Fu, X., Juang, J.H., Hsieh, I.C., Wen, M.S., Liu, S.J., 2020. Codelivery of Sustainable Antimicrobial Agents and Platelet-Derived Growth Factor via Biodegradable Nanofibers for Repair of Diabetic Infectious Wounds. ACS Infect. Dis. 6, 2688-2697. https://doi.org/10.1021/acsinfecdis.0c00321

Leese, G.P., Soto-pedre, E., Scho, C., 2020. Independent Observational Analysis of Ulcer Outcomes for SINBAD and University of Texas Ulcer Scoring Systems. Diabetes Care 1-6. https://doi.org/10.2337/dc20-1817

Lehrman, J., 2020. Combining the Benefits of Collagen and Negative Pressure Wound Therapy to Heal a Chronic Diabetic Foot Ulcer: A Case Report. Wounds A Compend. Clin. Res. Pract. 32, 11-13.

Li, H., Liu, S., Li, L., 2016. Rheological study on 3D printability of alginate hydrogel and effect of graphene oxide. Int. J. Bioprinting 2, 54-66. https://doi.org/10.18063/IJB.2016.02.007

Li, J., Chen, M., Fan, X., Zhou, H., 2016. Recent advances in bioprinting techniques: Approaches, applications and future prospects. J. Transl. Med. 14, 1-15. https://doi.org/10.1186/s12967-016-1028-0

Li, Y., Dahhan, O., Filipe, C.D.M., Brennan, J.D., Pelton, R.H., Brennan, J.D., 2018. Optimizing piezoelectric inkjet printing of silica sols for biosensor production. J. SolGel Sci. Technol. 87, 657-664. https://doi.org/10.1007/s10971-018-4762-3 Lietz, A.M., Kushner, M.J., 2018. Molecular admixtures and impurities in atmospheric 
pressure plasma jets. J. Appl. Phys. 124. https://doi.org/10.1063/1.5049430

Linger, R.J., Belikoff, E.J., Yan, Y., Li, F., Wantuch, H.A., Fitzsimons, H.L., Scott, M.J., 2016. Towards next generation maggot debridement therapy: Transgenic Lucilia sericata larvae that produce and secrete a human growth factor. BMC Biotechnol. 16, 1-12. https://doi.org/10.1186/s12896-016-0263-z

Liu, Jing, Chi, J., Wang, K., Liu, X., Liu, Jie, Gu, F., 2016. Full-thickness wound healing using 3D bioprinted gelatin-alginate scaffolds in mice: A histopathological study. Int. J. Clin. Exp. Pathol. 9, 11197-11205.

Liu, S., He, C.-Z., Cai, Y.-T., Xing, Q.-P., Guo, Y.-Z., Chen, Z.-L., Su, J.-L., Yang, L.-P., 2017. Evaluation of negative-pressure wound therapy for patients with diabetic foot ulcers: systematic review and meta-analysis. Ther. Clin. Risk Manag. 13-533.

Losi, P., Briganti, E., Errico, C., Lisell, A., Sanguinettia, E., Chiellini, F., Soldania, G., 2013. Fibrin-based scaffold incorporating VEGF- and bFGF-loaded nanoparticles stimulates wound healing in diabetic mice. Acta Biomater. 9, 7814-7821. https://doi.org/https://doi.org/10.1016/j.actbio.2013.04.019

Lüscher, T.F., Creager, M.A., Beckman, J.A., Cosentino, F., 2003. Diabetes and vascular disease. Pathophysiology, clinical consequences, and medical therapy: Part II. Circulation 108, 1655-1661. https://doi.org/10.1161/01.CIR.0000089189.70578.E2

Ma, Z., Li, Z., Shou, K., Jian, C., Li, P., Niu, Y., Qi, B., Yu, A., 2017. Negative pressure wound therapy: Regulating blood flow perfusion and microvessel maturation through microvascular pericytes. Int. J. Mol. Med. 40, 1415-1425. https://doi.org/10.3892/ijmm.2017.3131

Mallet, M.L., Hadjivassiliou, M., Sarrigiannis, P.G., Zis, P., 2020. The Role of Oxidative Stress in Peripheral Neuropathy. J. Mol. Neurosci. 70, 1009-1017. https://doi.org/10.1007/s12031-020-01495-x

Malone-Povolny, M.J., Maloney, S.E., Schoenfisch, M.H., 2019. Nitric Oxide Therapy for Diabetic Wound Healing. Adv. Healthc. Mater. 8. https://doi.org/10.1002/adhm.201801210.

Manna, B., Nahirniak, P., Morrison, C., 2020. Wound Debridement, in: StatPearls. StatPearls Publishing, Treasure Island, Florida.

MARSTON, W., HANFT, J., NORWOOD, P., POLLAK, R., 2003. The Efficacy and Safety of Dermagraft in improving the healing of chronic diabetic foot ulcers: results of a prospective randomized trial. Diabetes Care 26, 1701-1705.

McCormack, A., Highley, C.B., Leslie, N.R., Melchels, F.P.W., 2020. 3D Printing in Suspension Baths: Keeping the Promises of Bioprinting Afloat. Trends Biotechnol. 38, 584-593. https://doi.org/10.1016/j.tibtech.2019.12.020

Mellor, L.F., Huebner, P., Cai, S., Mohiti-Asli, M., Taylor, M.A., Spang, J., Shirwaiker, R.A., Loboa, E.G., 2017. Fabrication and Evaluation of Electrospun, 3D-Bioplotted, and Combination of Electrospun/3D-Bioplotted Scaffolds for Tissue Engineering Applications. Biomed Res. Int. 2017. https://doi.org/10.1155/2017/6956794

Mirpour, S., Fathollah, S., Mansouri, P., Larijani, B., Ghoranneviss, M., Mohajeri Tehrani, M., Amini, M.R., 2020. Cold atmospheric plasma as an effective method to treat diabetic foot ulcers: A randomized clinical trial. Sci. Rep. 10, 1-9. https://doi.org/10.1038/s41598-020-67232-x

Mishra, S.C., Cousty-Pech, F., Martini, J., Hanaire-Broutin, H., 2001. Diabetic foot. Rev. du Prat. 51, 1788-1792.

Missoni, E.M., Kalenic, S., Vukelic, M., De Syo, D., Belicza, M., Kern, J., Babic, V.V., 2006. Uloga kvasaca u infekciji rane dijabetičkog stopala. Acta Medica Croat. 60, 4350.

Moeinzadeh, S., Park, Y., Lin, S., Peter, Y., 2021. In-situ stable injectable collagen-based 
hydrogels for cell and growth factor delivery. Materialia 15, 100954. https://doi.org/10.1016/j.mtla.2020.100954

Mohammadi, M.R., Rabbani, S., Bahrami, S.H., Joghataei, M.T., Moayer, F., 2016. Antibacterial performance and in vivo diabetic wound healing of curcumin loaded gum tragacanth/poly( $\varepsilon$-caprolactone) electrospun nanofibers. Mater. Sci. Eng. C 69, 11831191. https://doi.org/10.1016/j.msec.2016.08.032

Morona, J.K., Buckley, E.S., Jones, S., Reddin, E.A., Merlin, T.L., 2013. Comparison of the clinical effectiveness of different off-loading devices for the treatment of neuropathic foot ulcers in patients with diabetes: a systematic review and meta-analysis. Diabetes. Metab. Res. Rev. 29, 183-193.

Motawea, A., Abd El-Gawad, A.E.G.H., Borg, T., Motawea, M., Tarshoby, M., 2019. The impact of topical phenytoin loaded nanostructured lipid carriers in diabetic foot ulceration. Foot 40, 14-21. https://doi.org/10.1016/j.foot.2019.03.007

Motley, T.A., Gilligan, A.M., Lange, D.L., Waycaster, C.R., Dickerson, J.E., 2015. Costeffectiveness of clostridial collagenase ointment on wound closure in patients with diabetic foot ulcers: Economic analysis of results from a multicenter, randomized, openlabel trial. J. Foot Ankle Res. 8, 1-12. https://doi.org/10.1186/s13047-015-0065-X

Muhammad, T.S., Shaheen, N., Shukr, I., Ahmed, M.I., 2015. Comparison of Negative Pressure Wound Therapy Using Vacuum-Assisted Closure with Advanced Moist Wound Therapy in the Treatment of Diabetic Foot Ulcers.

Nair, N.R., Sekhar, V.C., Nampoothiri, K.M., Pandey, A, 2017. Biodegradation of Biopolymers, in: Pandey, Ashok, Negi, S., Soccol, C.R. (Eds.), Current Developments in Biotechnology and Bioengineering. Elsevier, pp. 739-755. https://doi.org/https://doi.org/10.1016/B978-0-444-63662-1.00032-4

Naseri, E., Butler, H., MacNevin, W., Ahmed, M., Ahmadi, A., 2020. Low-temperature solvent-based 3D printing of PLGA: a parametric printability study. Drug Dev. Ind. Pharm. 46, 173-178. https://doi.org/10.1080/03639045.2019.1711389

National Insititute for Health and Care Excellence (NICE), 2015. Diabetic foot problems : prevention and management. Ng19 1-49.

National Institue for Health and Care Excellence, 2020. Phenytoin [WWW Document]. URL https://bnf.nice.org.uk/drug/phenytoin.html (accessed 12.30.20).

Nayak, S.B., Pereira, L.P., Maharaj, D., 2007. Wound healing activity of Carica papaya L. in experimentally induced diabetic rats. Indian J. Exp. Biol. 45, 739-743.

Needham Coding, 2020. What is continuous inkjet technology? [WWW Document]. URL https://www.needham-coding.com/what-is-continuous-inkjet-technology/ (accessed 12.23.20).

Negro, A., Cherbuin, T., Lutolf, M.P., 2018. 3D Inkjet Printing of Complex, Cell-Laden Hydrogel Structures. Sci. Rep. 8, 1-9. https://doi.org/10.1038/s41598-018-35504-2

Nesterova, A.P., Klimov, E.A., Zharkova, M., Sozin, S., Sobolev, V., V.Ivanikova, N., Shkrob, M., Yuryev, A., 2020. Endocrine, nutritional, and metabolic diseases, in: Nesterova, A.P., Klimov, E.A., Zharkova, M., Sozin, S., Sobolev, V., Ivanikova, N. V., Shkrob, M., Yuryev, A. (Eds.), Disease Pathways. Elsevier, pp. 121-2118. https://doi.org/https://doi.org/10.1016/B978-0-12-817086-1.00004-X

Nicol, M.K.J., Brubaker, T.R., Honish, B.J., Simmons, A.N., Kazemi, A., Geissel, M.A., Whalen, C.T., Siedlecki, C.A., Bilén, S.G., Knecht, S.D., Kirimanjeswara, G.S., 2020. Antibacterial effects of low-temperature plasma generated by atmospheric-pressure plasma jet are mediated by reactive oxygen species. Sci. Rep. 10, 1-11. https://doi.org/10.1038/s41598-020-59652-6

Olingy, C.E., San Emeterio, C.L., Ogle, M.E., Krieger, J.R., Bruce, A.C., Pfau, D.D., Jordan, B.T., Peirce, S.M., Botchwey, E.A., 2017. Non-classical monocytes are biased 
progenitors of wound healing macrophages during soft tissue injury. Sci. Rep. 7, 1-16. https://doi.org/10.1038/s41598-017-00477-1

Ortega, E.S., Sanz-Garcia, A., Pernia-Espinoza, A., Escobedo-Lucea, C., 2019. Efficient fabrication of polycaprolactone scaffolds for printing hybrid tissue-engineered constructs. Materials (Basel). 12, 1-18. https://doi.org/10.3390/ma12040613

Patel, S., Srivastava, S., Singh, M.R., Singh, D., 2019. Mechanistic insight into diabetic wounds: Pathogenesis, molecular targets and treatment strategies to pace wound healing. Biomed. Pharmacother. 112, 108615. https://doi.org/10.1016/j.biopha.2019.108615

Patil, V., Patil, R., Kariholu, P.L., Patil, L.S., Shahapur, P., 2013. Topical phenytoin application in grade $\mathrm{i}$ and ii diabetic foot ulcers:A prospective study. J. Clin. Diagnostic Res. 7, 2238-2240. https://doi.org/10.7860/JCDR/2013/5713.3480

Pensa, N.W., Curry, A.S., Bonvallet, P.P., Bellis, N.F., Rettig, K.M., Reddy, M.S., Eberhardt, A.W., Bellis, S.L., 2019. 3D printed mesh reinforcements enhance the mechanical properties of electrospun scaffolds. Biomater. Res. 23, 1-7. https://doi.org/10.1186/s40824-019-0171-0

Peter-Riesch, B., 2016. The Diabetic Foot: The Never-Ending Challenge, in: Stettler, C., E, C., Diem, P. (Eds.), Novelties in Diabetes. Karger, Basel, pp. 108-134.

Petreaca, M., Martins-Green, M., 2020. The dynamics of cell-extracellular matrix interactions, with implications for tissue engineering, in: Lanza, R., Langer, R., Vancanti, J.P., Atala, A. (Eds.), Principles of Tissue Engineering. https://doi.org/https://doi.org/10.1016/C2018-0-03818-9

Petruzzi, L., Corbo, M.R., Campaniello, D., Speranza, B., Sinigaglia, M., Bevilacqua, A., 2020. Antifungal and antibacterial effect of propolis: A comparative hit for food-borne pseudomonas, enterobacteriaceae and fungi. Foods 9. https://doi.org/10.3390/foods9050559

Pierce, G.F., Mustoe, T.A., Altrock, B.W., Deuel, T.F., Thomason, A., 1991. Role of plateletderived growth factor in wound healing. J. Cell. Biochem. 45, 319-326.

Ponnusamy, Y., Chear, N.J.Y., Ramanathan, S., Lai, C.S., 2015. Polyphenols rich fraction of Dicranopteris linearis promotes fibroblast cell migration and proliferation in vitro. J. Ethnopharmacol. 168, 305-314. https://doi.org/10.1016/j.jep.2015.03.062

Pop-Busui, R., Boulton, A.J.M., Feldman, E.L., Bril, V., Freeman, R., Malik, R.A., Sosenko, J.M., Ziegler, D., 2017. Diabetic neuropathy: A position statement by the American diabetes association. Diabetes Care 40, 136-154. https://doi.org/10.2337/dc16-2042

Price, B.L., Morley, R., Bowling, F.L., Lovering, A.M., Dobson, C.B., 2020. Susceptibility of monomicrobial or polymicrobial biofilms derived from infected diabetic foot ulcers to topical or systemic antibiotics in vitro. PLoS One 15, 1-14. https://doi.org/10.1371/journal.pone.0228704

Prompers, L., Huijberts, M., Apelqvist, J., Jude, E., Piaggesi, A., Bakker, K., Edmonds, M., Holstein, P., Jirkovska, A., Mauricio, D., Ragnarson Tennvall, G., Reike, H., Spraul, M., Uccioli, L., Urbancic, V., Van Acker, K., Van Baal, J., Van Merode, F., Schaper, N., 2007. High prevalence of ischaemia, infection and serious comorbidity in patients with diabetic foot disease in Europe. Baseline results from the Eurodiale study. Diabetologia 50, 18-25. https://doi.org/10.1007/s00125-006-0491-1

Qin, Y., 2016. Applications of advanced technologies in the development of functional medical textile materials, in: Qin, Y. (Ed.), Medical Textile Materials. Woodhead Publishing, pp. 55-70. https://doi.org/https://doi.org/10.1016/B978-0-08-1006184.00005-4.

Ren, J.W., Chan, K.M., Lai, P.K.K., Lau, C.B.S., Yu, H., Leung, P.C., Fung, K.P., Yu, W.F.X., Cho, C.H., 2012. Extracts from Radix Astragali and Radix Rehmanniae promote keratinocyte proliferation by regulating expression of growth factor receptors. 
Phyther. Res. 26, 1547-1554. https://doi.org/10.1002/ptr.4615

Ren, X., Han, Y., Wang, J., Jiang, Y., Yi, Z., Xu, H., Ke, Q., 2018. An aligned porous electrospun fibrous membrane with controlled drug delivery - An efficient strategy to accelerate diabetic wound healing with improved angiogenesis. Acta Biomater. 70, 140153. https://doi.org/10.1016/j.actbio.2018.02.010

Rider, P., Kačarević, Ž.P., Alkildani, S., Retnasingh, S., Barbeck, M., 2018. Bioprinting of tissue engineering scaffolds. J. Tissue Eng. 9. https://doi.org/10.1177/2041731418802090

Riella, K.R., Marinho, R.R., Santos, J.S., Pereira-Filho, R.N., Cardoso, J.C., AlbuquerqueJunior, R.L.C., Thomazzi, S.M., 2012. Anti-inflammatory and cicatrizing activities of thymol, a monoterpene of the essential oil from Lippia gracilis, in rodents. J. Ethnopharmacol. 143, 656-663. https://doi.org/10.1016/j.jep.2012.07.028

Robinson, M., Dougla, S., Willerth, S.M., 2017. Mechanically stable fibrin scaffolds promote viability and induce neurite outgrowth in neural aggregates derived from human induced pluripotent stem cells 1-9. https://doi.org/10.1038/s41598-017-06570-9

Sabale, P., Bhimani, B., Prajapati, C., Sabalea, V., 2012. An overview of medicinal plants as wound healers. J. Appl. Pharm. Sci. 2, 143-150. https://doi.org/10.7324/JAPS.2012.21127

Sahu, B., Prusty, A., Tudu, B., 2018. Total contact casting versus traditional dressing in diabetic foot ulcers. J. Orthop. Surg. 26, 1-4. https://doi.org/10.1177/2309499018802486

Saif, A. Bin, Jabbar, S., Akhtar, M.S., Mushtaq, A., Tariq, M., 2019. Effects of topical Vancomycin Dressing on Methicillin-Resistant Staphylococcus Aureus (MRSA) positive diabetic foot ulcers. Pakistan J. Med. Sci. 35, 1099-1103. https://doi.org/10.12669/pjms.35.4.368

Samadian, H., Zamiri, S., Ehterami, A., Farzamfar, S., Vaez, A., Khastar, H., Alam, M., Ai, A., Derakhshankhah, H., Allahyari, Z., Goodarzi, A., Salehi, M., 2020. Electrospun cellulose acetate/gelatin nanofibrous wound dressing containing berberine for diabetic foot ulcer healing: in vitro and in vivo studies. Sci. Rep. 10, 1-12. https://doi.org/10.1038/s41598-020-65268-7

Santilli, F., Zaccardi, F., Liani, R., Petrucci, G., Simeone, P., Pitocco, D., Tripaldi, R., Rizzi, A., Formoso, G., Pontecorvi, A., Angelucci, E., Pagliaccia, F., Golato, M., De Leva, F., Vitacolonna, E., Rocca, B., Consoli, A., Patrono, C., 2020. In vivo thromboxanedependent platelet activation is persistently enhanced in subjects with impaired glucose tolerance. Diabetes. Metab. Res. Rev. 36, 1-9. https://doi.org/10.1002/dmrr.3232 Sawaya, A.P., Stone, R.C., Brooks, S.R., Pastar, I., Jozic, I., Hasneen, K., O’Neill, K., Mehdizadeh, S., Head, C.R., Strbo, N., Morasso, M.I., Tomic-Canic, M., 2020. Deregulated immune cell recruitment orchestrated by FOXM1 impairs human diabetic wound healing. Nat. Commun. 11, 1-14. https://doi.org/10.1038/s41467-020-18276-0

Seidel, D., Storck, M., Lawall, H., Wozniak, G., Mauckner, P., Hochlenert, D., Wetzel-Roth, W., Sondern, K., Hahn, M., Rothenaicher, G., Krönert, T., Zink, K., Neugebauer, E., 2020. Negative pressure wound therapy compared with standard moist wound care on diabetic foot ulcers in real-life clinical practice: Results of the German DiaFu-RCT. BMJ Open 10, 1-16. https://doi.org/10.1136/bmjopen-2018-026345

Sharma, Y., Jeyabalan, G., Singh, R., Semwal, A., 2013. Current Aspects of Wound Healing Agents From Medicinal Plants : A Review. J. Med. Plants Stud. 1, 1-11.

Shatnawi, N.J., Al-Zoubi, N.A., Hawamdeh, H.M., Khader, Y.S., Garaibeh, K., Heis, H.A., 2018. Diabetes, Metabolic Syndrome and Obesity: Targets and Therapy Dovepress Predictors of major lower limb amputation in type 2 diabetic patients referred for hospital care with diabetic foot syndrome. Diabetes, Metab. Syndr. Obes. Targets Ther. 
11-313.

Shi, R., Lian, W., Han, S., Cao, C., Jin, Y., Yuan, Y., Zhao, H., Li, M., 2018. Nanospheremediated co-delivery of VEGF-A and PDGF-B genes for accelerating diabetic foot ulcers healing in rats. Gene Ther. 25, 425-438. https://doi.org/10.1038/s41434-0180027-6

Shi, R., Lian, W., Jin, Y., Cao, C., Han, S., Yang, X., Zhao, S., Li, M., Zhao, H., 2020. Role and effect of vein-transplanted human umbilical cord mesenchymal stem cells in the repair of diabetic foot ulcers in rats. Acta Biochim. Biophys. Sin. (Shanghai). 52, 620 630. https://doi.org/10.1093/abbs/gmaa039

Skardal, A., Atala, A., 2015. Biomaterials for Integration with 3-D Bioprinting. Ann. Biomed. Eng. 43, 730-746. https://doi.org/10.1007/s10439-014-1207-1

Soltan, N., Ning, L., Mohabatpour, F., Papagerakis, P., Chen, X., 2019. Printability and Cell Viability in Bioprinting Alginate Dialdehyde- Gelatin Sca ff olds. ACS Biomater. Sci. Eng. 5, 2976-2987. https://doi.org/10.1021/acsbiomaterials.9b00167

Song, P., Zhou, C., Fan, H., Zhang, B., Pei, X., Fan, Y., Jiang, Q., Bao, R., Yang, Q., Dong, Z., Zhang, X., 2018. Novel 3D porous biocomposite scaffolds fabricated by fused deposition modeling and gas foaming combined technology. Compos. Part B Eng. 152, 151-159. https://doi.org/10.1016/j.compositesb.2018.06.029

Spampinato, S.F., Caruso, G.I., De Pasquale, R., Sortino, M.A., Merlo, S., 2020. The treatment of impaired wound healing in diabetes: Looking among old drugs. Pharmaceuticals 13, 1-17. https://doi.org/10.3390/ph13040060

Sriphutkiat, Y., Kasetsirikul, S., Ketpun, D., Zhou, Y., 2019. Cell alignment and accumulation using acoustic nozzle for bioprinting. Sci. Rep. 1-12. https://doi.org/10.1038/s41598-019-54330-8

Stubenitsky, B.M., Brasile, L., Rebellato, L.M., Hawinkels, H., Haisch, C., Kon, M., 2009. Delayed skin allograft rejection following matrix membrane pretreatment. J. Plast. Reconstr. Aesthetic Surg. 62, 520-525. https://doi.org/10.1016/j.bjps.2007.12.001

Sudhir, S., Dk, D., Thiagarajan, K., P, D.N., 2020. Efficacy of total contact cast application versus conventional dressings in the management of plantar diabetic ulcers 4, 70-72.

Sukanya, V.S., Mohanan, P. V., 2018. Degradation of Poly( $\varepsilon$-caprolactone) and biointeractions with mouse bone marrow mesenchymal stem cells. Colloids Surfaces B Biointerfaces 163, 107-118. https://doi.org/10.1016/j.colsurfb.2017.12.039

Surucu, S., Turkoglu Sasmazel, H., 2016. Development of core-shell coaxially electrospun composite PCL/chitosan scaffolds. Int. J. Biol. Macromol. 92, 321-328. https://doi.org/10.1016/j.ijbiomac.2016.07.013

Swezey, L., 2016. Diabetic foot ulcer classification systems [WWW Document]. URL https://woundeducators.com/diabetic-foot-ulcer/]; (accessed 11.20.20).

Takagi, D., Lin, W., Matsumoto, T., Yaginuma, H., Hemmi, N., Hatada, S., Seo, M., 2019. High-precision three-dimensional inkjet technology for live cell bioprinting. Int. J. Bioprinting 5, 27-38. https://doi.org/10.18063/ijb.v5i2.208

Talib, S., Ewadh, M.J., Mohammed, Z., Jeddoa, A., 2020. Gene Reports The association of vascular endothelial growth factor polymorphism ( rs699947) with diabetic foot ulcer and oxidative status. Gene Reports 19, 100606. https://doi.org/10.1016/j.genrep.2020.100606

Tan, W.S., Arulselvan, P., Ng, S.F., Mat Taib, C.N., Sarian, M.N., Fakurazi, S., 2019. Improvement of diabetic wound healing by topical application of Vicenin-2 hydrocolloid film on Sprague Dawley rats 11 Medical and Health Sciences 1103 Clinical Sciences. BMC Complement. Altern. Med. 19, 1-16. https://doi.org/10.1186/s12906-018-2427-y

Tan, Y.J., Tan, X., Yeong, W.Y., Tor, S.B., 2016. Hybrid microscaffold-based 3D bioprinting 
of multi-cellular constructs with high compressive strength: A new biofabrication strategy. Sci. Rep. 6, 1-13. https://doi.org/10.1038/srep39140

Tardivo, J.P., Serrano, R., Zimmermann, L.M., Matos, L.L., Baptista, M.S., Pinhal, M.A.S., Atallah, Á.N., 2017. Is surgical debridement necessary in the diabetic foot treated with photodynamic therapy? Diabet. Foot Ankle 8.

Teodora, A., Rios, C., Camilla, B., Cardoso, O., Elisa, M., Ribeiro, S., Fernando, R., Freitas, S., 2015. Synthesis, Characterization, and Study of PLGA Copolymer in Vitro Degradation. J. Biomed. Mater. Nanobiotechnology 6, 8-19.

Thomas, B., Kurien, J.S., Jose, T., Ulahannan, S.E., Varghese, S.A., 2017. Topical timolol promotes healing of chronic leg ulcer. J. Vasc. Surg. 5, 844-850. https://doi.org/10.1016/j.jvsv.2017.04.019

Thomas, D., Nath, M.S., Mathew, N., Reshmy, R., Philip, E., Latha, M.S., 2020. Journal of Drug Delivery Science and Technology Alginate film modified with aloevera gel and cellulose nanocrystals for wound dressing application : Preparation, characterization and in vitro evaluation. J. Drug Deliv. Sci. Technol. 59, 101894. https://doi.org/10.1016/j.jddst.2020.101894

Tian, Z., Liu, W., Li, G., 2016. The microstructure and stability of collagen hydrogel crosslinked by glutaraldehyde. Polym. Degrad. Stab. 130, 264-270. https://doi.org/10.1016/j.polymdegradstab.2016.06.015

Tonge, X.N., Widnall, J.C., Jackson, G., Platt, S., 2019. A ten-year retrospective study investigating the rate of venous thromboembolism in patients who require immobilization in a total contact lower limb cast. Bone Jt. J. 101.

Trachtenberg, J.E., Placone, J.K., Smith, B.T., Piard, C.M., Santoro, M., Scott, D.W., Fisher, J.P., Mikos, A.G., 2016. Extrusion-Based 3D Printing of Poly(propylene fumarate) in a Full-Factorial Design. ACS Biomater. Sci. Eng. 2, 1771-1780. https://doi.org/10.1021/acsbiomaterials.6b00026

Tsai, Y., Li, S., Hu, S., Chang, W., Jeng, U., Hsu, S., 2015. Synthesis of Thermoresponsive Amphiphilic Polyurethane Gel as a New Cell Printing Material near Body Temperature. ACS Appl. Mater. Interfaces 7, 27613-27623. https://doi.org/10.1021/acsami.5b10697

Uçkay, I., Kressmann, B., Di Tommaso, S., Portela, M., Alwan, H., Vuagnat, H., Maître, S., Paoli, C., Lipsky, B.A., 2018. A randomized controlled trial of the safety and efficacy of a topical gentamicin-collagen sponge in diabetic patients with a mild foot ulcer infection. SAGE Open Med. 6, 1-5. https://doi.org/10.1177/2050312118773950

Vatan, A., Saltoglu, N., Yemisen, M., Balkan, I.I., Surme, S., Demiray, T., Mete, B., Tabak, F., 2018. Association between biofilm and multi/extensive drug resistance in diabetic foot infection. Int. J. Clin. Pract. 72, 1-7. https://doi.org/10.1111/ijcp.13060

Visser, J., Peters, B., Burger, T.J., Boomstra, J., Dhert, W.J.A., Melchels, F.P.W., Malda, J., 2013. Biofabrication of multi-material anatomically shaped tissue constructs. Biomaterials 5.

Volmer-Thole, M., Lobmann, R., 2016. Neuropathy and diabetic foot syndrome. Int. J. Mol. Sci. 17. https://doi.org/10.3390/ijms17060917

Walker, J.L., Santoro, M., 2017. Processing and production of bioresorbable polymer scaffolds for tissue engineering, in: Perale, G., Hilborn, J. (Eds.), Bioresorbable Polymers for Biomedical Applications. Woodhead Publishing, pp. 181-203.

Wallace, H.A., Basehore, B.M., Zito, P.M., 2020. Wound Healing Phases [WWW Document]. URL https://www.ncbi.nlm.nih.gov/books/NBK470443/ (accessed 11.20.20).

Wang, M., Li, H., Yang, Y., Yuan, K., Zhou, F., Liu, H., Zhou, Q., Yang, S., Tang, T., 2021. A 3D-bioprinted scaffold with doxycycline-controlled BMP2-expressing cells for inducing bone regeneration and inhibiting bacterial infection. Bioact. Mater. 6, 1318- 
1329. https://doi.org/10.1016/j.bioactmat.2020.10.022

Wang, S., Xiong, Y., Chen, J., Ghanem, A., Wang, Y., Yang, J., Sun, B., 2019. Three Dimensional Printing Bilayer Membrane Scaffold Promotes Wound Healing. Front. Bioeng. Biotechnol. 7, 1-11. https://doi.org/10.3389/fbioe.2019.00348

Wang, T., Li, X., Fan, L., Chen, B., Liu, J., Tao, Y., Wang, X., 2019. Negative pressure wound therapy promoted wound healing by suppressing inflammation via downregulating MAPK-JNK signaling pathway in diabetic foot patients. Diabetes Res. Clin. Pract. 150, 81-89. https://doi.org/10.1016/j.diabres.2019.02.024

Wang, W., Caetano, G., Ambler, W.S., Blaker, J.J., Frade, M.A., Mandal, P., Diver, C., Bártolo, P., 2016. Enhancing the hydrophilicity and cell attachment of 3D printed PCL/graphene scaffolds for bone tissue engineering. Materials (Basel). 9. https://doi.org/10.3390/ma9120992

Weltmann, K.D., Kinde, E., Von Woedtke, T., Hähnel, M., Stieber, M., Brandenburg, R., 2010. Atmospheric-pressure plasma sources: Prospective tools for plasma medicine. Pure Appl. Chem. 82, 1223-1237. https://doi.org/10.1351/PAC-CON-09-10-35

Wheeler, J.S.R., Reynolds, S.W., Lancaster, S., Romanguera, V.S., Yeates, S.G., 2014. Polymer degradation during continuous ink-jet printing. Polym. Degrad. Stab. 105, 116121. https://doi.org/10.1016/j.polymdegradstab.2014.04.007

Wilgus, T.A., Roy, S., McDaniel, J.C., 2013. Neutrophils and Wound Repair: Positive Actions and Negative Reactions. Adv. Wound Care 2, 379-388. https://doi.org/10.1089/wound.2012.0383

World Health Organisation, 2020. The top 10 causes of death [WWW Document]. URL https://www.who.int/news-room/fact-sheets/detail/the-top-10-causes-of-death

Wound Source, 2019. Debridement Options: Considerations in Selecting Debridement Methods [WWW Document]. URL https://www.woundsource.com/blog/debridementoptions-considerations-in-selecting-debridement-methods (accessed 12.30.20).

Wu, J., Jin, Z., Zheng, H., Yan, L.J., 2016. Sources and implications of NADH/NAD+ redox imbalance in diabetes and its complications. Diabetes, Metab. Syndr. Obes. Targets Ther. 9, 145-153. https://doi.org/10.2147/DMSO.S106087

Xiang, J., Wang, S., He, Y., Xu, L., Zhang, S., Tang, Z., 2019. Reasonable Glycemic Control Would Help Wound Healing During the Treatment of Diabetic Foot Ulcers. Diabetes Ther. 10, 95-105. https://doi.org/10.1007/s13300-018-0536-8

Xie, X., Liu, X., Li, Y., Luo, L., Yuan, W., Chen, B., Liang, G., Shen, R., Li, H., Huang, S., Duan, C., 2020. Advanced Glycation End Products Enhance Biofilm Formation by Promoting Extracellular DNA Release Through sigB Upregulation in Staphylococcus aureus. Front. Microbiol. 11, 1-12. https://doi.org/10.3389/fmicb.2020.01479

Yaghoobi, R., Kazerouni, A., kazerouni, O., 2013. Evidence for clinical use of honey in wound healing as an anti-bacterial, anti-inflammatory anti-oxidant and anti-viral agent: A review. Jundishapur J. Nat. Pharm. Prod. 8, 100-104. https://doi.org/10.17795/jjnpp9487

Yan, L., 2018. Redox imbalance stress in diabetes mellitus: Role of the polyol pathway. Anim. Model. Exp. Med. 1, 7-13. https://doi.org/10.1002/ame2.12001

Yanez, M., Rincon, J., Dones, A., De Maria, C., Gonzales, R., Boland, T., 2015. In vivo assessment of printed microvasculature in a bilayer skin graft to treat full-thickness wounds. Tissue Eng. - Part A 21, 224-233. https://doi.org/10.1089/ten.tea.2013.0561

Yang, S., Gu, Z., Lu, C., Zhang, T., Guo, X., Xue, G., Zhang, L., 2020. Neutrophil Extracellular Traps Are Markers of Wound Healing Impairment in Patients with Diabetic Foot Ulcers Treated in a Multidisciplinary Setting. Adv. Wound Care 9, 16-27. https://doi.org/10.1089/wound.2019.0943

Yaseen, H.S., Asif, M., Saadullah, M., Mahrukh, Asghar, S., Shams, M.U., Bazmi, R.R., 
Saleem, M., Yousaf, H.M., Yaseen, M., 2020. Methanolic extract of Ephedra ciliata promotes wound healing and arrests inflammatory cascade in vivo through downregulation of TNF- $\alpha$. Inflammopharmacology 28, 1691-1704. https://doi.org/10.1007/s10787-020-00713-7

Yazdanpanah, L., 2015. Literature review on the management of diabetic foot ulcer. World J. Diabetes 6, 37. https://doi.org/10.4239/wjd.v6.i1.37

Zenão, S., Aires, A., Dias, C., Saavedra, M.J., Fernandes, C., 2017. Antibacterial potential of Urtica dioica and Lavandula angustifolia extracts against methicillin resistant Staphylococcus aureus isolated from diabetic foot ulcers. J. Herb. Med. 10, 1-7. https://doi.org/10.1016/j.hermed.2017.05.003

Zhang, B., Gao, L., Gu, L., Yang, H., Luo, Y., Ma, L., 2017. High-resolution 3D Bioprinting System for Fabricating Cell-laden Hydrogel Scaffolds with High Cellular Activities. Procedia CIRP 65, 219-224. https://doi.org/10.1016/j.procir.2017.04.017

Zheng, Z., Liu, Y., Yang, Y., Tang, J., Cheng, B., 2017. Topical 1\% propranolol cream promotes cutaneous wound healing in spontaneously diabetic mice. Wound Repair Regen. 25, 389-397. https://doi.org/10.1111/wrr.12546

Zhou, X., Tao, Y., Chen, E., Wang, J., Fang, W., Zhao, T., Liang, C., Li, F., Chen, Q., 2018. Genipin-cross-linked type II collagen scaffold promotes the differentiation of adiposederived stem cells into nucleus pulposus-like cells. J. Biomed. Mater. Res. - Part A 106, 1258-1268. https://doi.org/10.1002/jbm.a.36325

Zhuang, P., Ng, W.L., An, J., Chua, C.K., Tan, L.P., 2019. Layer-by-layer ultraviolet assisted extrusion-based (UAE) bioprinting of hydrogel constructs with high aspect ratio for soft tissue engineering applications. PLoS One 14, 1-21. https://doi.org/10.1371/journal.pone.0216776

Zimmermann, J.L., Shimizu, T., Schmidt, H.U., Li, Y.F., Morfill, G.E., Isbary, G., 2012. Test for bacterial resistance build-up against plasma treatment. New J. Phys. 14. https://doi.org/10.1088/1367-2630/14/7/073037

Zubair, M., Ahmad, J., 2019. Potential risk factors and outcomes of infection with multidrug resistance among diabetic patients having ulcers: 7 years study. Diabetes Metab. Syndr. Clin. Res. Rev. 13, 414-419. 
2156 Figure 1. Overview of the normal wound healing process (left) versus the impaired diabetic

2157 wound healing process (right); reprinted from (Spampinato et al., 2020), with permission.

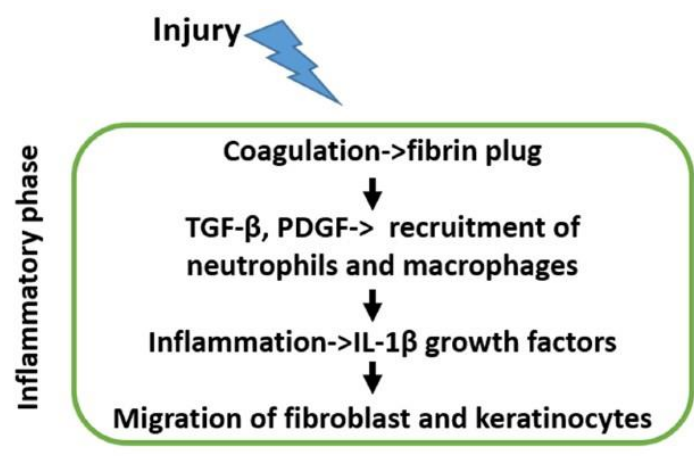

Chronic inflammation-> Higher IL-1 $\beta$ and TNF $\alpha$

Dysfunctional macrophages

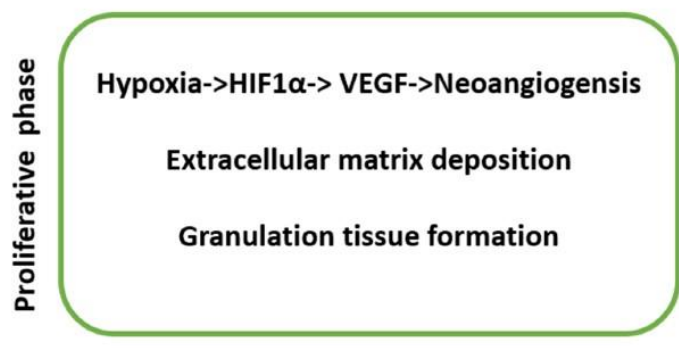

Decreased angiogenesis

Disequilibrium between MMPs and TIMPs-> altered ECM

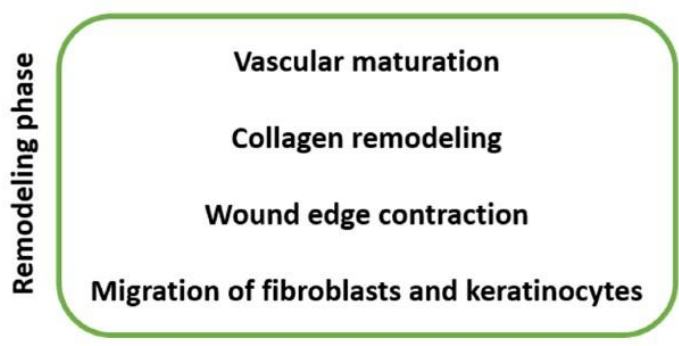

Decreased pericyte function
reduced vascular maturation
Decreased wound
strengthening 
2160 Figure 2. Schematic representation of single electrospinning apparatus setup; reprinted from 2161 (Chen et al., 2019), with permission.

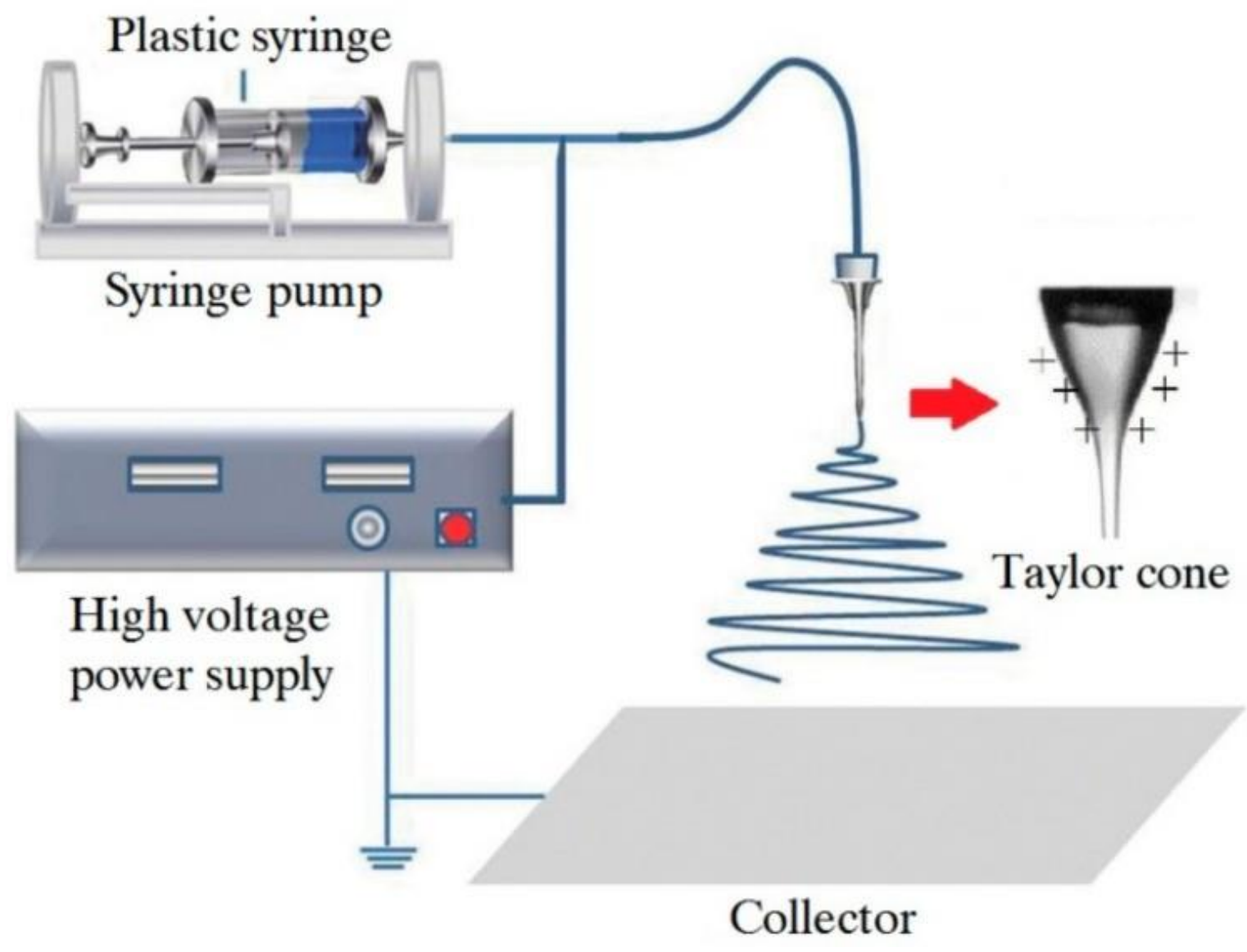


Figure 3. Schematic representation of FDM; reprinted from (Gebisa and Lemu, 2018), with permission.

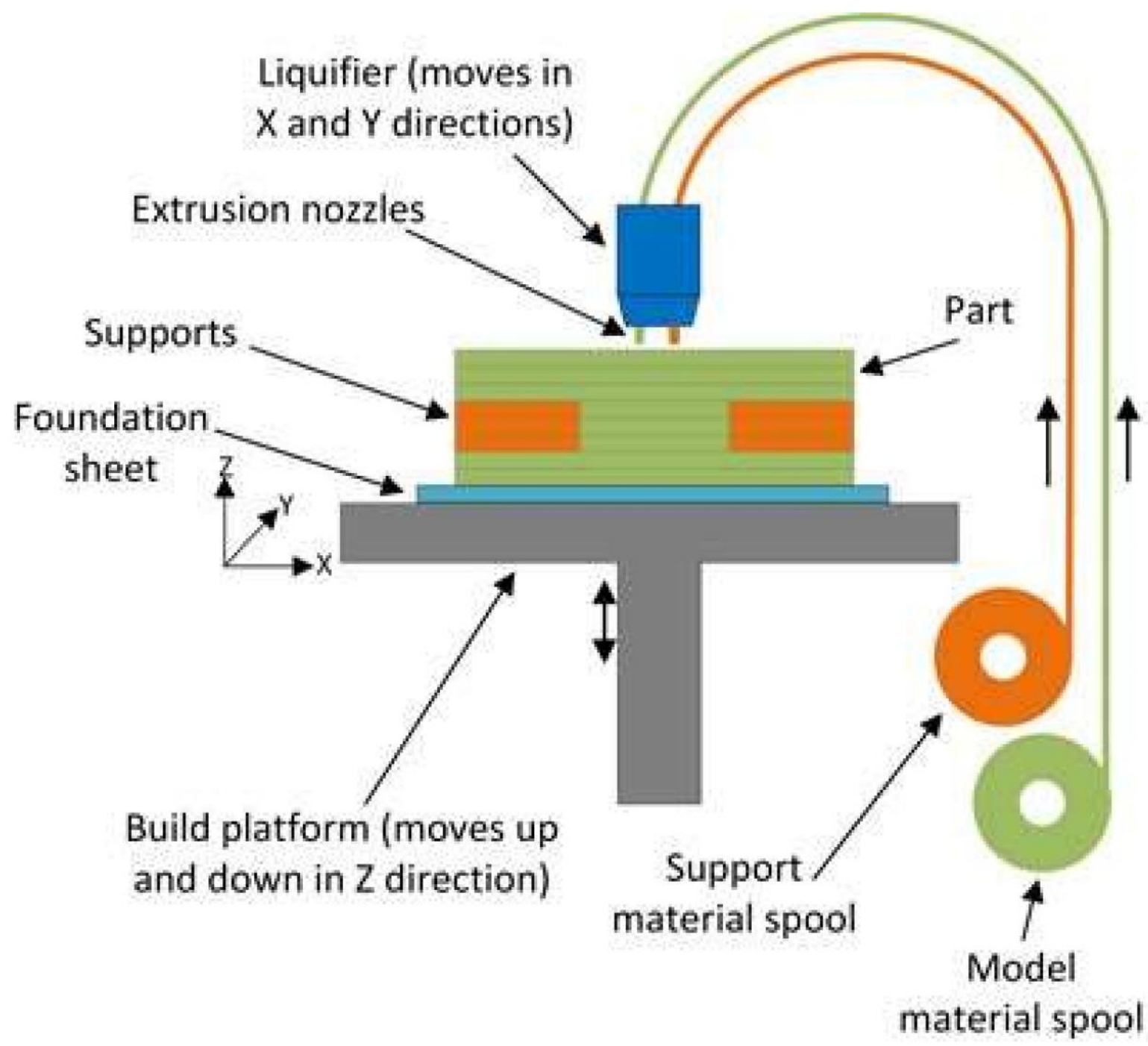


International Journal of Pharmaceutics

2167 Figure 4. Schematic illustration of (a) continuous inkjet (CIJ) and drop-on-demand (DOD) 2168 printing systems using (b) thermal and (c) piezoelectric technology; reprinted from (Alamán et 2169 al., 2016), with permission.

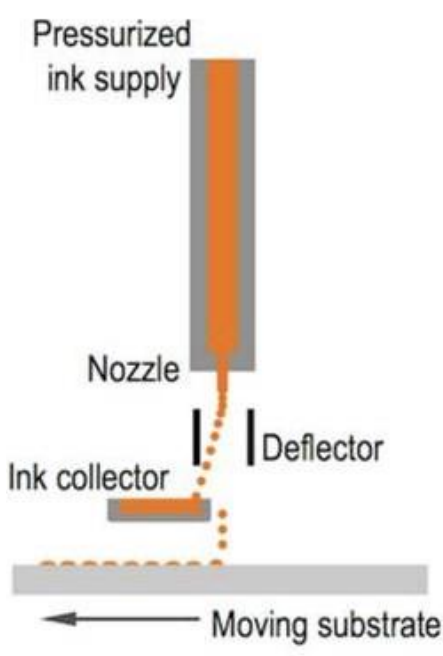

(a)

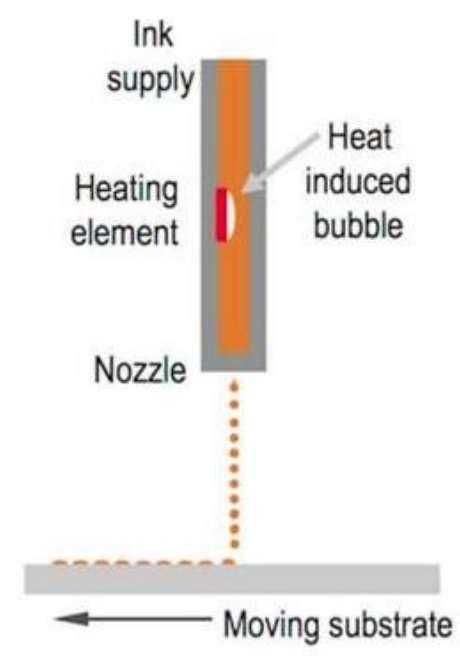

(b)

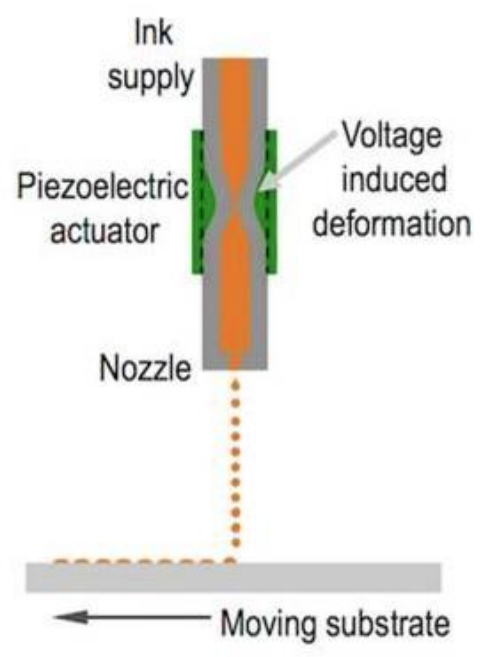

(c) 
International Journal of Pharmaceutics

2172 Figure 5. Schematic representation of extrusion-based bioprinting technologies; reprinted from 2173 (Kryou et al., 2019), with permission.

\section{Extrusion bioprinting}

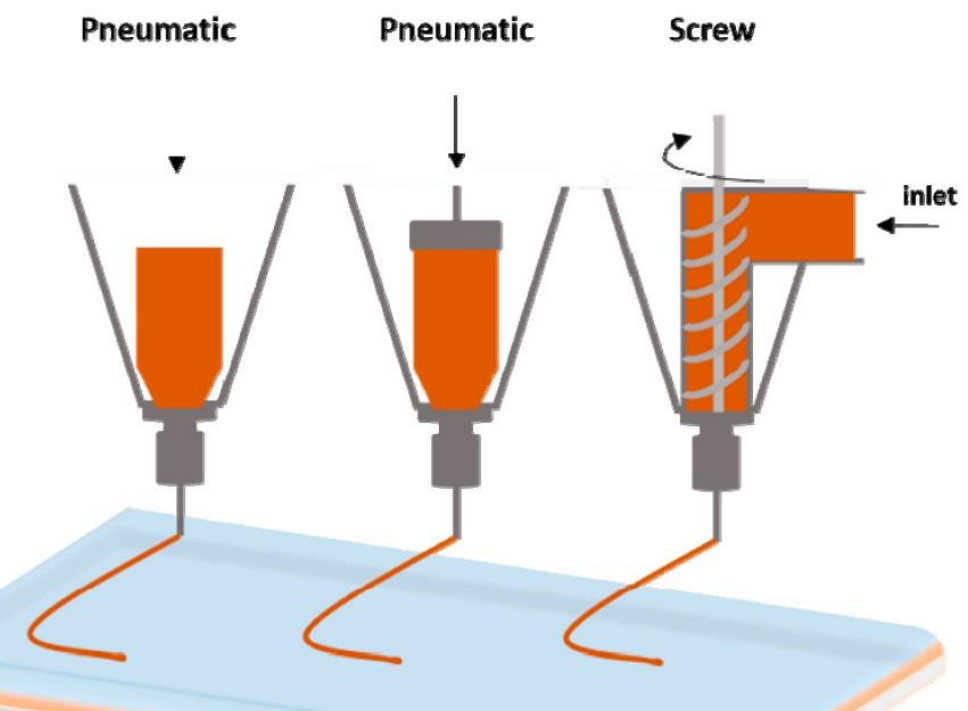


2176 Figure 6. Schematic representation of laser-assisted bioprinting, where (a) show a transparent 2177 glass, (b) illustrates the thin metal layer and (c) the vaporization-induced bubble; reprinted from 2178 (Kačarević et al., 2018), with permission.

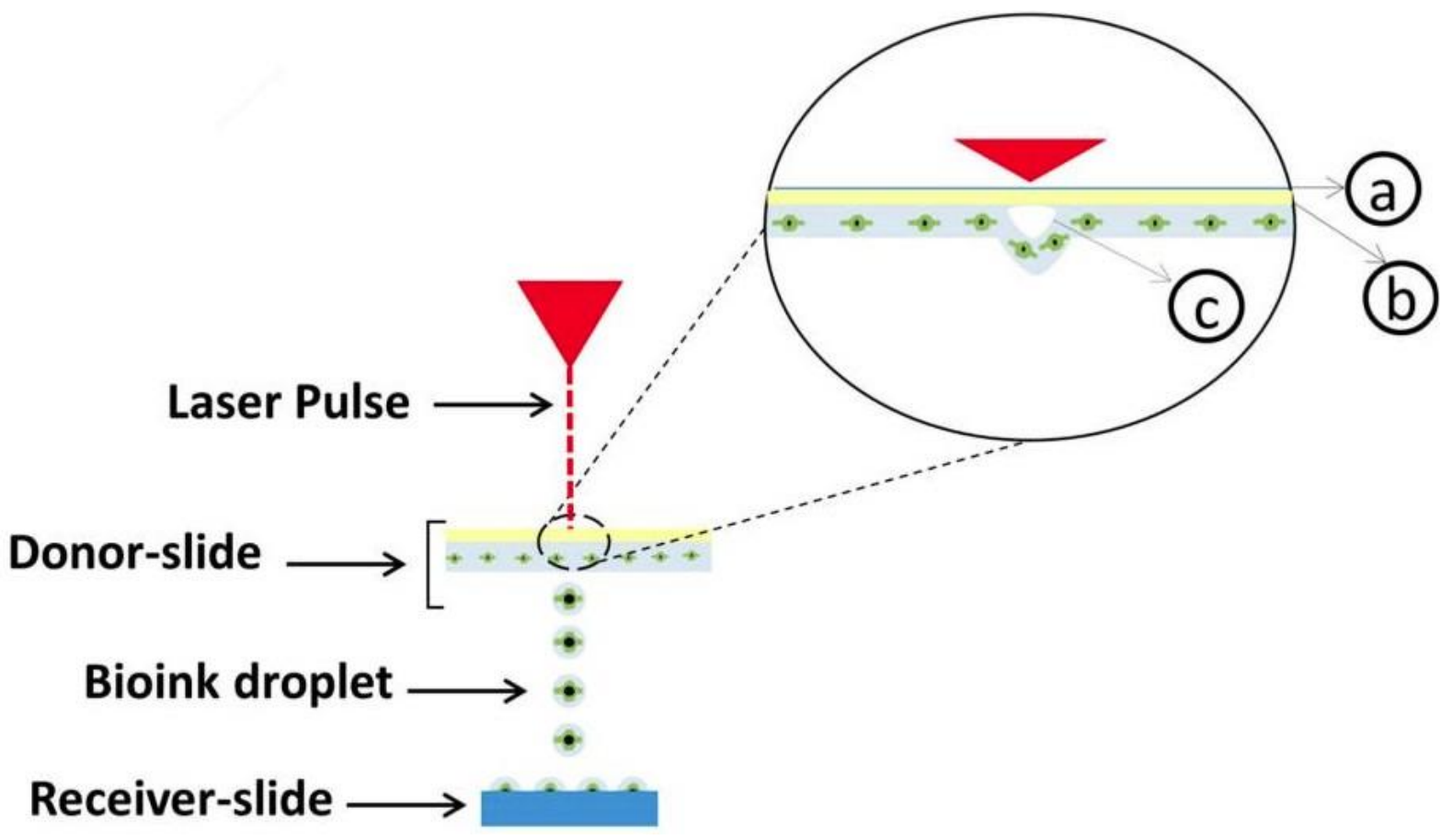


International Journal of Pharmaceutics

2181 Figure 7. Stress-strain curves of sodium alginate films after dipped into variety of 2182 concentrations of $\mathrm{CaCl}_{2}$ for 2 and 8 min; reprinted from (Fadhilah et al., 2019), with permission.
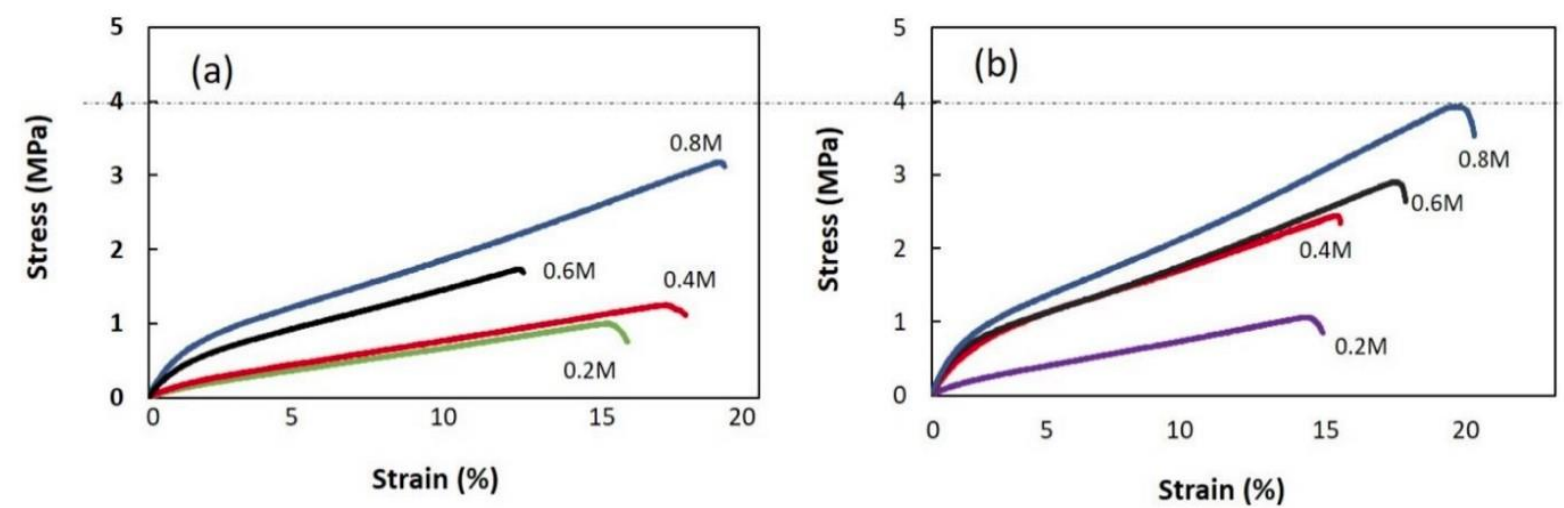

2184 
2185 Figure 8. Graphic representation of PLGA-alginate bilayer membrane; reprinted from (Wang 2186 et al 2019), with permission.

2187

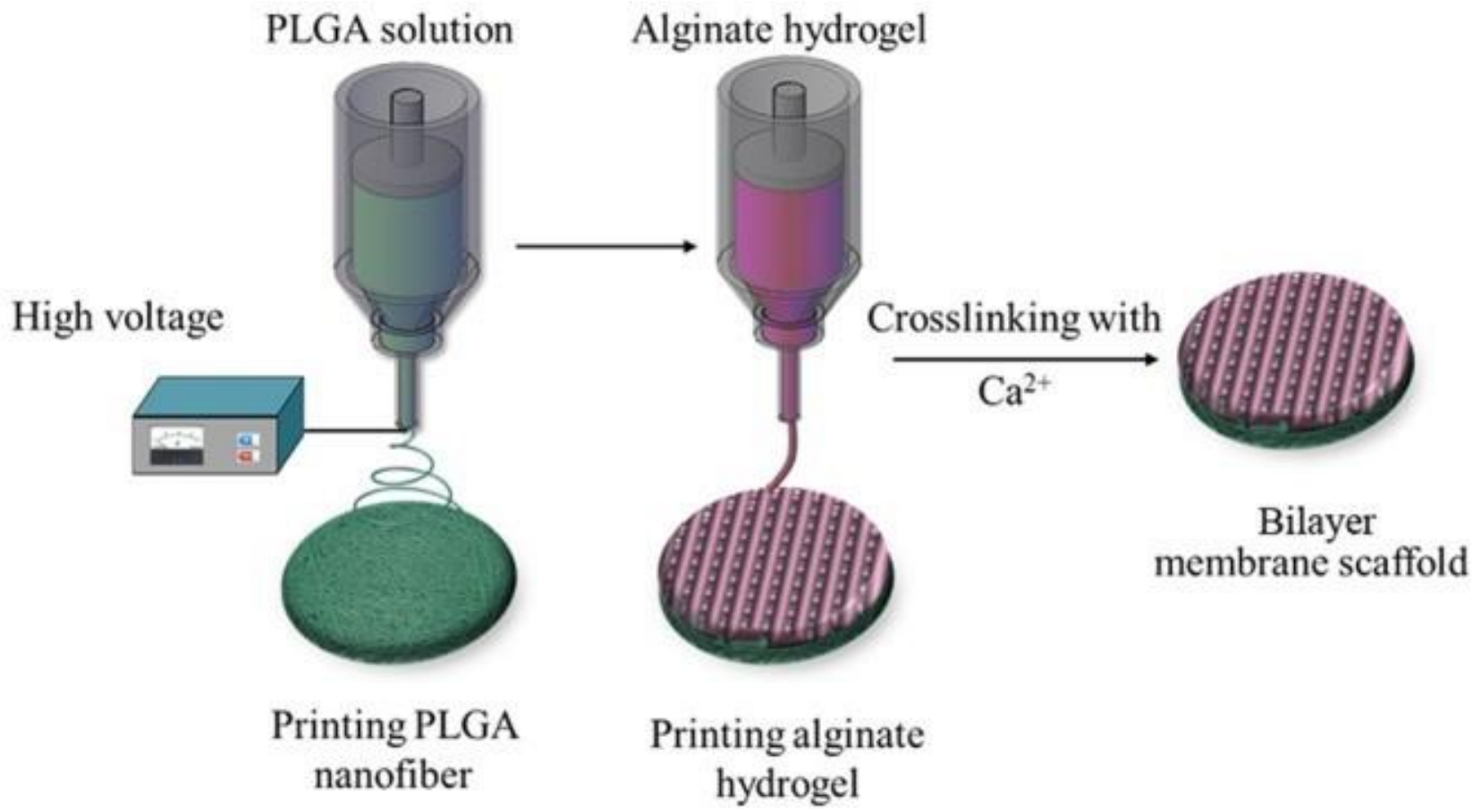


2190 Figure 9. Schematic representation of an atmospheric-pressure plasma jet system (APPJ). The 2191 APPJ consists of a quartz tube. Copper ring electrodes are located on the outside of the tube 2192 separated by $10 \mathrm{~mm}$ and with the ground electrode located $10 \mathrm{~mm}$ from the jet exit. gAS 2193 admixture flows through the tube and is excited by a high-voltage amplifier; reprinted from 2194 (Nicol et al., 2020), with permission.
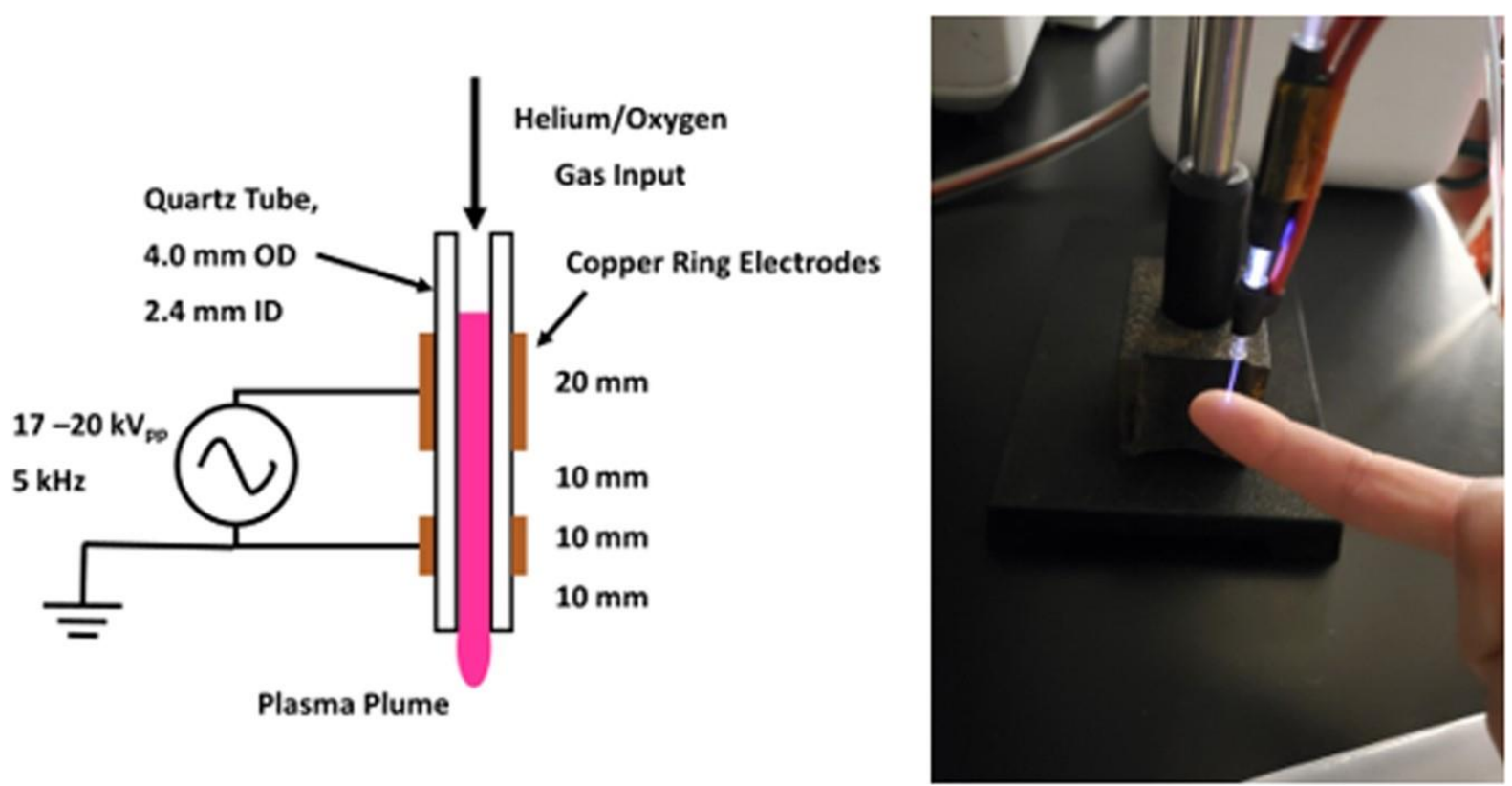
Table 1: Standard therapies used to treat DFU

\begin{tabular}{|c|c|c|}
\hline Method & Description & References \\
\hline Offloading & $\begin{array}{l}\text { Non-removable knee-high total contact cast (TTC) devices are } \\
\text { the gold standard option for neuropathic plantar or midfoot } \\
\text { DFU. } \\
\text { TTCs have been shown to greatly reduce the time for DFU } \\
\text { healing when compared to conventional dressings. } \\
\text { Non-removable devices are more effective than removable } \\
\text { devices. } \\
\text { Low risk of venous thrombo-embolism (VTE) associated with } \\
\text { TCC use. }\end{array}$ & $\begin{array}{l}\text { (Bus et al., 2020; } \\
\text { King et al., 2017; } \\
\text { Morona et al., } \\
\text { 2013; Sahu et al., } \\
\text { 2018; Sudhir et } \\
\text { al., 2020; Tonge et } \\
\text { al., 2019) }\end{array}$ \\
\hline $\begin{array}{l}\text { Glycaemic } \\
\text { control }\end{array}$ & $\begin{array}{l}\text { Lower HbA1C levels are associated with faster healing rates. } \\
\text { HbA1C levels between } 7-8 \% \text { provide benefit to the wound } \\
\text { healing of DFU. } \\
\text { Negative correlation has been reported between } 1.0 \% \text { increases } \\
\text { in HbA1C levels and the rate of DFU wound healing. } \\
\text { Raised HbA1C has been associated with improved wound } \\
\text { healing in patients where baseline HbA1C was below } 7.5 \% \text {. }\end{array}$ & $\begin{array}{l}\text { (Christman et al., } \\
\text { 2011; Dhatariya et } \\
\text { al., 2018; Fesseha } \\
\text { et al., 2018; } \\
\text { Gorantla et al., } \\
\text { 2020; Kumar et } \\
\text { al., 2016; Xiang et } \\
\text { al., 2019) }\end{array}$ \\
\hline Debridement & $\begin{array}{l}\text { Debridement is the removal of necrotic and senescent tissues as } \\
\text { well as foreign and infected materials from a wound. } \\
\text { Surgical debridement: large-scale removable of both non-viable } \\
\text { tissue and immediately-surrounding viable tissue. } \\
\text { Biological debridement: maggot debridement therapy } \\
\text { accelerates wound healing. Genetically engineered maggots } \\
\text { can be used to secrete human platelet derived growth factor. } \\
\text { Mechanical debridement: application of a wet gauze which then } \\
\text { adheres to the skin and, upon its removal, results in non- } \\
\text { selective removal of dead tissue surrounding the wound. } \\
\text { Enzymatic debridement: uses natural proteolytic enzymes to } \\
\text { remove non-viable tissue in a selective manner. Clostridial } \\
\text { collagenase ointment (CCO) is commonly used to successfully } \\
\text { treat neuropathic non-ischemic DFU. }\end{array}$ & $\begin{array}{l}\text { (Ananian, 2020; } \\
\text { Azad et al., 2016; } \\
\text { Healthline, 2019; } \\
\text { Jimenez et al., } \\
\text { 2017; Linger et } \\
\text { al., 2016; Motley } \\
\text { et al., 2015; } \\
\text { Tardivo et al., } \\
\text { 2017; Wound } \\
\text { Source, 2019) }\end{array}$ \\
\hline $\begin{array}{l}\text { Infection } \\
\text { management }\end{array}$ & $\begin{array}{l}\text { Approximately } 40 \% \text { of DFU become infected. } \\
\text { Before treatment commences microorganisms involved need to } \\
\text { be identified and infection severity classified. } \\
\text { Mild infection: Oral administration of appropriate antibiotic for } \\
\text { up to seven days. } \\
\text { Moderate infection: Antibiotic administered either orally or } \\
\text { intravenously, for greater than seven days, or for six weeks in } \\
\text { the case of osteomyelitis. } \\
\text { Severe infection: antibiotic combination treatment. }\end{array}$ & $\begin{array}{l}\text { (Bus et al., 2019; } \\
\text { Jia et al., 2017; } \\
\text { National Insititute } \\
\text { for Health and } \\
\text { Care Excellence } \\
\text { (NICE), 2015) }\end{array}$ \\
\hline
\end{tabular}


Table 2: Advanced therapies used to treat DFU

\begin{tabular}{|c|c|c|}
\hline Method & Description & References \\
\hline $\begin{array}{l}\text { Wound } \\
\text { dressing }\end{array}$ & $\begin{array}{l}\text { Hydrogel dressings, amorphous topical applications which } \\
\text { adhere to the site of injury, are used most commonly. } \\
\text { Hydrogels provide the benefit of tuneable properties, such as } \\
\text { porosity, whilst also mimicking the natural granulation tissue } \\
\text { which promotes biocompatibility. } \\
\text { Hydrogel dressings are more effective than hydrofiber } \\
\text { dressings. } \\
\text { Hydrogel dressings can be laden with cells and growth factors. } \\
\text { Large burst release phases can be observed, reducing their } \\
\text { viability in the treatment of chronic ulceration where sustained } \\
\text { drug release would be more effective. }\end{array}$ & $\begin{array}{l}\text { (Chai et al., 2017; } \\
\text { Chen et al., 2015; } \\
\text { Hajimiri et al., } \\
\text { 2016; Motley et } \\
\text { al., 2015) }\end{array}$ \\
\hline $\begin{array}{l}\text { Negative } \\
\text { pressure } \\
\text { wound } \\
\text { therapy } \\
\text { (NPWT) }\end{array}$ & $\begin{array}{l}\text { NPWT promotes healing of acute and chronic wounds through } \\
\text { use of negative pressure in a closed system. } \\
\text { Decreases mRNA expression of IL-1B, IL- } 6 \text {, TNF- } \alpha \text {, iNOS } \\
\text { and MMP-9, while upregulating VEGF and TGF-B1 } \\
\text { expression. } \\
\text { Improves blood flow and micro-vessel maturation in diabetic } \\
\text { wounds and promotes a moist wound environment, which is } \\
\text { favourable for healing. } \\
\text { NPWT is not more effective in the treatment of DFU compared } \\
\text { to moist wound dressings. } \\
\text { Limited effect on the reducing amputations. }\end{array}$ & $\begin{array}{l}\text { (Abdullah Al- } \\
\text { Mallah, 2018; } \\
\text { Jung et al., 2016; } \\
\text { Junker et al., } \\
\text { 2013; Karam et } \\
\text { al., 2018; Ma et } \\
\text { al., } 2017 \text {; } \\
\text { Muhammad et al., } \\
\text { 2015; Seidel et } \\
\text { al., 2020; T. } \\
\text { Wang et al., } \\
\text { 2019) }\end{array}$ \\
\hline $\begin{array}{l}\text { Skin } \\
\text { substitutes }\end{array}$ & $\begin{array}{l}\text { Skin grafts such FDA-approved Dermagraft }{ }^{\circledR} \text { have shown } \\
\text { improved healing of chronic wounds, without adverse events. } \\
\text { The potential of this method has been demonstrated through } \\
\text { acellular membranes bioengineered with collagen, } \\
\text { proteoglycans and glycoproteins, resulting in delayed onset of } \\
\text { rejection in vivo. } \\
\text { SIKVAV (Ser-Ile-Lys-Val-Ala-Val) peptide-modified } \\
\text { chitosan hydrogel displayed more rapid wound healing, with } \\
\text { greater collagen deposition, myofibroblast deposition and } \\
\text { angiogenesis, compared to positive and negative controls. }\end{array}$ & $\begin{array}{l}\text { (Chen et al., } \\
\text { 2018; Marston et } \\
\text { al., } \quad 2003 \text {; } \\
\text { Stubenitsky et al., } \\
2009 \text { ) }\end{array}$ \\
\hline
\end{tabular}


International Journal of Pharmaceutics

Table 3: Advantages and disadvantages of electrospinning

\begin{tabular}{|c|c|c|c|}
\hline Method & Advantages & Disadvantages & References \\
\hline Electrospinning & $\begin{array}{l}\text { High porosity structures } \\
\text { Tuneable pore size } \\
\text { Good reproducibility } \\
\text { High drug loading } \\
\text { Wide variety of materials } \\
\text { Nanoscale fibers } \\
\text { Allows well distributed } \\
\text { cellular attachment } \\
\text { Can be used alongside 3D } \\
\text { printing } \\
\text { Cost-effective and easily } \\
\text { scaled-up } \\
\text { Coaxial methods can improve } \\
\text { mechanical properties of the } \\
\text { scaffold }\end{array}$ & $\begin{array}{l}\text { Additional processing steps } \\
\text { such as crosslinking may be } \\
\text { required to achieve } \\
\text { scaffolds with sufficient } \\
\text { mechanical strength } \\
\text { Highly volatile solvents } \\
\text { may be required during } \\
\text { production }\end{array}$ & $\begin{array}{l}\text { (Junker et al., } \\
\text { 2013; } \\
\text { Mohammadi et } \\
\text { al., 2016; Ren et } \\
\text { al., } 2018 \text {; } \\
\text { Samadian et al., } \\
\text { 2020; Surucu and } \\
\text { Turkoglu } \\
\text { Sasmazel, 2016) }\end{array}$ \\
\hline
\end{tabular}


Table 4: Advantages and disadvantages of fused deposition modelling

\begin{tabular}{|c|c|c|c|}
\hline Method & Advantages & Disadvantages & References \\
\hline $\begin{array}{l}\text { Fused } \\
\text { deposition } \\
\text { modelling } \\
(\text { FDM) }\end{array}$ & $\begin{array}{l}\text { Produces scaffolds of various } \\
\text { designs and geometries } \\
\text { Easy modification of scaffold } \\
\text { designs } \\
\text { Rapid production (minutes to } \\
\text { hours) } \\
\text { Easily scaled-up } \\
\text { Can produce scaffolds with } \\
\text { good mechanical properties, no } \\
\text { cytotoxicity and which } \\
\text { promote cellular attachment } \\
\text { and proliferation } \\
\text { Can print high viscosity } \\
\text { solutions } \\
\text { No solvents required } \\
\text { Can achieve better mechanical } \\
\text { properties than electrospinning } \\
\text { Production of large scaffolds } \\
\text { Can be used in combination } \\
\text { with other techniques such as } \\
\text { gas foaming }\end{array}$ & $\begin{array}{l}\text { Scaffolds produced by this } \\
\text { method may not be suitable } \\
\text { for tissue engineering } \\
\text { purposes due to their limited } \\
\text { flexibility } \\
\text { Requires high shear, high } \\
\text { temperature and high } \\
\text { pressures are often required } \\
\text { May require additional steps } \\
\text { such as crosslinking of the } \\
\text { biomaterial }\end{array}$ & $\begin{array}{l}\text { (Domingos et al., } \\
\text { 2009; Gao et al., } \\
\text { 2020; Guo et al., } \\
\text { 2009; Intini et al., } \\
\text { 2018; Kovalcik et } \\
\text { al., 2020; Song et } \\
\text { al., 2018; } \\
\text { Trachtenberg et } \\
\text { al., 2016) }\end{array}$ \\
\hline
\end{tabular}


Table 5: Advantages and disadvantages of bioprinting techniques.

\begin{tabular}{|c|c|c|c|}
\hline Method & Advantages & Disadvantages & References \\
\hline $\begin{array}{l}\text { Inkjet-based } \\
\text { bioprinting }\end{array}$ & $\begin{array}{l}\text { Low-cost method } \\
\text { High cell loading and viability } \\
\text { Control of droplet size } \\
\text { High resolutions achieved } \\
(100 \mu \mathrm{m}) \\
\text { Easily scaled-up } \\
\text { Has been used for in situ } \\
\text { bioprinting purposes } \\
\text { Direct printing of cells and } \\
\text { growth factors }\end{array}$ & $\begin{array}{l}\text { May require additional } \\
\text { processing steps such as } \\
\text { crosslinking of the bioink } \\
\text { Polymer degradation has been } \\
\text { associated with continuous } \\
\text { inkjet bioprinting }\end{array}$ & $\begin{array}{l}\text { (Albanna et } \\
\text { al., 2019; Haas } \\
\text { et al., 2017; } \\
\text { Negro et al., } \\
2018 ; \text { Takagi } \\
\text { et al., 2019; } \\
\text { Wheeler et al., } \\
\text { 2014; Yanez et } \\
\text { al., 2015; } \\
\text { Zhang et al., } \\
\text { 2017) }\end{array}$ \\
\hline $\begin{array}{l}\text { Extrusion- } \\
\text { based } \\
\text { bioprinting }\end{array}$ & $\begin{array}{l}\text { Most suitable bioprinting } \\
\text { method for large scaffolds and } \\
\text { soft tissue purposes } \\
\text { Low-cost method } \\
\text { Moderate }(300 \mu \mathrm{m}-600 \mu \mathrm{m}) \text { to } \\
\text { high }(200 \mu \mathrm{m}) \text { resolution } \\
\text { High seeding capacities } \\
\text { Suitable for high viscosity } \\
\text { materials } \\
\text { Low printing temperatures and } \\
\text { pressures in some cases } \\
\text { Direct printing of cells and } \\
\text { growth factors }\end{array}$ & $\begin{array}{l}\text { Printing of high viscosity } \\
\text { materials will require faster } \\
\text { printing speeds, thus negatively } \\
\text { affecting cell viability } \\
\text { May require additional steps } \\
\text { such as crosslinking of the } \\
\text { bioink }\end{array}$ & $\begin{array}{l}\text { (Cubo et al., } \\
2016 ; \\
\text { Fakhruddin et } \\
\text { al., 2018; Frost } \\
\text { et al., 2019; } \\
\text { Kolesky et al., } \\
2016 \text {; } \\
\text { McCormack et } \\
\text { al., 2020; } \\
\text { Soltan et al., } \\
2019 \text { Tan et } \\
\text { al., 2016; } \\
\text { Visser et al., } \\
\text { 2013; Zhuang } \\
\text { et al., 2019) }\end{array}$ \\
\hline $\begin{array}{l}\text { Laser- } \\
\text { assisted } \\
\text { bioprinting }\end{array}$ & $\begin{array}{l}\text { No printing nozzle required } \\
\text { High speed printing } \\
\text { High resolutions } \\
\text { High cell densities } \\
\text { Has been used for in situ } \\
\text { bioprinting purposes }\end{array}$ & $\begin{array}{l}\text { Time-consuming preparation } \\
\text { Expensive } \\
\text { Laser is a potential disruption to } \\
\text { cell viability }\end{array}$ & $\begin{array}{l}\text { (Guillotin et } \\
\text { al., 2010; } \\
\text { Keriquel et al., } \\
\text { 2017; } \\
\text { Kérourédan et } \\
\text { al., 2019b) }\end{array}$ \\
\hline
\end{tabular}


Table 6: Natural polymers for 3D bioprinted scaffolds

\begin{tabular}{|c|c|c|c|}
\hline Material & Advantages & Disadvantages & References \\
\hline Collagen & $\begin{array}{l}\text { Highly biocompatible and non- } \\
\text { toxic } \\
\text { pH neutralisation at a temperature } \\
\text { of } 37^{\circ} \mathrm{C} \text { is required for gelation of } \\
\text { collagen (gelation occurs at a low } \\
\text { temperature i.e. no high } \\
\text { temperatures are required which } \\
\text { could affect cell viability) } \\
\text { Highly permeable }\end{array}$ & $\begin{array}{l}\text { Poor mechanical properties } \\
\text { Long gelation times } \quad(\sim 30 \\
\text { minutes }) \\
\text { Commonly crosslinked using } \\
\text { chemical and physical methods } \\
\text { Low viscosity }\end{array}$ & $\begin{array}{l}\text { (Bou-Akl et al., } \\
\text { 2013; Carolina } \\
\text { et al., 2020; } \\
\text { Davidenko et } \\
\text { al., 2015; Dong } \\
\text { and Lv, 2016; } \\
\text { Heo et al., 2016; } \\
\text { Kozlowska et } \\
\text { al., 2017; } \\
\text { Skardal and } \\
\text { Atala, 2015; } \\
\text { Tian et al., } \\
\text { 2016; Zhou et } \\
\text { al., 2018) }\end{array}$ \\
\hline Gelatin & $\begin{array}{l}\text { High availability at low cost } \\
\text { Low immunogenicity and high } \\
\text { biocompatibility } \\
\text { Structurally similar to collagen } \\
\text { Promotes cell adhesion and } \\
\text { proliferation } \\
\text { Good injectability }\end{array}$ & $\begin{array}{l}\text { Native gelatin has reversible } \\
\text { temperature-dependent } \\
\text { transition } \\
\text { Lack of thermal stability } \\
\text { Faster degradation rates } \\
\text { Poor mechanical properties }\end{array}$ & $\begin{array}{l}\text { (Augustine et } \\
\text { al., 2021a; Bello } \\
\text { et al., 2020; } \\
\text { Cheng et al., } \\
2019 \text { ) }\end{array}$ \\
\hline Alginate & $\begin{array}{l}\text { Non-toxic and biocompatible } \\
\text { Easily modified } \\
\text { Maintains moist } \quad \text { wound } \\
\text { environment }\end{array}$ & $\begin{array}{l}\text { Poor mechanical properties } \\
\text { Exhibits shear-thinning behaviour } \\
\text { Requires chemical crosslinking to } \\
\text { form hydrogel }\end{array}$ & $\begin{array}{l}\text { (Chuang et al., } \\
\text { 2017; Fadhilah } \\
\text { et al., 2019; } \\
\text { Gwon et al., } \\
\text { 2015; H. Li et } \\
\text { al., 2016; } \\
\text { Thomas et al., } \\
\text { 2020) }\end{array}$ \\
\hline Fibrin & $\begin{array}{l}\text { Promotes cell adhesion } \\
\text { Biocompatible } \\
\text { Excellent wound healing ability }\end{array}$ & $\begin{array}{l}\text { Long gelation time ( } ~ 30 \text { minutes) } \\
\text { High viscosity can lead to poor } \\
\text { extrusion } \\
\text { Poor mechanical properties and } \\
\text { rapid degradation } \\
\text { Poor shape fidelity }\end{array}$ & $\begin{array}{l}\text { (Climov et al., } \\
\text { 2016; Cubo et } \\
\text { al., 2016; de } \\
\text { Melo et al., } \\
\text { 2020; Losi et } \\
\text { al., 2013; } \\
\text { Robinson et al., } \\
\text { 2017) }\end{array}$ \\
\hline
\end{tabular}


International Journal of Pharmaceutics

2215 Table 7 Rheological data of sodium alginate films that immersed in different concentrations 2216 of $\mathrm{CaCl}_{2}$ (Fadhilah et al., 2019).

\begin{tabular}{ccclc}
\hline Molarity $\mathrm{CaCl}_{2}(\mathrm{M})$ & Period $(\mathrm{min})$ & $\sigma(\mathrm{MPa})$ & $\varepsilon(\%)$ & $\mathrm{YM}(\mathrm{MPa})$ \\
\hline 0.2 & 2 & $1.00 \pm 0.2$ & $15.21 \pm 1.1$ & $8.26 \pm 2.3$ \\
& 8 & $1.05 \pm 0.2$ & $15.19 \pm 1.5$ & $9.23 \pm 0.6$ \\
0.4 & 2 & $1.25 \pm 0.2$ & $16.90 \pm 2.5$ & $9.64 \pm 2.0$ \\
& 8 & $2.43 \pm 0.2$ & $16.25 \pm 1.0$ & $20.96 \pm 10.6$ \\
0.6 & 2 & $1.82 \pm 0.2$ & $12.22 \pm 3.2$ & $17.88 \pm 6.1$ \\
& 8 & $2.90 \pm 0.5$ & $18.63 \pm 3.1$ & $24.26 \pm 12.1$ \\
0.8 & 2 & $3.14 \pm 1.2$ & $18.83 \pm 3.0$ & $24.97 \pm 10.2$ \\
& 8 & $3.92 \pm 0.3$ & $21.08 \pm 1.3$ & $27.81 \pm 7.5$ \\
\hline
\end{tabular}

2217

2218 
2219 Table 8: Synthetic polymers for 3D bioprinted scaffolds.

\begin{tabular}{|c|c|c|c|}
\hline Material & Advantages & Disadvantages & References \\
\hline $\begin{array}{l}\text { Poly(lactic-co- } \\
\text { glycolic acid) }\end{array}$ & $\begin{array}{l}\text { Biocompatible } \\
\text { Low-cost and wide } \\
\text { availability } \\
\text { Good mechanical properties } \\
\text { Degradation rate can be easily } \\
\text { modified }\end{array}$ & $\begin{array}{l}\text { Higher temperatures and } \\
\text { pressures required for printing } \\
\text { compared to natural polymers }\end{array}$ & $\begin{array}{l}\text { (Allevi, 2020; } \\
\text { Keles et al., } \\
\text { 2015; S. Wang } \\
\text { et al., 2019) }\end{array}$ \\
\hline Polycaprolactone & $\begin{array}{l}\text { Ease of processing due to low } \\
\text { melting point and gelation } \\
\text { temperatures } \\
\text { Slow rate of degradation } \\
\text { Non-toxic and biocompatible } \\
\text { Good mechanical properties }\end{array}$ & $\begin{array}{l}\text { Requires high printing } \\
\text { temperatures and pressures } \\
\text { due to high viscosity } \\
\text { Longer printing times due to } \\
\text { high viscosity } \\
\text { Hydrophobic nature can affect } \\
\text { cell adhesion }\end{array}$ & $\begin{array}{l}\text { (Azimi et al., } \\
\text { 2014; Burns et } \\
\text { al., 2010; } \\
\text { Cellink, 2020; } \\
\text { Nair et al., } \\
\text { 2017; Sukanya } \\
\text { and Mohanan, } \\
\text { 2018; Wang et } \\
\text { al., 2016) }\end{array}$ \\
\hline Polyurethane & $\begin{array}{l}\text { Good mechanical properties } \\
\text { Good elasticity } \\
\text { Biocompatible } \\
\text { Excellent printability at low } \\
\text { temperatures } \\
\text { Promotes cell adhesion and } \\
\text { proliferation }\end{array}$ & $\begin{array}{l}\text { Often requires additional } \\
\text { crosslinking stage during } \\
\text { processing }\end{array}$ & $\begin{array}{l}\text { (Hsieh and } \\
\text { Hsu, 2019; } \\
\text { Tsai et al., } \\
2015)\end{array}$ \\
\hline $\begin{array}{l}\text { Polyethylene } \\
\text { glycol }\end{array}$ & $\begin{array}{l}\text { Promising wound healing } \\
\text { capabilities when used in } \\
\text { combination with sodium } \\
\text { alginate } \\
\text { Promotes M2 macrophage } \\
\text { polarisation } \\
\text { Good mechanical properties } \\
\text { Easily modified }\end{array}$ & $\begin{array}{l}\text { PEG requires additional } \\
\text { processing step such as } \\
\text { modification to PEDGA or } \\
\text { addition of other supporting } \\
\text { biomaterials, increasing costs } \\
\text { and production time }\end{array}$ & $\begin{array}{l}\text { (Asawa et al., } \\
\text { 2018; Cheng } \\
\text { and Chen, } \\
\text { 2017; Ilhan et } \\
\text { al., 2020) }\end{array}$ \\
\hline
\end{tabular}

